\title{
次氯酸比色荧光探针的研究进展
}

\author{
余青陈晓丽刘华张奇龙 \\ (贵州医科大学基础医学院 贵阳 550025)
}

\begin{abstract}
摘要 次氯酸 $(\mathrm{HClO})$ 和次氯酸钠 $(\mathrm{NaClO})$ 广泛存在于生命体和环境中, 并与生命体的健康或疾病密切相关. 近年来, 为 揭示 $\mathrm{HClO}$ 对生物体的作用及作用机制, 已经设计出许多 $\mathrm{HClO}$ 比色苂光探针, 这些次氯酸比色苂光探针由于具有灵 敏、快速、高选择性、可视化和实时监测等优点而被用于环境或生物体中 $\mathrm{HClO}$ 或 $\mathrm{ClO}^{-}$的检测. 根据探针对 $\mathrm{HClO}$ 识 别机制的不同, 将 $\mathrm{HClO}$ 比色荧光探针分为五大类, 总结评价近五年来次氯酸比色荧光探针的设计、特征及实际应用. 关键词 次氯酸; 苂光比色探针; 识别机制; 应用
\end{abstract}

\section{Recent Progress in Colorimetric and Fluorimetric Probes for the Detection of Hypochlorous Acid}

\author{
Yu, Qing Chen, Xiaoli Liu, Hua Zhang, Qilong* \\ (Guizhou Medical University, School of Basic Medicine, Guiyang 550025)
}

\begin{abstract}
Hypochlorous acid $(\mathrm{HClO})$ and sodium hypochlorite $(\mathrm{NaClO})$ exist widely in living organisms and environment and is closely related to the health or disease of living organisms. In recent years, in order to reveal the effect and mechanism of $\mathrm{HClO}$ on living organisms, many $\mathrm{HClO}$ colorimetric and fluorimetric probes have been designed and applied to the detection $\mathrm{HClO}$ or $\mathrm{ClO}^{-}$in environment or living organisms due to their sensitivity, rapidity, high selectivity and real-time monitoring. According to the different recognition mechanism of probes for $\mathrm{HClO}, \mathrm{HCO}$ colorimetric fluorescent probes are divided into five categories. The design, characteristics and practical application of hypochlorite colorimetric fluorescent probes in the past five years are summarized and evaluated.

Keywords hypochlorous acid; colorimetric and fluorimetric probe; recognition mechanism; application
\end{abstract}

次氯酸 $(\mathrm{HClO})$ 作为重要的弱酸性生物活性氧之一 (ROS), 在生命体内通过白细胞中的髓过氧化物酶催化 产生内生性的次氯酸 $\left(\mathrm{Cl}_{2}+\mathrm{H}_{2} \mathrm{O} \rightarrow \mathrm{HClO}\right)$, 生命体内的 $\mathrm{HClO}$ 和次氯酸根 $\left(\mathrm{ClO}^{-}\right)$广泛存在于生物体的各个细 胞、组织、器官和各个细胞器中, 外源性的 $\mathrm{HClO} / \mathrm{ClO}^{-}$ 主要是水的氯化消毒产生 $\left(\mathrm{Cl}_{2}+\mathrm{H}_{2} \mathrm{O}_{2} \rightarrow \mathrm{HClO}\right)$. 氯化消 毒作为最常用的水处理方法, 广泛应用于自来水、井水、 瓶装水等生活饮用水处理以及游泳池和医院的消毒. 在 一定的生理条件下, 大约一半的 $\mathrm{HClO}$ 解离成 $\mathrm{ClO}^{-[1,2]}$, 生物细胞中一定浓度的 $\mathrm{HClO} / \mathrm{ClO}^{-}$在维持细胞形态、保 持细胞正常生理功能、细胞信号转导、维持内环境稳态 以及免疫防御系统中发挥着重要的作用 ${ }^{[3]}$. 而含氯消毒 剂的过量使用使人们过度地暴露于 $\mathrm{HClO} / \mathrm{ClO}^{-}$, 从而引 起哮喘、食道炎、喉炎和自发性呕吐. 并且生命体内过
量的 $\mathrm{HClO} / \mathrm{ClO}^{-}$会导致蛋白质、碳水化合物和脂类等生 物基本成分被大量破坏，从而导致与之相关的组织和细 胞的调亡或坏死，进一步增加阿尔茨海默病、神经退行 性疾病、糖尿病、心血管疾病、风湿性关节炎和癌症等 疾病的发生风险 ${ }^{[4 ~ 10]}$. 因此, 快速、灵敏的检测方法对 于识别检测环境和生命体内的 $\mathrm{HClO} / \mathrm{ClO}^{-}$具有重要意 义.

检测 $\mathrm{HClO} / \mathrm{ClO}^{-}$的传统方法包括碘还原滴定法、电

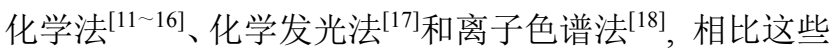
方法, 光谱法(比色法和荧光法)对生物体和水环境中 $\mathrm{HClO} / \mathrm{ClO}^{-}$的检测简单高效、成本低, 并且不需要昂贵 的大型仪器. 近年来, 研究人员设计合成了很多基于不 同检测机制识别 $\mathrm{HClO} / \mathrm{ClO}^{-}$的比色荧光探针，这些探针 既具有比色识别功能, 即肉眼就能实现对环境中

* Corresponding author. E-mail: gzuqlzhang@126.com

Received November 4, 2019; revised December 21, 2019; published online January 15, 2020

Project supported by the Science and Technology Foundation of Guizhou Province (Nos. [2019]2792, [2018]5779-14).

贵州省科学技术基金(Nos. [2019]2792, [2018]5779-14)资助项目. 
$\mathrm{HClO} / \mathrm{ClO}^{-}$的定性识别并结合紫外可见吸收光谱进行 定量检测, 又能通过苂光光谱定量识别 $\mathrm{HClO} / \mathrm{ClO}^{-}$, 以 便将此类传感器应用于生物体内 $\mathrm{HClO} / \mathrm{ClO}^{-}$的苂光检 测. 赵宝祥等 ${ }^{[19,20]}$ 经根据不同的苂光基团和不同的识别 机制, 对近几年的 $\mathrm{HClO}$ 苂光探针进行总结综述. 本文 将在此基础上进一步归纳近五年来的 $\mathrm{HClO} / \mathrm{ClO}^{-}$比色 荧光探针, 根据识别 $\mathrm{HClO} / \mathrm{ClO}^{-}$的原子或基团的不同分 为硫族化物、 $\mathrm{N}$ 原子、碳碳双键、甲氧基苯酚和甲氧基 苯胺五组, 着重总结评价近五年来 $\mathrm{HClO} / \mathrm{ClO}^{-}$荧光比色 探针的设计、特征及实际应用, 以期为学者的后续研究 提供帮助.

\section{1 硫族(S, Se, Te)化合物识别组}

$\mathrm{HClO} / \mathrm{ClO}^{-}$具有强氧化性, 很容易通过氯化或氧化 反应与硫族化合物生成 $\mathrm{S}(\mathrm{Se})-\mathrm{Cl}$ 或 $\mathrm{S}(\mathrm{Se})=\mathrm{O}$ 作为中间 体, 然后水解. 利用硫族化合物的这一特性, 很多苂光 比色探针由此设计合成.

\section{1 硫化物与 $\mathrm{HClO}$ 的氧化反应}

2015 年, 张向阳等 ${ }^{[21]}$ 根据光诱导的电子转移(PET) 作用设计合成了以硒化物为识别单元，7-硝基苯并-2-氧 杂-1,3-二唑(NBD)为苂光团的能肉眼识别 $\mathrm{ClO}^{-}$的可逆 荧光探针 1 (Eq. 1). 探针 1 具有高选择性, 高灵敏度并 能快速 $(<10 \mathrm{~s})$ 地检测 $\mathrm{ClO}^{-}$. 在 $\mathrm{CH}_{3} \mathrm{CN}-\mathrm{PBS}(0.05$ $\mathrm{mol} / \mathrm{L}, V: V=1: 1, \mathrm{pH}=7.4)$ 溶液中, 激发状态下, 由 于从硒化物到 NBD 的 PET 过程, 探针 1 只产生微弱的 苂光; 加入 $\mathrm{ClO}^{-}$后, 硒化物氧化成硒氧化物, 阻止了 PET 作用, 探针 1 在 $544 \mathrm{~nm}$ 的荧光强度增加了 32 倍, 溶 液从橙色变成黄色; $\mathrm{ClO}^{-}$浓度在 $5 \times 10^{-8} \sim 1.20 \times 10^{-4}$ $\mathrm{mol} / \mathrm{L}$ 范围内, $544 \mathrm{~nm}$ 处的苂光强度与 $\mathrm{ClO}^{-}$浓度呈线性
相关，检测限低至 $3.3 \mathrm{nmol} / \mathrm{L}(\mathrm{S} / \mathrm{N}=3)$. 其他 $\mathrm{ROS} / \mathrm{RNS}$ (如・ OH, $\mathrm{ONOO}^{-},{ }^{1} \mathrm{O}_{2}, \cdot \mathrm{O}_{2}^{-}, \mathrm{NO} \cdot \mathrm{H}_{2} \mathrm{O}_{2},{ }^{t} \mathrm{BuOOH}$, $\mathrm{NO}_{2}^{-}, \mathrm{NO}_{3}^{-}$) 和常见金属离子(如 $\mathrm{Fe}^{3+}, \mathrm{Cu}^{2+}, \mathrm{Hg}^{2+}$ )均不 干扰探针 1 对 $\mathrm{ClO}^{-}$的识别检测. 而且探针 $\mathbf{1}$ 具有可逆性 和良好的膜通透性, 成功实现了在 Hela 细胞中的 $\mathrm{ClO}^{-}$ 苂光成像.

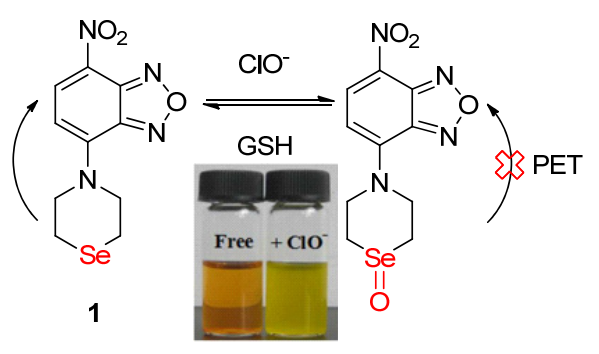

张浩力等 ${ }^{[22]}$ 在 2017 年报道了以两个氧硫杂环戊烷 为 $\mathrm{HClO}$ 识别位点, 并以寡聚(对苯乙烯)(OPV)骨架为双 光子显色团的高选择性和高灵敏度的荧光比色探针 2 (Scheme 1). 在双光子激发下, 该探针与 $\mathrm{HClO}$ 反应后表 现出明显的苂光 “打开” 现象. 利用 $\mathrm{HClO}$ 的强氧化性, 探针 2 首先被氧化成中间产物亚砜化合物和砜化合物, 最后氧硫杂环戊烷环被水解. 在 PBS-EtOH [0.1 mol/L, $V: V=1: 1, \mathrm{pH}=7.4$, 体积分数为 $0.25 \%$ 的四氢呋喃 (THF)]溶液中, 探针 2 的紫外可见吸收光谱最大吸收峰 在 $400 \mathrm{~nm}$, 加入 $\mathrm{HClO}$ 后最大吸收峰发生大约 $20 \mathrm{~nm}$ 的 红移, 溶液颜色由绿色变为黄色, 间接证明了醛基的形 成. 单光子苂光光谱表明, 探针 2 可以实现对 $\mathrm{HClO}$ 的 比率识别, 加入 $\mathrm{HClO}$ 后, 其本身在 $446 \mathrm{~nm}$ 的发射强度 降低,一个新的发射带在 $534 \mathrm{~nm}$ 处出现, 并且苂光强度 比率 $\left(I_{534} / I_{446}\right)$ 与 $\mathrm{HClO}$ 浓度 $(0 \sim 2.5 \mu \mathrm{mol} / \mathrm{L})$ 呈线性关系.

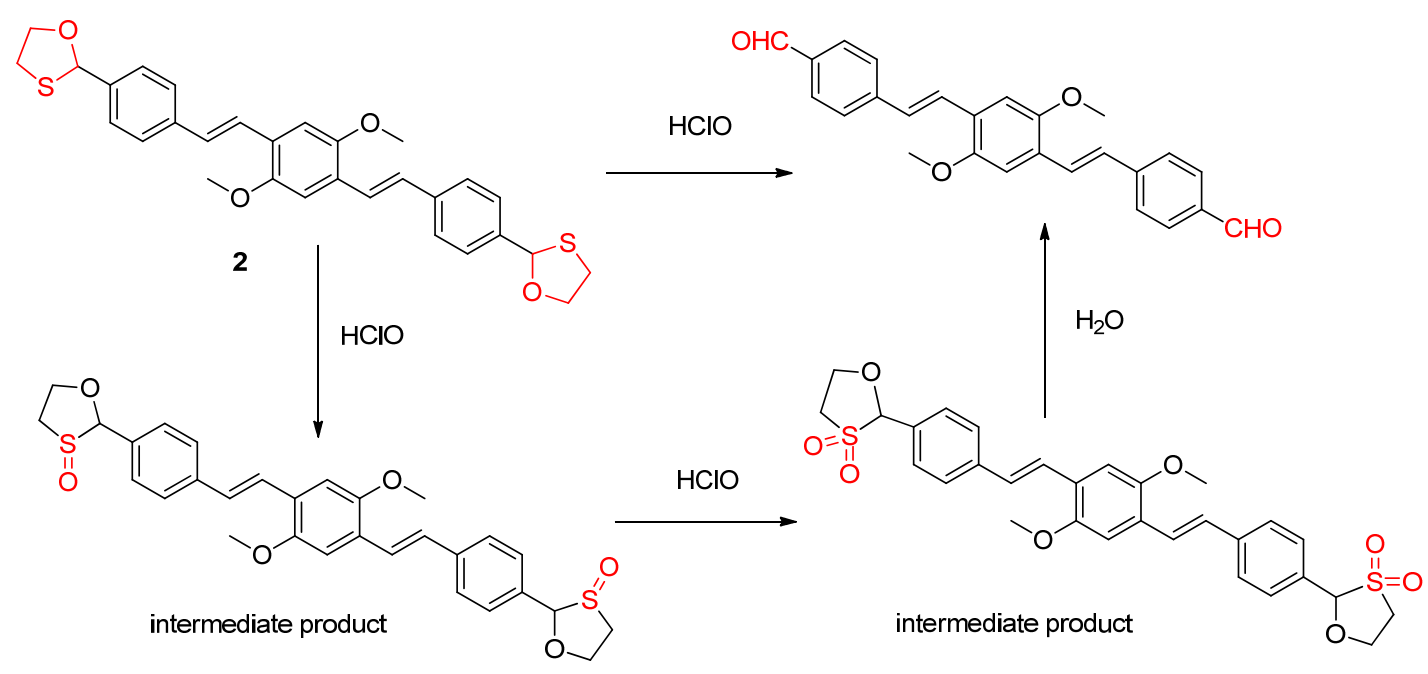

图式 1 探针 2 与 $\mathrm{HClO}$ 的反应机理

Scheme 1 Reaction mechanism of probe 2 with $\mathrm{HClO}$ 
探针 2 和探针 2 与 $\mathrm{HClO}$ 的反应产物通过在 $\mathrm{THF}$ 中 700 800 nm 范围内进行双光子吸收截面测量, 结果显 示, 在 $740 \mathrm{~nm}$ 处双光子截面分别为 105.2 和 $2020.5 \mathrm{GM}$ $\left(1 \mathrm{GM}=10^{-50} \mathrm{~cm}^{4} \cdot \mathrm{s} \bullet\right.$ photon $\left.{ }^{-1}\right)$. 探针 2 和探针 2 与 $\mathrm{HClO}$ 的反应产物的苂光双光子作用截面分别为 78.9 和 $1131.5 \mathrm{GM}$. 这表明加入 $\mathrm{HClO}$ 后, 探针 2 的双光子作用 截面增强了 15 倍, 该探针可作为双光子 “关-开” 模式 探针识别检测 HClO. 再者, 探针 2 具有良好的生物相容 性和低细胞毒性, 已经被成功应用于活小胶质细胞内脂 多糖中内源性 $\mathrm{HClO}$ 的双光子苂光成像.

同年, Choi 等 ${ }^{[23]}$ 开发了一种新型的基于苯基硒化物 二氯荧光素氧化转化为类似硒氧化物的 $\mathrm{ClO}^{-}$选择性荧 光比色探针 3 (Eq. 2). 在 PBS-DMF 缓冲液 $(V: V=99$ : $1, \mathrm{pH}=7.0)$ 中, 探针 $\mathbf{3}$ 与 $\mathrm{ClO}^{-}$反应后使溶液由粉红色变 为黄绿色, 实现探针 3 对 $\mathrm{ClO}^{-}$的裸眼识别. 苂光滴定实 验表明, 在 10 equiv. $\mathrm{ClO}^{-}$存在时, 探针 3 的荧光强度比 率 $\left(I / I_{0}\right)$ 增强了 450 倍 $\left(\lambda_{\mathrm{ex}}=500 \mathrm{~nm}, \lambda_{\mathrm{em}}=519 \mathrm{~nm}\right)$, 并且 探针 3 的荧光强度比率 $\left(I / I_{0}\right)$ 与 $\mathrm{ClO}^{-}$浓度 $\left(0 \sim 9.0 \times 10^{-6}\right.$ $\mathrm{mol} / \mathrm{L}$ )呈线性关系, 检测限低至 $39 \mathrm{nmol} / \mathrm{L}$, 足以用于自 来水或其他化学和工业中 $\mathrm{ClO}^{-}$的定量检测. 并且探针 3 的选择性高, 不受 $\mathrm{pH}$ 值影响, 其他常见金属阳离子和 阴离子不引起或仅稍微引起探针 3 的苂光强度比率 $\left(I / I_{0}\right)$ 的变化. 最后, Choi 等将红绿蓝(RGB)分析智能手机应 用程序(Excel, Microsoft Corporation)与探针 3 结合起来, 测量了标准次氯酸盐溶液和制备的自来水样品中 $\mathrm{ClO}-$ 的绿色苂光水平, 利用不同浓度的标准 $\mathrm{ClO}^{-}$溶液, 得到 了基于智能手机的滴定曲线, 并对自来水中 $\mathrm{ClO}^{-}$浓度 进行了现场分析.

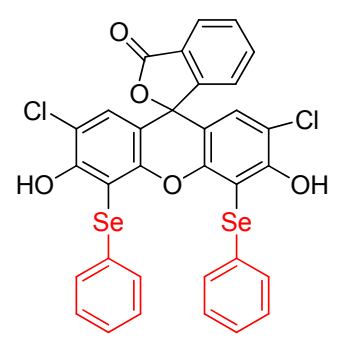

3

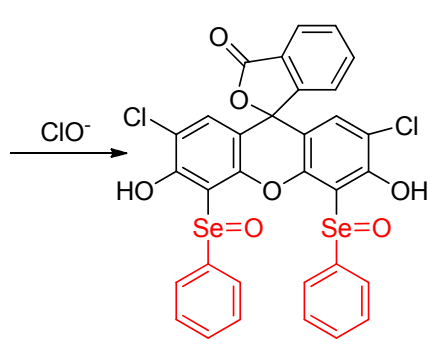

$$
\text { (1) }
$$

Soni 等 ${ }^{[24]}$ 设计合成了基于吩噻嗪-BODIPY 二元结 构的不含金属的 “关-开” 型可逆性苂光探针 4. 该探针 的二元结构中 BODIPY 作为光敏信号单元, 吩噻嗪作为 $\mathrm{ClO}^{-}$的识别反应部位. 探针 4 具有合成简单、成本低和 检测效果好等优点. 更重要的是, 由于 BODIPY 本身的 荧光被从吩噻嗪到 BODIPY 的 PET 过程淬灭使得探针 4 的溶液没有荧光, 但与 $\mathrm{ClO}^{-}$作用后生成亚砜和砜而抑 制 PET 作用, 发出 BODIPY 的荧光(Eq. 3). 加入 $\mathrm{Na}_{2} \mathrm{~S}$ 后生成 $\mathrm{H}_{2} \mathrm{~S}$, 从而使探针 4 回复到原来的状态, 苂光消
失, 这种可逆性至少可以重复 3 次. 在 PBS-乙腈(CAN) 缓冲溶液 $(V: V=9: 1)$ 中, 随着 $\mathrm{ClO}^{-}$的加入, 探针 4 在 $510 \mathrm{~nm}$ 处的荧光强度增加了 5 倍 $\left(\lambda_{\mathrm{ex}}=485 \mathrm{~nm}\right)$, 并与 $\mathrm{ClO}^{-}$浓度 $\left(0.7 \times 10^{-6} \sim 4 \times 10^{-6} \mathrm{~mol} / \mathrm{L}\right)$ 呈线性关系, 检测 限为 $0.72 \mu \mathrm{mol} / \mathrm{L}$, 同时肉眼可观察到溶液从黄色变为 绿色. 加入 $\mathrm{ClO}^{-}$后，探针 4 的苂光强度显著增加后能够 至少保持 $15 \mathrm{~min}$ 不变, 反应时间的结果表明探针 $\mathbf{4}$ 能够 用于实时检测 $\mathrm{ClO}^{-}$. 探针 4 的选择性高, 其他 ROS (如 $\left.\mathrm{H}_{2} \mathrm{O}_{2}, \cdot \mathrm{OH}, \cdot \mathrm{O}_{2}^{-},{ }^{1} \mathrm{O}_{2}\right)$ 不引起其荧光强度比率 $\left(I / I_{0}\right)$ 的变 化. 将探针 4 应用于 84 消毒液中 $\mathrm{ClO}^{-}$的定量检测并研 究了其细胞毒性, 结果表明探针 4 的细胞毒性低有望用 于细胞中 $\mathrm{ClO}^{-}$的检测.

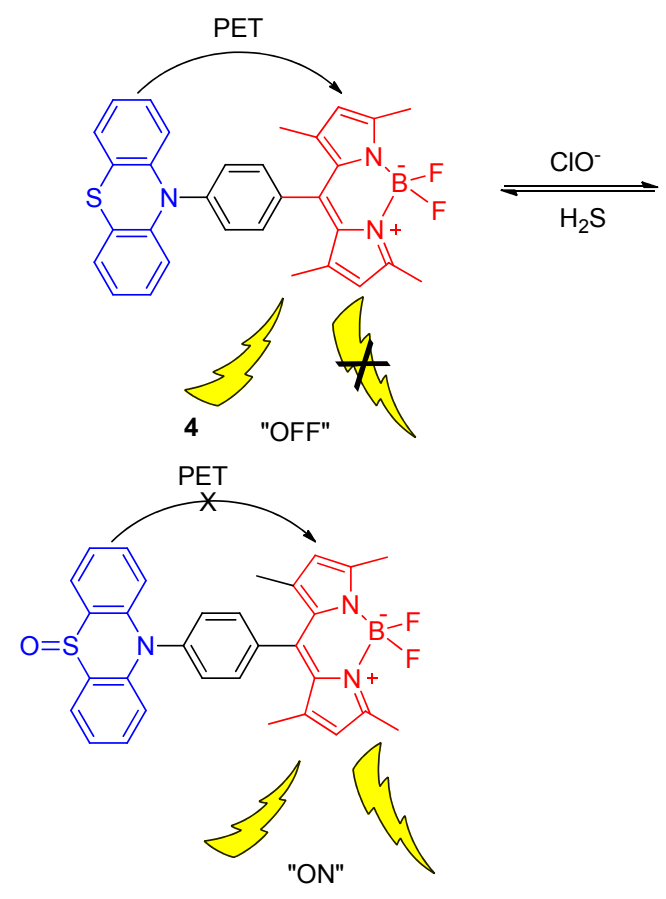

Chiu 课题组 ${ }^{[25]}$ 于 2017 年报道了一种基于苂光共聚 纳米点的从远红外到近红外的比率型苂光比色探针 $\mathbf{5}$ (Eq. 4). 利用了聚合物设计灵活的优点, 将目标敏感和 目标惰性苂光团结合到单一共轭聚合物中, 避免了其他 纳米探针中存在的泄漏或差异等光漂白问题. $\mathrm{ClO}^{-}$氧化 探针 5 中的能量供体苂光团, 从而中断 FRET 过程, 引 起苂光光谱的巨大变化. 随着 $\mathrm{ClO}^{-}$的加入, 探针 $\mathbf{5}$ 的荧 光强度比率 $\left(I_{540} / I_{680}\right)$ 增加了 40 倍, 肉眼可观察到溶液颜 色由黄色最终变为无色, 苂光颜色从黄色变为绿色, 而 其他常见 $\operatorname{ROS}\left(\mathrm{H}_{2} \mathrm{O}_{2}, \cdot \mathrm{OH}, \cdot \mathrm{O}_{2}^{-},{ }^{t} \mathrm{BuOO} \bullet\right.$ 和 $\left.\mathrm{ONOO}^{-}\right)$, GSH, Hcy, Cys 和二硫苏糖醇(DTT)不会引起其苂光强 度比率 $\left(I_{540} / I_{680}\right)$ 和苂光颜色的变化, 探针 5 不仅具有反 应迅速、选择性高和 $\mathrm{pH}$ 范围广等优点, 还具有很好的 稳定性和优异的生物相容性, 并且利用双通道检测已经 


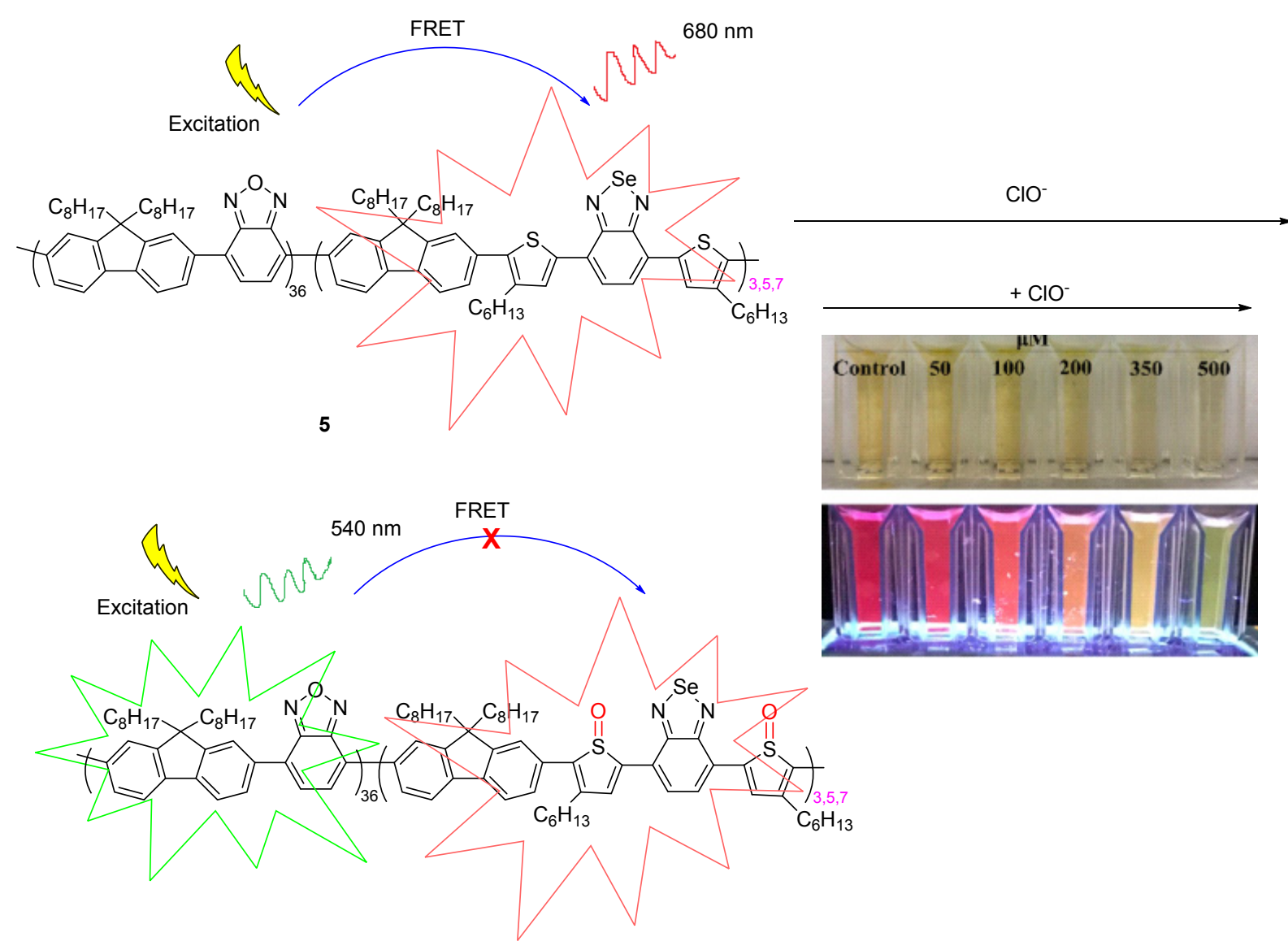

(4)

将其成功应用于巨噬细胞中 $\mathrm{HClO}$ 的动态监测和活的腹 膜炎小鼠的脂多糖(LPS)诱导产生的 $\mathrm{ClO}^{-}$苂光成像. 这 表明, 这类具有多种优点的探针将有望用于生命体中 $\mathrm{HClO}$ 的苂光成像, 为考察生命体中 $\mathrm{HClO}$ 的生理和病 理作用提供了一种有价值的分析手段.

同年, 范曲力等 ${ }^{[26]}$ 利用自组装方法开发了可激活 和可降解的光声 (PA) 纳米荧光比色探针 6 (Eq. 5), 用于 $\mathrm{HClO}$ 的体内苂光成像. 利用 $\mathrm{HClO}$ 的强氧化性, 探针 6 分子结构中的硫化物被氧化成相应的砜类. 该纳米探针 对 $\mathrm{HClO}$ 表现出灵敏和特异性的比率型光学信号, 并被 成功用于活鼠肿瘤细胞中 $\mathrm{HClO}$ 比率型苂光成像.

叶勇等 ${ }^{[27]}$ 也于 2017 年设计合成了一种基于分子内 电荷转移 (ICT) 的以溶酶体为靶向的具有可逆性的 $\mathrm{HClO}$ 双光子苂光比色探针 7 (Eq. 6). 该探针以甲基硫醚 (MeS)为调制器, 利用甲基亚砜易还原成硫醚的氧化还 原化学性质, 实现了 $\mathrm{HClO}$ 和 $\mathrm{GSH}$ 之间的氧化还原循 环, 通过可逆性实验 $(>5$ 次) 证明了探针 7 可以连续检测 $\mathrm{HClO}$ 和 $\mathrm{GSH}$ 之间的氧化还原循环. 在生理条件下 $(0.01$ $\mathrm{mol} / \mathrm{L} \mathrm{PBS}, \mathrm{pH}=7.4)$, 探针 7 中的硫醚部分被 $\mathrm{ClO}^{-}$选择 性氧化, 其他 $\mathrm{ROS}\left(\mathrm{H}_{2} \mathrm{O}_{2}, \mathrm{~S}_{2} \mathrm{O}_{8}^{2-}, \mathrm{HClO}_{4}, \mathrm{NO} \cdot, \cdot \mathrm{O}_{2}^{-}\right)$和 阴离子 $\left(\mathrm{AcO}^{-}, \mathrm{Br}^{-}, \mathrm{Cl}^{-}, \mathrm{CO}_{3}^{2-}, \mathrm{F}^{-}, \mathrm{H}_{2} \mathrm{PO}_{4}^{-}, \mathrm{HCO}_{3}^{-}\right.$, $\mathrm{HPO}_{4}^{2-}, \mathrm{I}^{-}, \mathrm{NO}_{3}^{-}, \mathrm{PO}_{4}^{3-}, \mathrm{SO}_{4}^{2-}$ ) 几乎不会引起探针 7

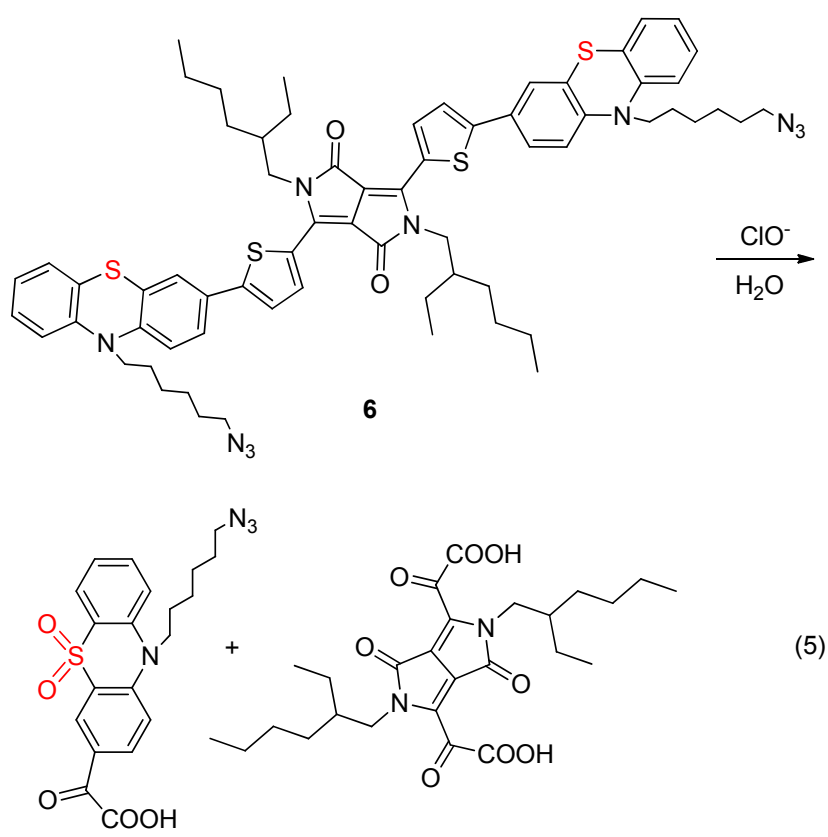

溶液的颜色、紫外可见吸收光谱和苂光光谱的变化. 加 入 $\mathrm{ClO}^{-}$后, 探针 7 的紫外可见吸收光谱表现出比率型变 化, 溶液从黄色变为无色. 该探针溶液本身由于其高效 的 ICT 分别在 $405 \mathrm{~nm}$ (单光子激发波长)和 $800 \mathrm{~nm}$ (双光 子激发波长)的激发下表现出强荧光. 10 equiv. $\mathrm{ClO}^{-}$的 
加入使得探针 7 在 $505 \mathrm{~nm}$ 处的绿色荧光快速淬灭, 其他 竞争离子不会干扰该探针对 $\mathrm{ClO}^{-}$的检测. 而且, 探针 7 在 $505 \mathrm{~nm}$ 处的苂光强度与 $\mathrm{ClO}^{-}$浓度 $(3 \sim 150 \mu \mathrm{mol} / \mathrm{L})$ 呈 线性关系 $\left(Y=196.51584-39.56486 X, R^{2}=0.99376\right)$, 检 测限为 $0.674 \mu \mathrm{mol} / \mathrm{L}$. 探针 7 对 $\mathrm{ClO}^{-}$检测的 $\mathrm{pH}$ 范围广, 表明该探针可以用于溶酶体和复杂环境中 $\mathrm{ClO}^{-}$的识别 检测. 细胞实验证明, 探针 7 具有很好的膜透过性, 由 于长波长激发有效地降低了背景荧光, 已经被成功地应 用于溶酶体活细胞中高分辨率的双光子 $\mathrm{HClO}$ 成像, 为 探索 $\mathrm{HClO}$ 在活细胞中的生理和病理功能提供了一个很 好的工具.

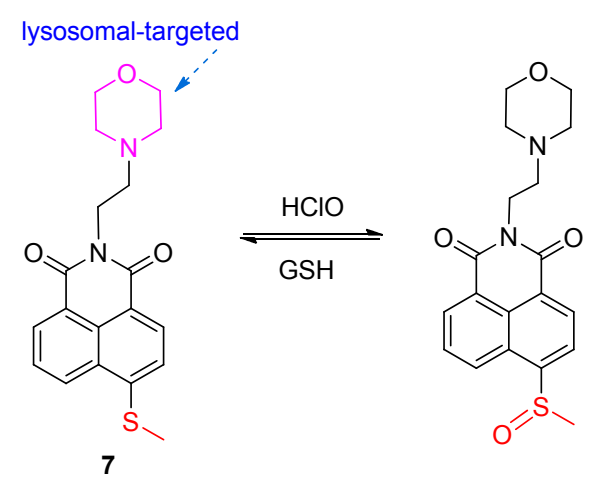

2018 年, 孟庆涛等 ${ }^{[28]}$ 报道了以硫醚为 $\mathrm{HClO}$ 识别部 位, 将硫醚与吩噻嗪一喹啉结合起来的一种简单的 $\mathrm{HClO}$ 荧光比色传感器 8 (Eq. 7). 探针 8 具有很大的斯托克斯 位移 $(128 \mathrm{~nm})$ 、高灵敏度和高选择性, 并能快速定性和 定量识别检测 $\mathrm{HClO}$. 在 PBS-DMSO 缓冲液 $(0.02 \mathrm{~mol} / \mathrm{L}$, $V: V=9: 1, \mathrm{pH}=7.4)$ 中, 逐渐加入 $\mathrm{HClO}$ 后, 探针 8 本 身在 $490 \mathrm{~nm}$ 的吸光峰值降低, $440 \mathrm{~nm}$ 处出现了新的吸 收峰, 并在 $478 \mathrm{~nm}$ 处出现一个等吸收点, 溶液由棕色变 为黄色. 同样条件下, 探针 $\mathbf{8}$ 本身只有微弱的苂光, 苂 光量子产率为 0.0029 , 加入 6 equiv. $\mathrm{ClO}^{-}$后, $588 \mathrm{~nm}$ 处 的荧光强度增强 75 倍 $\left(\lambda_{\mathrm{ex}}=460 \mathrm{~nm}\right)$, 荧光量子产率为 0.177 , 检测限低至 $15.6 \mathrm{nmol} / \mathrm{L}$. 这是由于 $\mathrm{ClO}^{-}$选择性 地将探针 8 中的硫醚氧化成亚砜. 而且该探针能够在酸 性、中性和碱性环境中实现对 $\mathrm{ClO}^{-}$的快速荧光反应, 表 明探针 8 有望实现对生物系统中 $\mathrm{ClO}^{-}$的实时荧光成像. 将探针 8 与苂光成像和流式细胞分析结合起来, 实现了 MCF-7 细胞系的单细胞 HClO 检测, 并且成功实现了成 年斑马鱼和裸鼠体内的内源性 $\mathrm{HClO}$ 成像. 这类探针有 望为 $\mathrm{HClO}$ 在活体中的生理和病理作用的进一步研究做 出贡献.

紧接着, 王本花等 ${ }^{[29]}$ 研究了基于黄酮衍生物的具 有长波长发射和大的斯托克斯位移 (140 nm) 的 $\mathrm{HClO}$ 比 率比色苂光探针 9 (Eq. 8). 该探针以吩噻嗪作为电子供 体, 以 $\mathrm{HClO}$ 识别基团, $\mathrm{HClO}$ 能将吩噻嗪基团的供电子

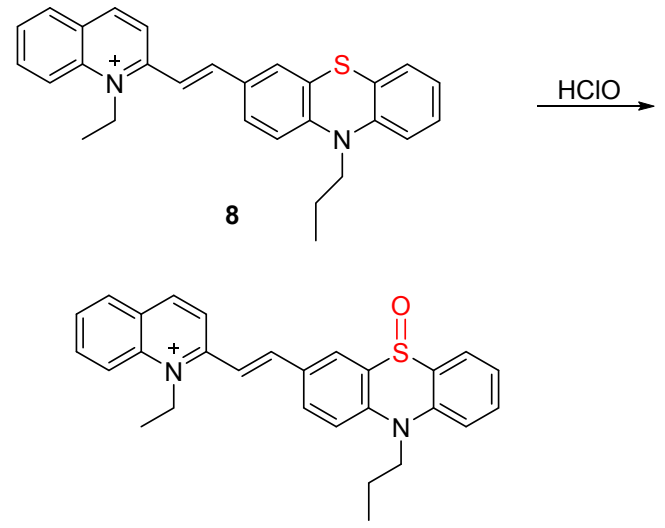

体二价硫原子氧化成一个吸电子体一一亚砜基团，通过 ICT 作用, 引起巨大的光谱蓝移和长波长发射. 在 $25{ }^{\circ} \mathrm{C}, 0.02 \mathrm{~mol} / \mathrm{L}$ 着乙基哌嗪乙硫磺酸(HEPES)缓冲液 $(0.001 \mathrm{~mol} / \mathrm{L} \mathrm{CTAB}, \mathrm{pH}=7.4)$ 中, 探针 9 的溶液本身在 $446 \mathrm{~nm}$ 有一个强吸收峰, $586 \mathrm{~nm}$ 处有一个主要的发射条 带, 加入 $\mathrm{HClO}$ 引起肉眼可见的溶液颜色变化 $($ 从黄色变 为无色)和苂光颜色变化 (从橙色变为绿色), 苂光光谱中 呈现出 $586 \mathrm{~nm}$ 处苂光强度降低和 $524 \mathrm{~nm}$ 处出现一个新 的发射带的比率型变化. 并且该探针在 524 和 $586 \mathrm{~nm}$ 的 苂光强度比率 $\left(I_{524} / I_{586}\right)$ 与 $\mathrm{HClO}$ 浓度 $(0 \sim 6$ equiv. $)$ 呈现出 良好的线性关系, 检测限低至 $6.6 \mathrm{nmol} / \mathrm{L}$, 表明探针 9 的灵敏度高. 其他相关分析物 (PBS, ${ }^{1} \mathrm{O}_{2}, \mathrm{H}_{2} \mathrm{O}_{2}, \cdot \mathrm{O}_{2}^{-}$, $\mathrm{NO}, \bullet \mathrm{OH}, \mathrm{ONOO}^{-}$, ROO• ${ }^{t} \mathrm{BuOOH}, \mathrm{Hcy}, \mathrm{Cys}, \mathrm{GSH}, \mathrm{SH}^{-}$, $\mathrm{HSO}_{3}^{-}, \mathrm{S}_{2} \mathrm{O}_{3}^{2-}, \mathrm{SO}_{4}^{2-}, \mathrm{Br}^{-}, \mathrm{I}^{-}, \mathrm{K}^{+}, \mathrm{Na}^{+}$和 $\mathrm{Fe}^{3+}$ )引起探 针 9 苂光强度的变化可以忽略不计, 表明该探针的选择 性高. 该探针细胞毒性低, 已被成功用于斑马鱼体内 $\mathrm{HClO}$ 的苂光成像.

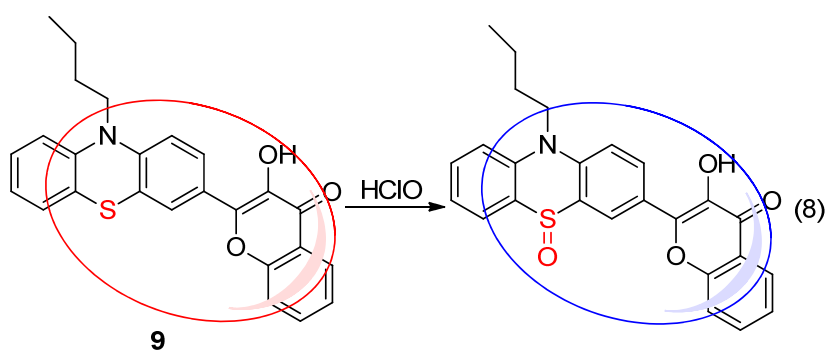

最近，周艳梅等 ${ }^{[30]}$ 也设计合成了一种基于硫醚被 $\mathrm{ClO}^{-}$选择性氧化成亚砜的具有非常大的斯托克斯位移 $\left(\lambda_{\mathrm{ex}}=345 \mathrm{~nm}, \lambda_{\mathrm{em}}=513 \mathrm{~nm}, \Delta \lambda=168 \mathrm{~nm}\right)$ 的比色苂光探 针 10 (Eq. 9). 该探针对 $\mathrm{HClO}$ 的反应非常快速 $(<10 \mathrm{~s})$, 并且具有很宽的 $\mathrm{pH}$ 响应范围. 在室温下 $0.01 \mathrm{~mol} / \mathrm{L} \mathrm{PBS}$ 缓冲液(含水量 $99.5 \%, \mathrm{pH}=7.4)$ 中, 各种相关物质 $(20$ equiv. $\mathrm{H}_{2} \mathrm{O}_{2}, \cdot \mathrm{OH},{ }^{1} \mathrm{O}_{2}, \mathrm{NO} \cdot \mathrm{NO}_{3}^{-},{ }^{t} \mathrm{BuOOH},{ }^{t} \mathrm{BuO} \cdot$, $\mathrm{Cr}_{2} \mathrm{O}_{7}^{2-}, \mathrm{CH}_{3} \mathrm{COO}^{-}, \mathrm{HCOO}^{-}, \mathrm{MnO}_{4}^{2-}, \mathrm{HPO}_{4}^{2-}, \mathrm{NO}_{2}^{-}$, $\mathrm{SO}_{3}^{2-}, \mathrm{F}^{-}, \mathrm{NH}_{3} \cdot \mathrm{H}_{2} \mathrm{O}, \mathrm{ONOO}^{-}, \mathrm{Cys}, \mathrm{GSH}$ )均不会引起探 
针 10 的溶液颜色、紫外可见吸收光谱和苂光光谱的变 化, 并且探针 10 的色度图(CIE)颜色坐标仅对 $\mathrm{ClO}^{-}$有明 显的变化, 而对其他分析物没有明显的变化. 随着 $\mathrm{ClO}^{-}$ 的加入, 探针 $\mathbf{1 0}$ 的溶液颜色从黄色逐渐裉去, 荧光颜色 从黄绿色变为青色, $550 \mathrm{~nm}$ 处的苂光信号逐渐减弱, 并 且逐渐在 $513 \mathrm{~nm}$ 处出现一个新的发射峰(图 1). 探针 10 在 $513 \mathrm{~nm}$ 处的苂光强度增加与 $\mathrm{ClO}^{-}$浓度 $(0 \sim 100$ $\mu \mathrm{mol} / \mathrm{L})$ 呈线性 $\left(R^{2}=0.996\right)$, 检测限为 $449.76 \mathrm{nmol} / \mathrm{L}$. 随 后，该探针成功的用于 $\mathrm{PC} 12$ 细胞中 $\mathrm{HClO}$ 的苂光成像.
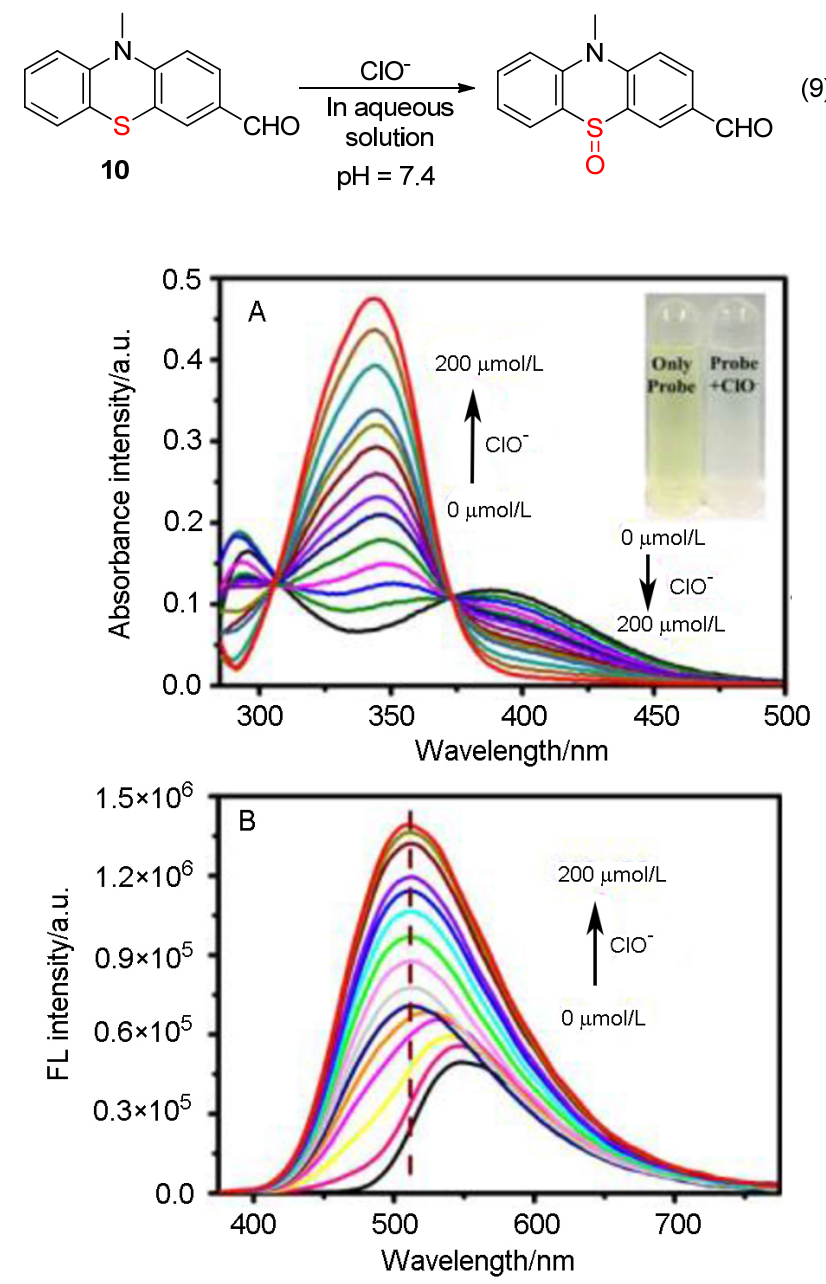

图 1 探针 10 和不同浓度 $\mathrm{ClO}^{-}$作用的吸收光谱图(A)和荧光 发射图(B)以及相应的颜色变化

Figure 1 (A) Absorption spectra and (B) emission spectra of the probe 10 with different concentrations of $\mathrm{ClO}^{-}$and corresponding color changes

\section{2 消除硫化物}

2013 年, 韩守法等 ${ }^{[31]}$ 基于福斯特共振能量转移 (FRET) 原理, 研究了以包含有异硫氰酸荧光素(FITC)的 二氧化硅纳米颗粒作为供体染料和一种高度选择性的 罗丹明衍生物为受体染料的比率型荧光比色 $\mathrm{HClO}$ 纳米 探针 11 (Eq. 10). 该纳米探针能被 $\mathrm{HClO}$ 氧化, 使分子内
硫醚开环，随后引起罗丹明衍生的化学剂量计的 $\beta$ 消除， 使无荧光的化学计量计转变成具有强荧光的罗丹明受 体. 潜在的干扰物质如 $\mathrm{H}_{2} \mathrm{O}_{2}, \mathrm{NO} \cdot \cdot \cdot \mathrm{OH}, \mathrm{ROO} \cdot \boldsymbol{O}^{-}$, $\mathrm{Na}^{+}, \mathrm{K}^{+}, \mathrm{Ca}^{2+}, \mathrm{Zn}^{2+}, \mathrm{Pb}^{2+}, \mathrm{Fe}^{3+}$ 和 $\mathrm{Fe}^{2+}$ 在含有纳米探针 11 的磷酸氢二钠-柠檬酸盐缓冲溶液中 $(\mathrm{pH}=5.0$ 或 7.4)不会引起纳米探针 11 苂光光谱和溶液颜色的改变. 而在 PBS $(\mathrm{pH}=7.4)$ 的缓冲溶液中 $\mathrm{HClO}$ 会引起探针 11 苂光强度比率 $\left(I_{586} / I_{526}\right)$ 的明显变化, 溶液颜色从无色变 为玫红色. 更重要的是, 将传统的流式细胞术与该纳米 探针结合起来可以实现活细胞溶酶体中 $\mathrm{HClO}$ 的比率荧 光成像, 这将有助于揭示 $\mathrm{HClO}$ 在细胞或动物中疾病或 健康的重要作用.
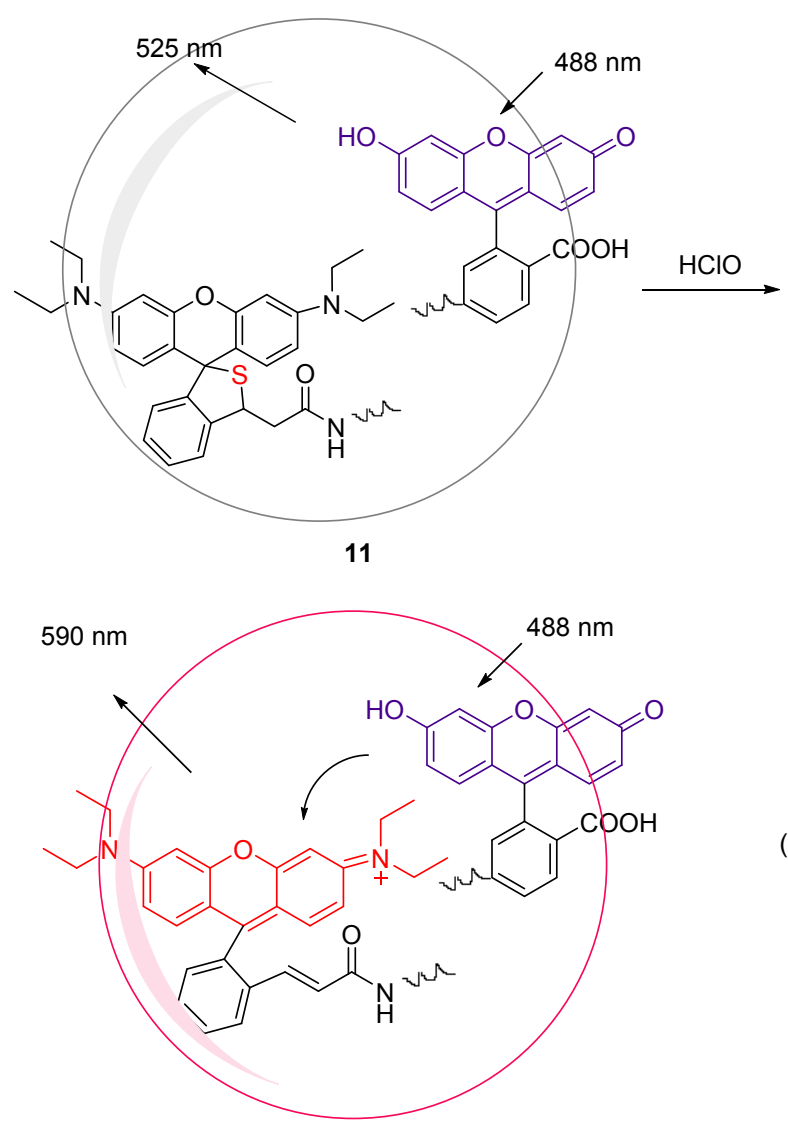

2014 年, 张其春课题组 ${ }^{[13]}$ 首次报道了一种选择性 检测 $\mathrm{HClO}$ 的上转换发光(UCL)传感器 12 (Eq. 11). 探针 12 的设计是基于聚丙烯酸(PPA)修饰的上转换发光纳米 苂光粉(UCNPs) 与罗丹明衍生物之间的发光共振能量传 递(LRET)过程，其中 UCNPs 作为能量供体，罗丹明衍 生物作为能量受体，罗丹明衍生物中的硫代氨基艮作为 保护基团迫使罗丹明采用封闭形式. 在 PBS 缓冲盐溶液 $(\mathrm{pH}=7.4)$ 中, 随着 $\mathrm{HClO}$ 的加入, 探针 12 在 $554 \mathrm{~nm}$ 处 微弱的吸收峰变得越来越强, 并且溶液从无色变为粉 色. 并且, 该纳米探针在 554 和 $800 \mathrm{~nm}$ 的 UCL 比率 $\left(\mathrm{UCL}_{554} / \mathrm{UCL}_{800}\right)$ 大小与 $\mathrm{HClO}$ 浓度 $(0 \sim 120 \mu \mathrm{mol} / \mathrm{L})$ 呈线 
性增长, 11 equiv. $\mathrm{HClO}$ 使比率型的 UCL 信号达到饱和, 检测限为 $0.32 \mu \mathrm{mol} / \mathrm{L}$. 相同条件下, 包括 $\mathrm{NO}_{2}^{-}, \mathrm{H}_{2} \mathrm{O}_{2}$, $\mathrm{ONOO}^{-}, \cdot \mathrm{OH}$ 和 $\cdot \mathrm{O}_{2}^{-}$在内的其他 $\mathrm{ROS}$ 和包括 $\mathrm{NO} \cdot$, ROO-及 NO-在内的 RNS 都不会引起探针 $\mathbf{1 2}$ 的溶液颜 色、紫外可见吸收光谱和比率型 UCL 强度的变化, 表明 $\mathrm{HClO}$ 选择性地将探针 $\mathbf{1 2}$ 中螺内酯开环, 接着氨基硫脲 脱硫形成 1,3,4-惡二唑. 更重要的是, 利用探针 $\mathbf{1 2}$ 本身 无背景荧光、无光漂白和更高的光穿透深度等优势, 已 经成功将其用于检测活细胞中的 $\mathrm{HClO}$, 并有望成为下 一代的化学工具研究生物系统中 $\mathrm{HClO}$ 的功能.

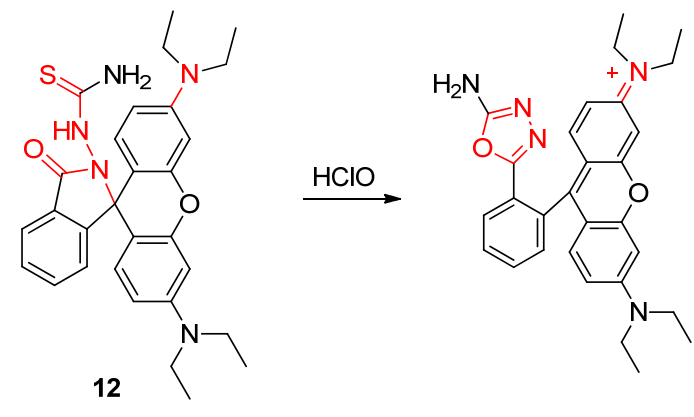

2016 年，俞汝勤等 ${ }^{[32]}$ 基于 2 -颈基乙醇对醛的保护 作用设计合成了一种具有超快响应和大斯托克斯位移 的 $\mathrm{HClO}$ 比色荧光探针 13 (Eq. 12). 在 $\mathrm{PBS}-\mathrm{CH}_{3} \mathrm{CN}$ 缓冲 液 $(0.02 \mathrm{~mol} / \mathrm{L}, V: V=1: 4, \mathrm{pH}=7.4)$ 中, 随着 $\mathrm{HClO}$ 的 加入, 探针 13 的溶液从淡黄色变成亮黄色, 紫外可见吸 收光谱出现红移. 在相同条件下, 由于探针 13 中的氧硫 杂环戊烷基团的吸电子能力较弱, 分子内电荷转移 (ICT) 效应受到抑制使得其苂光强度很低. 苂光滴定结 果表明, 加入 $\mathrm{HClO}$ 后探针 13 在 $585 \mathrm{~nm}$ 处的苂光强度 增强超过 187 倍. 这是由于 $\mathrm{HClO}$ 促进了 7-氧硫杂环戊 烷基团转变成醛基, 恢复了 ICT 效应. 探针 13 的斯托克 斯位移大至 $130 \mathrm{~nm}$, 可以减少在生物分析中的自荧光 和自吸收. 探针 13 的荧光强度与 $\mathrm{HClO}$ 浓度 $(0 \sim 40$ $\mu \mathrm{mol} / \mathrm{L}$ )呈线性关系, 检测限为 $50 \mathrm{nmol} / \mathrm{L}$. 该探针的 $\mathrm{pH}$ 范围广 $(\mathrm{pH}=4 \sim 9)$, 与 $\mathrm{HClO}$ 反应非常迅速 $(<1 \mathrm{~s})$, 具 有高灵敏度和高选择性. 并且该探针的细胞毒性低, 膜 渗透性好, 成功实现了实时、高对比度的对 HeLa 细胞 和 RAW 264.7 细胞的 $\mathrm{HClO}$ 生物成像.

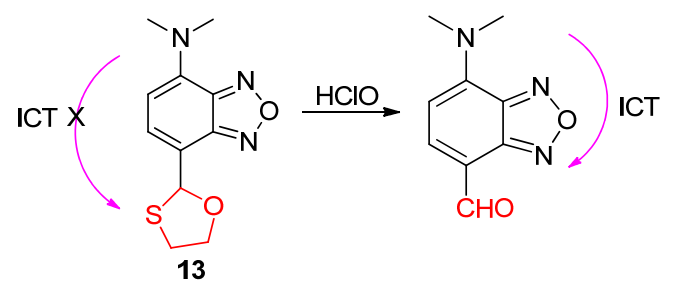

2017 年, 詹心琪团队 ${ }^{[33]}$ 以 $N$-苯基- $N$-乙烯胺硫脲取 代基作为识别单元, 对七甲基川菁色团的桥头进行修
饰，设计合成了近红外区激发和双发射波长的比率型 $\mathrm{HClO}$ 苂光比色探针 14 (Eq. 13). $\mathrm{HClO}$ 引起该探针桥头 $\mathrm{N}$ 原子供电子效应的改变, 通过给予胍基引起脱硫反 应，生成的化合物中的吸电子胍基团降低了氮原子向七 甲基川菁色团的供电子能力，导致最大吸收波长和激发 波长发生了较大的红移. 在 $\mathrm{pH}=7.4$ 的 PBS-DMF 缓冲 溶液 $(V: V=20: 80)$ 中, $\mathrm{HClO}$ 的加入引起探针 $\mathbf{1 4}$ 的紫 外可见吸收峰红移 $150 \mathrm{~nm}$ (从 650 到 $800 \mathrm{~nm}$ ), 溶液从蓝 色变为浅绿色. 以等吸收点 $730 \mathrm{~nm}$ 作为激发波长, 加入 $\mathrm{HClO}$ 后, 探针 14 的荧光光谱出现 760 和 $820 \mathrm{~nm}$ 比率 型的长波发射, 荧光强度比率 $\left(I_{820} / I_{760}\right)$ 与 $\mathrm{HClO}$ 浓度 $(1.0$ $\times 10^{-6} \sim 2.0 \times 10^{-5} \mathrm{~mol} / \mathrm{L}$ ) 呈线性关系, $R^{2}=0.9959$, 并 且该探针选择性高. 利用加标回收实验成功实现了探针 14 对自来水和人类血清样本中 $\mathrm{HClO}$ 的准确定量检测.

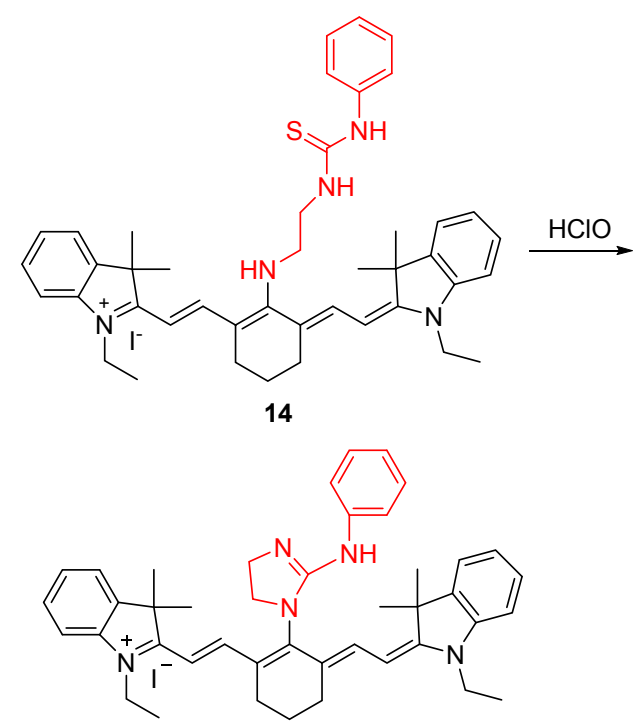

近年来，申世立等 ${ }^{[34]}$ 设计合成了一种新型的基于 荧光共振能量转移(FRET)过程和分子内脱硫 - 罗丹明螺 内开闭环机制的比率型 $\left(I_{588} / I_{463}\right) \mathrm{HClO}$ 荧光比色探针 $\mathbf{1 5}$ (Scheme 2). 探针 15 以溶酶体为靶向, 成功实现了活细 胞溶酶体中 $\mathrm{HClO}$ 的比率荧光成像. 在此基础上, 申世 立等 ${ }^{[35]}$ 再次报道了一种新型的同样以溶酶体为靶向, 基于分子内脱硫和罗丹明螺内开闭环机制的 $\mathrm{HClO}$ 苂光 比色探针 16 (Scheme 2). 比起探针 15, 探针 16 能实现 在水溶液中更快速的肉眼识别检测 $\mathrm{HClO}$, 并且检测限 更低, 更灵敏, 并被成功应用于活细胞溶酶体中 $\mathrm{HClO}$ 苂光成像.

2017 年, 钱鹰等 ${ }^{[36]}$ 报道了一种基于菜酰亚胺-罗丹 明结构的双光子 $\mathrm{HClO}$ 显色荧光探针 $\mathbf{1 7}$ (Eq. 14), $\mathrm{HClO}$ 引发罗丹明螺内酯开环、分子内脱硫和罗丹明硫代氨基 腿环化反应, 随后出现吡啶-萗酰亚胺(能量供 


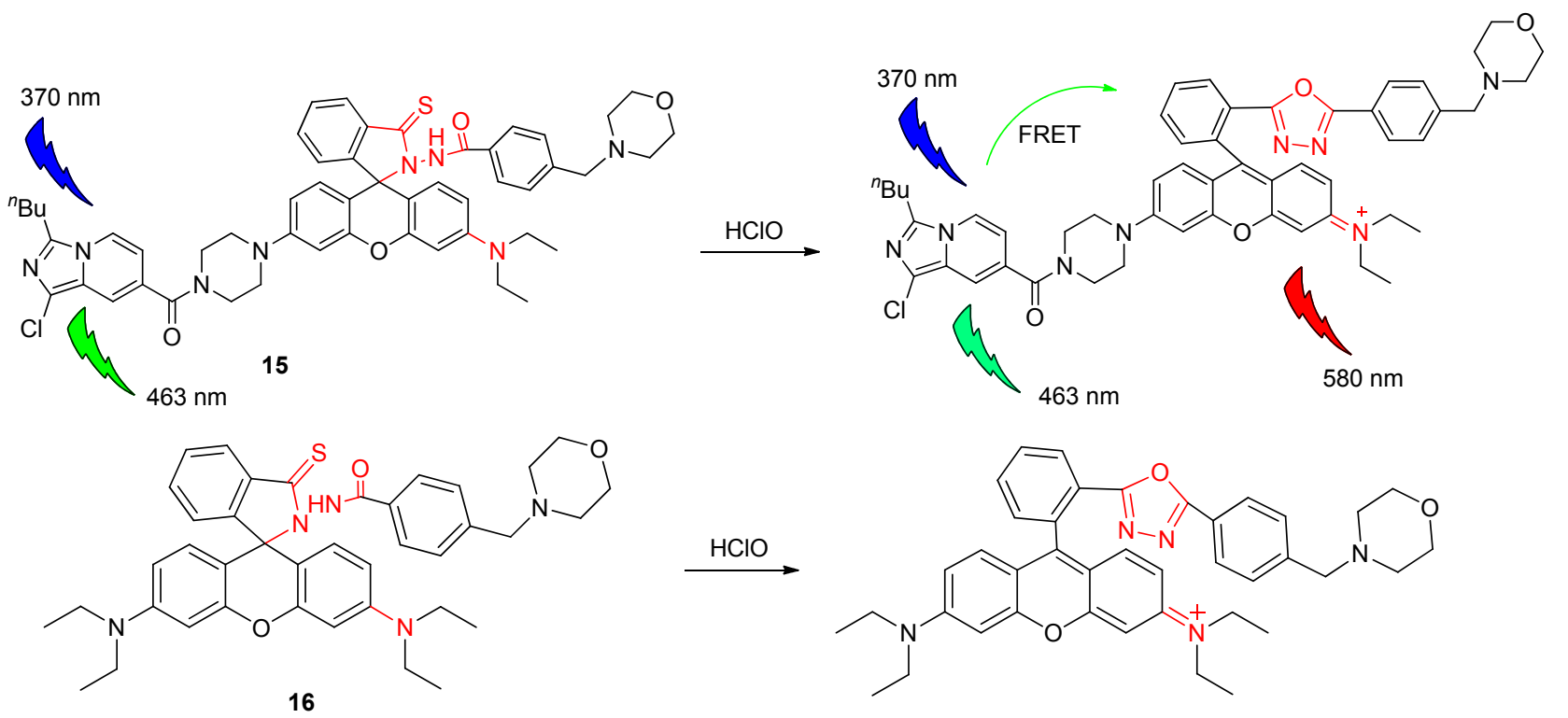

图式 2 探针 15 和 16 与 $\mathrm{HClO}$ 的反应机理

Scheme 2 Reaction mechanism of probes $\mathbf{1 5}$ and $\mathbf{1 6}$ with $\mathrm{HClO}$

体)向开环的罗丹明(能量受体)的 FRET. 双光子荧光激 发下, 探针本身无长波发射, $\mathrm{HClO}$ 的加入明显引起探针 17 在 $600 \mathrm{~nm}$ 处的罗丹明苂光发射, 伴随着溶液从无色 变为亮粉色. 该探针还被成功用于活细胞中 $\mathrm{HClO}$ 的苂 光成像.
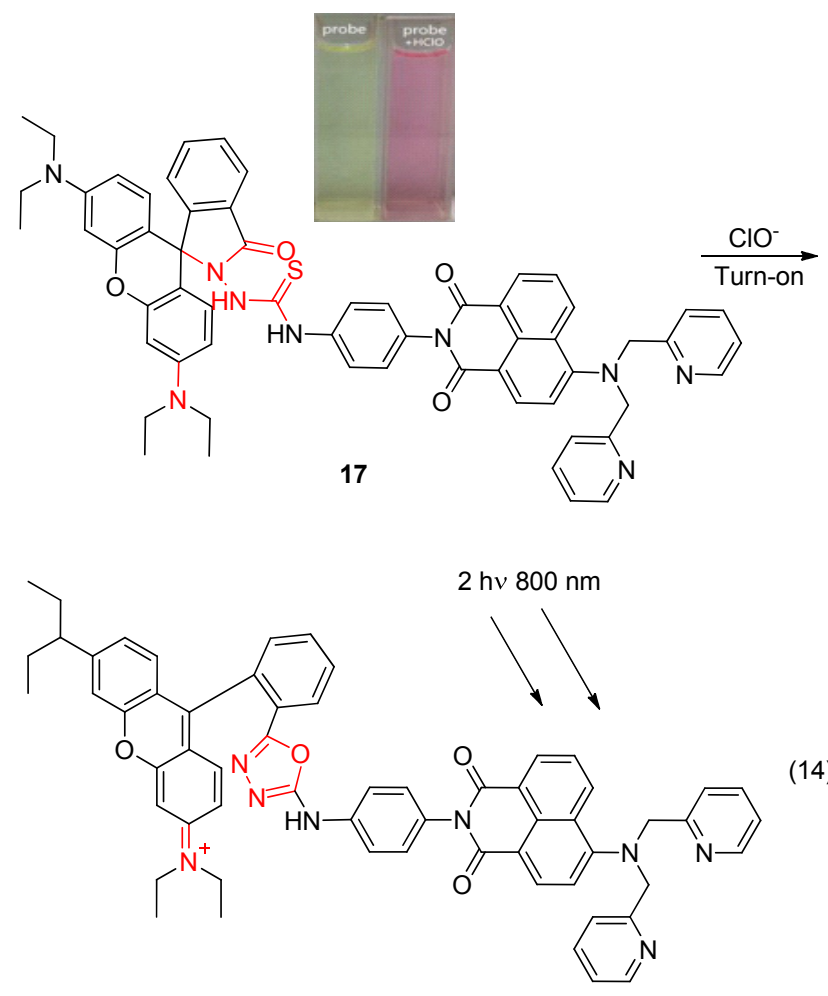

(14)

最近, 龚毅君等 ${ }^{[37]}$ 基于罗丹明类似物也设计合成 了一种具有长波长发射(近红外: $630 \mathrm{~nm}$ )的双光子 $\mathrm{HClO}$
荧光比色探针 18 (Eq. 15). 不同于其他 ROS 和 RNS, $\mathrm{HClO}$ 会引起这个新的苂光探针发生循环反应. 该探针 将双光子染料和作为识别基团的硫代螺内酯结合起来, 通过双光子显微镜可以实现对生物体系活细胞和组织 中 $\mathrm{HClO}$ 的荧光成像. $\mathrm{HClO}$ 可以氧化探针 $\mathbf{1 8}$ 中的 $\mathrm{S}$ 原 子形成碳缺电子中心，中间体会立即被邻近的酚羟基亲 核进攻，随着脱硫反应的进行，亲核环化反应完成，探 针 18 就转化为强荧光化合物. 在 PBS-二甲亚风(DMSO) 缓冲液 $(0.01 \mathrm{~mol} / \mathrm{L}, V: V=95: 5, \mathrm{pH}=7.4)$ 中, 随着 $\mathrm{HClO}$ 的加入, 探针 $\mathbf{1 8}$ 的溶液从无色变为紫红色, 实现 肉眼检测，同时苂光强度比率增大 106 倍. 在相同条件 下，其他 $\operatorname{ROS}$ 和 $\operatorname{RNS}\left(\right.$ 如 $\bullet \mathrm{O}_{2}^{-}, \cdot \mathrm{OH},{ }^{t} \mathrm{BuO} \cdot, \mathrm{ONOO}^{-}{ }^{\text {等 })}$ 均不会引起探针 18 荧光光谱的明显变化. $\mathrm{pH}$ 响应实验 表明, $\mathrm{pH}$ 从 4 到 8 范围内可以实现探针 $\mathbf{1 8}$ 对 $\mathrm{HClO}$ 比 较满意的响应. 该类型的探针可以准确定性和定量地实 现实际样本中 $\mathrm{HClO}$ 的识别检测.<smiles>CCN(CC)c1ccc2c(c1)OC1=C(CCc3cc(N)ccc31)C21C(=S)c2ccccc2N1c1ccccc1OC(C)C</smiles>

\section{3 其他含有硫化物的传感器}

2013 年, 韩守法等 ${ }^{[38]}$ 基于苯并噻唑啉设计合成了 一种 $\mathrm{HClO}$ 荧光比色探针 19 (Eq. 16). 在乙醇中, 探针 
19 的溶液无色无荧光, $\mathrm{ClO}^{-}$的加入引起该探针分子内脱 氧硫内酯的氧化开环, 溶液立刻变为深红色, 荧光迅速 增强, $590 \mathrm{~nm}$ 处的荧光强度与 $\mathrm{ClO}^{-}$浓度 $(0 \sim 60 \mu \mathrm{mol} / \mathrm{L})$ 呈线性关系 $\left(\lambda_{\mathrm{ex}}=560 \mathrm{~nm}\right)$. 相同条件下, 其他常见超氧 阴离子自由基和阴阳离子均不会引起探针 19 溶液颜色 和苂光强度的明显变化. 但是 $\mathrm{Fe}^{3+}$ 的加入会引起探针 19 的苂光强度发生明显增强, 这可能是因为 $\mathrm{Fe}^{3+}$ 促进 了分子内脱氧硫内酯的开环.

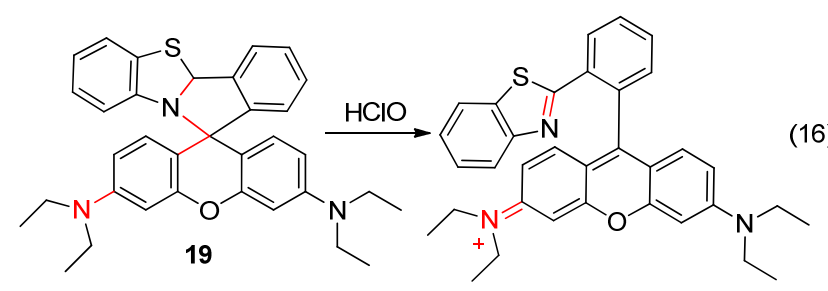

2015 年, 梅青松等 ${ }^{[39]}$ 报道了一种基于发光共振能 量转移(LRET)机制的上转换发光纳米传感器 20 (Eq. 17). 该纳米传感器以水分散的上转换纳米粒子作为能 量供体, 采用一种新型的 $\mathrm{ClO}^{-}$反应配位锌-二硫腙络合 物 $\left[\mathrm{Zn}(\mathrm{DZ})_{3}\right]$ 作为能量受体. 通过 $\mathrm{ClO}^{-}$选择性氧化破坏 $\mathrm{Zn}(\mathrm{DZ})_{3}$ 络合物中的 $\mathrm{Zn}-\mathrm{S}-\mathrm{C}$ 键, 可以有效地恢复 $\mathrm{Zn}(\mathrm{DZ})_{3}$ 络合物引起的猝灭上转换发光. 在 $\mathrm{pH}=7.4$ 的 $\mathrm{PBS}$ 缓冲液中, 随着 $\mathrm{ClO}^{-}$的加入, 纳米探针 $\mathbf{2 0}$ 的溶液 从红色先变为浅褐色, 最后变为淡黄色, 在 $540 \mathrm{~nm}$ 左右 的发射峰强度逐渐增强, 荧光强度与 $\mathrm{ClO}^{-}$浓度 $(0 \sim$ $2.0 \times 10^{-7} \mathrm{~mol} / \mathrm{L}$ ) 呈线性关系, 检测限低至 $3 \mathrm{nmol} / \mathrm{L}$, 如 此低的检测限可能是由于上转换检测的发光背景较低. 在同一环境中, 除了 $\mathrm{ClO}^{-}$与 $\mathrm{H}_{2} \mathrm{O}_{2}$ 反应生成的 ${ }^{1} \mathrm{O}_{2}$ 对纳 米探针的发光强度产生影响外 (可能是因为该反应残留 了部分 $\mathrm{ClO}^{-}$), 常见 ROS 和金属离子均不影响纳米探针 的发光强度. HeLa 细胞毒性试验表明, 纳米探针 $\mathbf{2 0}$ 在 较高浓度下 $\left(2 \mathrm{mg} \cdot \mathrm{mL}^{-1}\right)$ 对细胞的毒性很低, 结合共聚 焦激光扫描显微镜, 实现了在 $\mathrm{HeLa}$ 细胞中 $\mathrm{ClO}^{-}$的定性 和定量检测. 该纳米探针为高灵敏和高选择性追踪细胞 中的 $\mathrm{ClO}^{-}$提供了可能.

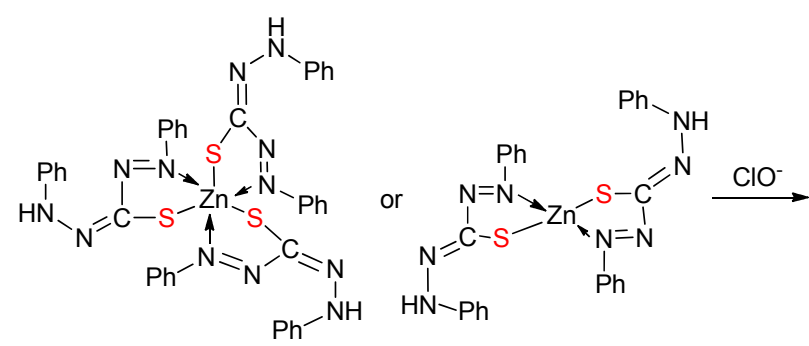

20<smiles>c1ccc(N=NC(=N/Nc2ccccc2)/C(/N=N/Nc2ccccc2)=N\Nc2ccccc2)cc1</smiles>

最近, 朱宝存等 ${ }^{[40]}$ 以硫代氨基甲酸酯为特异性识 别基团，设计合成了一种超快速超灵敏的溶酶体靶向的 $\mathrm{HClO}$ 荧光比色探针 21 (Eq. 18). 在 PBS 缓冲液( 0.005 $\mathrm{mol} / \mathrm{L}, \mathrm{pH}=7.4)$ 中, 探针 $\mathbf{2 1}$ 本身的荧光很弱, 可能是因 为螺内酯的闭环, $\mathrm{HClO}$ 的加入引起该探针硫代氨基甲 酸酯中的螺内酯开环并氧化裂解, $550 \mathrm{~nm}$ 处的苂光迅速 增强 $(<3 \mathrm{~s})$, 并且苂光强度与 $\mathrm{HClO}$ 浓度 $(50 \sim 450$ $\mathrm{nmol} / \mathrm{L})$ 之间存在很好的线性关系 $(Y=122.24 C+12519$, $\left.R^{2}=0.9985\right)$, 检测限低至 $0.12 \mathrm{nmol} / \mathrm{L}$, 比其他已报道的 溶酶体靶向 $\mathrm{HClO}$ 荧光探针的灵敏度高. $\mathrm{HClO}$ 的加入同 样使探针 21 溶液立马从淡黄色变为粉红色, 实现对 $\mathrm{HClO}$ 的肉眼检测. 相同环境下, 其他常见各种 ROS 均 不会引起该探针在 $550 \mathrm{~nm}$ 处苂光强度的明显变化. 细 胞实验表明，该探针可用于监测细胞内 $\mathrm{HClO}$ 的基线水 平及跟踪活细胞溶酶体内源性/外源性 $\mathrm{HClO}$ 水平的变 化.

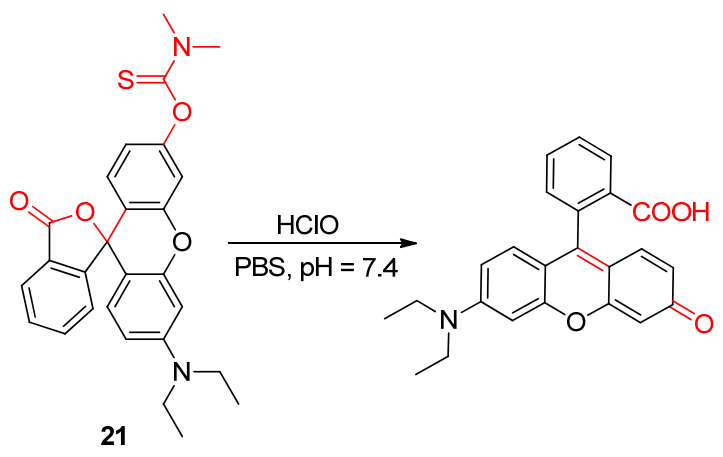

\section{2 含 $\mathbf{N}$ 原子的识别组}

\section{1 羟胺或肟作为识别基团}

羟胺或肜能与 $\mathrm{HClO}$ 快速反应生成相应的酫、腈氧 化物、羧酸等, $\mathrm{C}=\mathrm{N}$ 的去除引起荧光强度的变化. 近几 年来, 有很多荧光比色探针都是以羟胺或肜作为识别基 团来识别检测 $\mathrm{HClO}$.

2013 年, 吴水珠等 ${ }^{[41}$ 报道了一种基于 BODIPY 的 具有肜基和亲水性羧基的水溶性荧光比色探针 22 (Eq. 19). 在 $\mathrm{PBS}$ 缓冲液 $(0.1 \mathrm{~mol} / \mathrm{L}, \mathrm{pH}=7.4)$ 中，探针 22 本身 由于 $\mathrm{C}=\mathrm{N}$ 异构化激发态衰弱而无荧光, $\mathrm{ClO}^{-}$的加入去 除了肜基团, 还原了含有 BODIPY 的醛基，使溶液颜色 从粉红色变为淡黄色, 苂光增强, 并且苂光强度与 $\mathrm{ClO}^{-}$ 浓度 $(0 \sim 6 \mu \mathrm{mol} / \mathrm{L})$ 呈线性关系, 检测限 $(17.7 \mathrm{nmol} / \mathrm{L})$ 与 已经报道过的大多数荧光探针相比, 相对较低 $\left(\lambda_{\mathrm{ex}} / \lambda_{\mathrm{em}}=\right.$ 500/525 nm). 相反, 其他 ROS 和 RNS 都不会引起探针 22 荧光光谱的变化. 该探针也被成功用于活的 RAW 264.7 细胞中内源性 $\mathrm{ClO}^{-}$的荧光成像, 为细胞中内源性 和外源性 $\mathrm{ClO}^{-}$的苂光成像提供检测手段. 


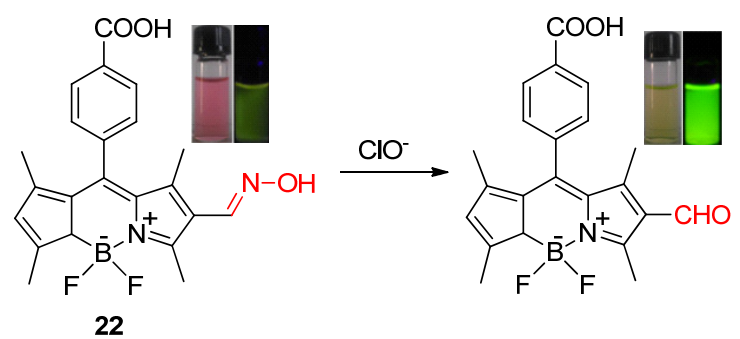

同年, 焚江莉等 ${ }^{[42]}$ 也成功地设计合成了一种基于 BODIPY 支架的含肜荧光比色探针 23 (Eq. 20), 并将其 用于线粒体中 $\mathrm{HClO}$ 的快速、高选择性荧光成像. 由于 $\mathrm{C}=\mathrm{N}$ 异构化, 探针 $\mathbf{2 3}$ 的苂光很弱, $\mathrm{ClO}^{-}$的加入使探针 23 的苂光强度快速变化, 这可能是因为肟基团消除生 成羧酸. 在 PBS-EtOH 混合溶液 $(0.01 \mathrm{~mol} / \mathrm{L}, V: V=9 / 1$, $\mathrm{pH}=7.4)$ 中, $\mathrm{ClO}^{-}$引起探针 $\mathbf{2 3}$ 在 $518 \mathrm{~nm}$ 处的紫外可见 吸收强度下降, 并出现一个新的吸收峰 $(505 \mathrm{~nm})$, 溶液 从粉红色变为黄色, 实现了对 $\mathrm{ClO}^{-}$的可视化检测. 随着 $\mathrm{ClO}^{-}$浓度的增加, $529 \mathrm{~nm}$ 处的荧光强度逐渐增强, 并在 50 equiv. $\mathrm{ClO}^{-}$处达到平台, 荧光强度增强了 35 倍, 荧 光量子产率从 0.045 增加到 $0.44\left(\lambda_{\mathrm{ex}}=480 \mathrm{~nm}\right)$. 另外, 该探针的选择性好, 其他 ROS 几乎不会引起探针 $\mathbf{2 3}$ 荧 光光谱的变化. 再者, 该探针的适用 $\mathrm{pH}$ 范围广, 探针 23 本身和该探针与 $\mathrm{ClO}^{-}$反应产物的苂光强度都不受 $\mathrm{pH}$ 值 $(\mathrm{pH}=3 \sim 12)$ 的影响. 鉴于该探针良好的化学和生物 特性, 结合共聚焦荧光成像, 已经将其成功应用于活细 胞线粒体中 $\mathrm{HClO}$ 的实时监测.

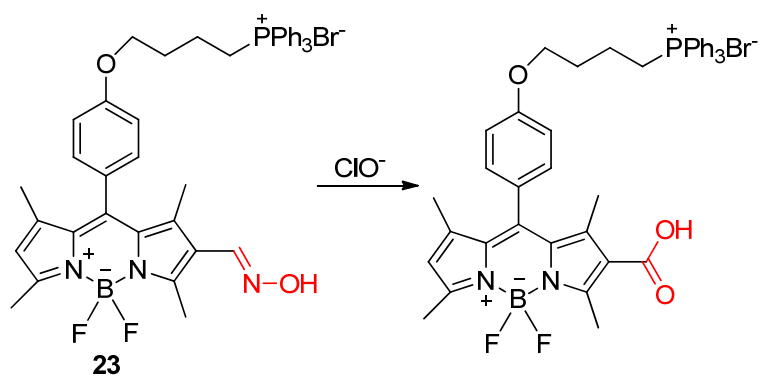

(20)

2016 年, 张小玲等 ${ }^{[43]}$ 设计合成了基于荎二甲酰亚 胺的 $\mathrm{HClO}$ 苂光比色探针 24 (Eq. 21). 该探针中的 $\mathrm{C}=\mathrm{N}$ 键作为 $\mathrm{HClO}$ 的识别基团, 通过 $\mathrm{HClO}$ 对该探针的氧化 脱氢反应, 去除 $\mathrm{C}=\mathrm{N}$ 键, 引起探针 24 的溶液颜色、紫 外可见吸收光谱和荧光光谱的变化, 从而实现对 $\mathrm{HClO}$ 的识别检测. 在室温下, $\mathrm{PBS}-\mathrm{CH}_{3} \mathrm{CH}_{2} \mathrm{OH}$ 溶液 $(0.05 \mathrm{~mol} /$ $\mathrm{L}, V: V=8: 2, \mathrm{pH}=7.4)$ 中, 探针 24 本身无苂光, 苂光 量子产率低(0.006), $\mathrm{ClO}^{-}$的加入使得该探针的苂光量子 产率迅速增加至 0.389 , 在 $510 \mathrm{~nm}$ 处的荧光强度增加 138 倍. 并且 $\mathrm{ClO}^{-}$的加入使得该探针的溶液从淡黄色变 为无色, 手持紫外灯 (365 nm)照射下发出强烈的绿色荧
光，反应只需几秒钟即可完成 $(<3 \mathrm{~s})$. 该探针具有很好 的选择性, 相同环境下, 包括 ROO•, $\mathrm{H}_{2} \mathrm{O}_{2}, \cdot \mathrm{OH}$, ${ }^{t} \mathrm{BuOOH},{ }^{t} \mathrm{BuO} \bullet, \mathrm{NO} \bullet$ 和 $\bullet \mathrm{O}_{2}^{-}$在内的其他 $\mathrm{ROS}$ 和 $\mathrm{RNS}$ 以 及包括 Cys, Hcy, GSH, K ${ }^{+}, \mathrm{Ca}^{2+}, \mathrm{Na}^{+}, \mathrm{NO}_{2}^{-}$和 $\mathrm{NO}_{3}^{-}$在 内的硫醇和离子几乎都不会引起该探针的荧光强度的 变化. 该探针能够实现对 $\mathrm{ClO}^{-}$的快速反应 $(<3 \mathrm{~s})$, 灵敏 度高(检测限为 $2.88 \mathrm{nmol} / \mathrm{L}$ ), 选择性好, 并且斯托克斯 位移大 $(75 \mathrm{~nm})$, 这些优良的化学性质使得其可以应用 于活体细胞中内源性 $\mathrm{ClO}^{-}$的实时定性及定量检测. 结 合共聚焦苂光成像技术，已经成功将其用于活细胞中 $\mathrm{ClO}^{-}$的荧光成像.

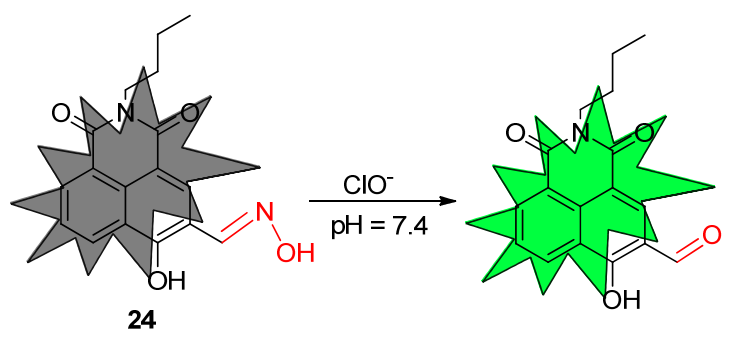

2017 年, 钱鹰等 ${ }^{[44]}$ 设计合成了一种新型吡啶基三 苯胺-BODIPY 醛肜的 $\mathrm{HClO}$ 荧光和肉眼可见的传感器 25 (Eq. 22). 该传感器通过 4-乙烯基吡啶基与三苯基胺BODIPY 结合形成了理想的共轭体系, 由于 $\mathrm{C}=\mathrm{N}$ 异构 化, 该传感器表现出微弱的荧光, $\mathrm{ClO}^{-}$氧化肟 $(\mathrm{C}=$ $\mathrm{NOH})$ 生成醛基，还原了 BODIPY 荧光团的荧光，使苂 光光谱发生显著变化. 在 PBS-THF 缓冲液 $(V: V=1: 1$, $\mathrm{pH}=7.4)$ 中, $\mathrm{ClO}^{-}$的加入使探针 $520 \mathrm{~nm}$ 处的吸收值显著 下降，肉眼可见溶液从粉色变为绿色. 同样条件下，随
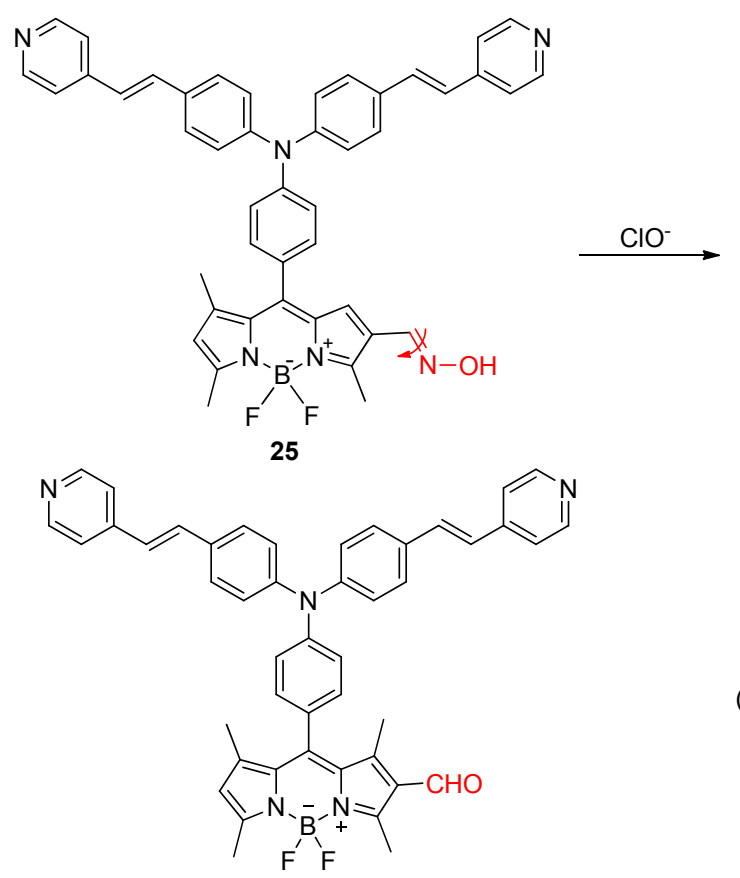
着 $\mathrm{ClO}^{-}$的加入, 探针在 508 和 $555 \mathrm{~nm}$ 处的苂光强度增加, 并逐渐在 $520 \mathrm{~nm}$ 处达到峰值, 并出现了苂光颜色变化 (从粉红色到绿色), 苂光强度增强 20 倍, 苂光量子产率 从 0.02 增加到 0.43 . 另外, 该探针的 $\mathrm{pH}$ 范围广, $\mathrm{pH}$ 值在 1 到 13 的范围内都不影响该探针对 $\mathrm{ClO}^{-}$的检测. 相同条 件下, 其他 ROS 几乎不会引起探针 25 的紫外可见吸收光 谱和荧光强度的明显变化. 该探针具备诸多优良性质, 有望在各种生物学和病理学过程中发挥重要作用.

\section{2 酰肼与 $\mathrm{HClO}$ 的氧化水解反应}

通过将某一个或两个荧光团与酰肼进行组装成螺 内酰胺的苂光团衍生物, 利用 $\mathrm{HClO} / \mathrm{ClO}^{-}$的强氧化性, 使螺内酰胺开环, 然后水解生成羧酸盐, 从而恢复苂光 团本身的荧光. 近年来, 利用这一识别机制, 设计合成 了很多苂光比色探针.

Goswami 等 ${ }^{[45,46]}$ 分别在 2014 年和 2015 年报道了两 个基于罗丹明-酰肼的 $\mathrm{HClO}$ 化学传感器 $\mathbf{2 6}$ 和 $\mathbf{2 7}$, 并都 成功制作成检测试纸用于 $\mathrm{HClO}$ 的肉眼检测. 由于两个 传感器中都存在螺内酰胺结构, 两个探针的荧光都很微 弱, $\mathrm{ClO}^{-}$能够氧化传感器 $\mathbf{2 6}$ 和 $\mathbf{2 7}$, 使螺内酰胺开环, 从 而使二者的苂光强度迅速增强, 具体检测机制见 Scheme 3. 在生理 $\mathrm{pH}, \mathrm{ClO}^{-}$的加入使两个化学传感器 的溶液从无色变为粉红色, 荧光强度明显增强, 还能实 现对 $\mathrm{HClO}$ 的定量检测. 并且传感器 $\mathbf{2 6}$ 和 27 都具有很 高的选择性和抗干扰性. 传感器 26 还成功实现了在人 类血细胞中对 $\mathrm{HClO}$ 的苂光成像. 传感器 27 的灵敏度超 高, 能实现对 $\mathrm{ClO}^{-}$纳米级检测, 已经被成功应用于自来 水中对 $\mathrm{HClO}$ 的定性及定量检测, 也被成功应用于活细 胞中 $\mathrm{HClO}$ 的苂光成像.
基于罗丹明-酰肼结构和螺内酰胺开闭环机制实现 对 $\mathrm{HClO}$ 检测的还有 2016 年 Long 等 ${ }^{[47]}$ 报道的两个 $\mathrm{HClO}$ 比色荧光探针 $\mathbf{2 8}$ 和 29 和林伟英的团队 ${ }^{[48]}$ 报道的 以溶酶体为靶向的比率型 $\mathrm{HClO}$ 显色荧光探针 30 (Scheme 4). 探针 $\mathbf{3 0}$ 中的酚羟基与苯并唑环的 $\mathrm{N}$ 原子之 间存在激发态分子内质子转移(ESIPT)过程, 在 $\mathrm{pH}=5.0$ 的 PBS-DMF 缓冲液 $(V: V=7: 3)$ 中, $\mathrm{ClO}^{-}$的加入使探 针 30 中的螺内环打开, 同时阻止了 ESIPT 过程, 使探针 30 的溶液从无色变为红色, 苂光强度比率 $\left(I_{586} / I_{450}\right)$ 迅速 增大 97 倍, 并成功实现了活细胞溶酶体中内源性和外 源性 $\mathrm{HClO}$ 水平的检测.

除此之外，于海波等 ${ }^{[49]}$ 最近也设计合成了一种基 于罗丹明 $\mathrm{B}$ 苂光团和 2-碳酰肼噻吩结构以酰肼作为识 别基团的 $\mathrm{HClO}$ 比色荧光探针 31, 通过氧化水解, $\mathrm{HClO}$ 使罗丹明的螺内酰胺开环生成羧酸基(Scheme 5), 从而 使探针 31 溶液颜色立刻从无色变为粉红色, 并发射罗 丹明 $\mathrm{B}$ 的强苂光. 该探针还制作成了测试条成功用于实 际水样中 $\mathrm{HClO}$ 的肉眼检测, 并成功实现活细胞线粒体 中 $\mathrm{HClO}$ 荧光成像.

2017 年, 赵宝祥课题组 ${ }^{[50]}$ 基于苂光共振能量转移 (FRET)和螺内酰胺的开闭环机制, 将香豆素-罗丹明两 个荧光团连接起来，设计合成了一种以线粒体为靶向的 比率型 $\mathrm{HClO}$ 显色荧光探针 32 (Scheme 6). 并实现了在 线粒体的生理 $\mathrm{pH}$ 下对 $\mathrm{HClO}$ 肉眼快速、高选择性和高 灵敏的比率 $\left(I_{570} / I_{483}\right)$ 检测, 并将其成功应用于活细胞线 粒体中内源性 $\mathrm{HClO}$ 的荧光成像. 最近, Wong 等 ${ }^{[51]}$ 也将 香豆素-罗丹明两种荧光团结合起来, 并在螺碳环上引 入磺胺酰肼基团作为 $\mathrm{HClO}$ 的识别部位, 设计合成了一

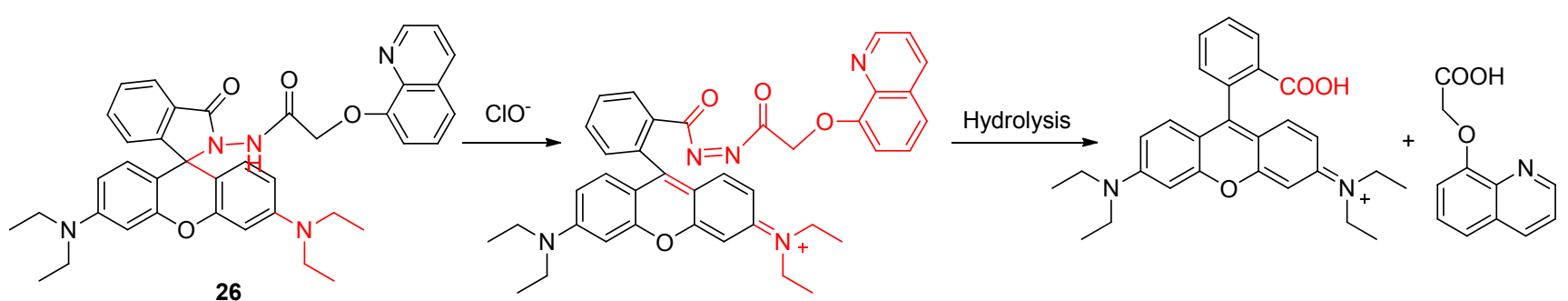

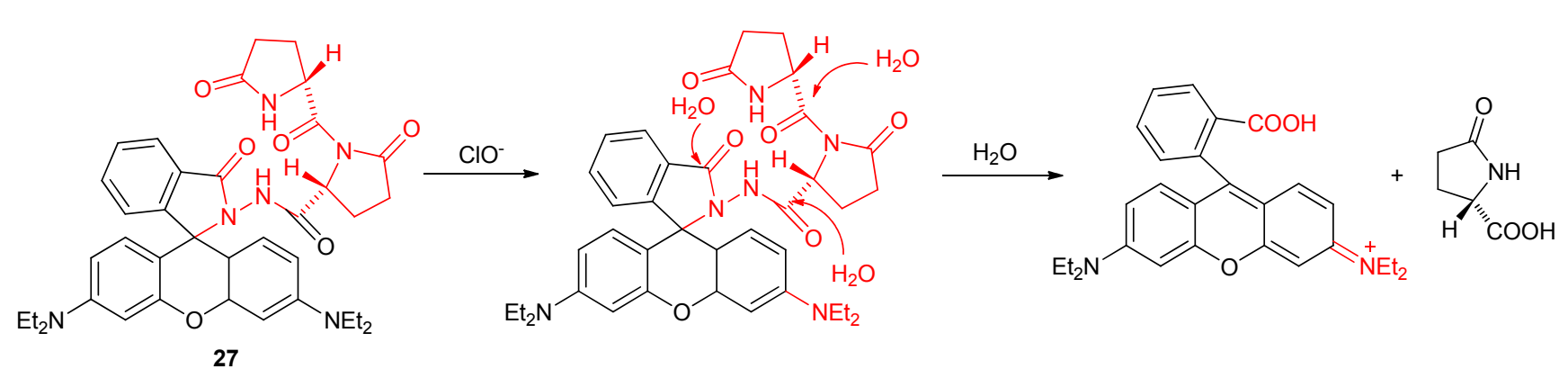

图式 3 探针 26 和 27 与 $\mathrm{ClO}^{-}$的反应机理

Scheme 3 Reaction mechanism of probes 26 and 27 with $\mathrm{ClO}^{-}$ 


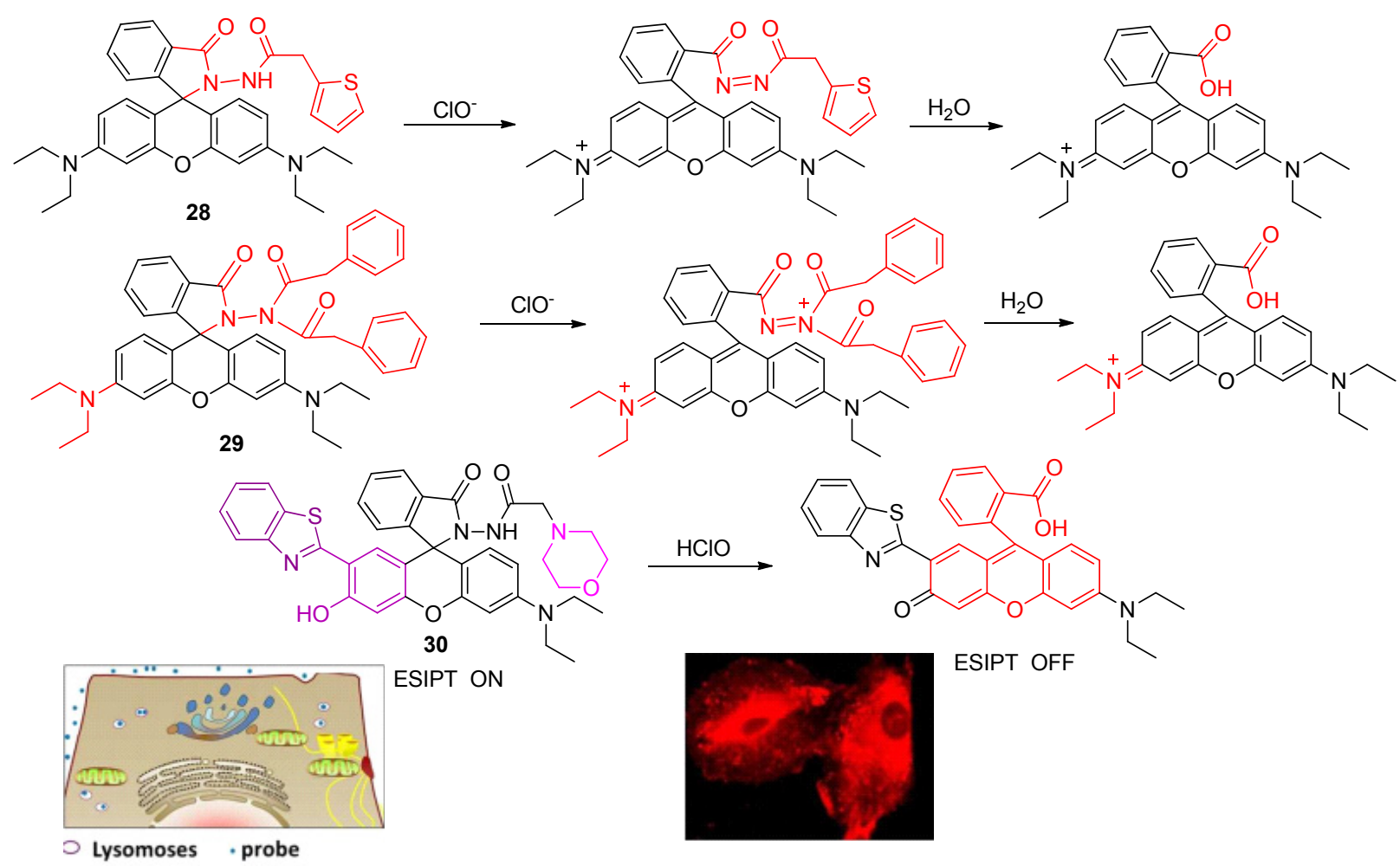

图式 4 探针 $28 \sim 30$ 与 $\mathrm{HClO} / \mathrm{ClO}^{-}$的反应机理以及探针 30 在活细胞溶酶体中的分布和 $\mathrm{HClO}$ 荣光成像

Scheme 4 Reaction mechanism of probes $\mathbf{2 8} \sim \mathbf{3 0}$ with $\mathrm{HClO} / \mathrm{ClO}^{-}$and the distribution of probe $\mathbf{3 0}$ in living cell lysosomes and $\mathrm{HClO}$ fluorescence imaging in living cell lysosomes

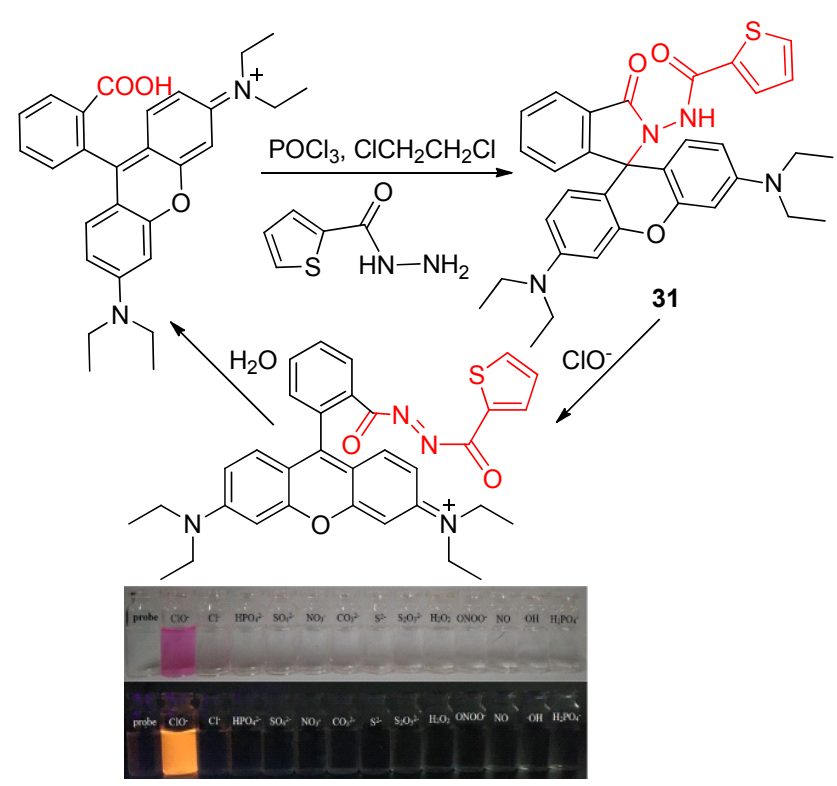

图式 5 探针 31 与 $\mathrm{ClO}^{-}$的反应机理以及不同阴离子和探针 $\mathbf{3 1}$ 在自然光和紫外灯下的颜色反应

Scheme 5 Reaction mechanism of probe 31 with $\mathrm{ClO}^{-}$and the color changes of dififferent anions with probe $\mathbf{3 1}$ under sunlight and UV light, respectively

种独特的、受 $\mathrm{pH}$ 调节的、具有高选择性和高灵敏度的 荧光比色探针 33 (Scheme 6). 酸性条件下, $\mathrm{HClO}$ 氧化该 探针使香豆素-罗丹明杂化物的五元螺环打开, 引起探

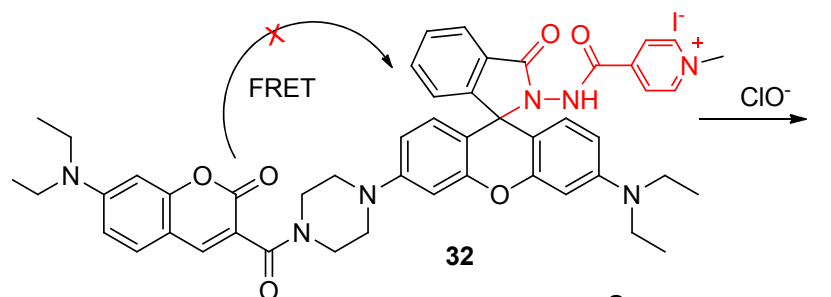<smiles></smiles>

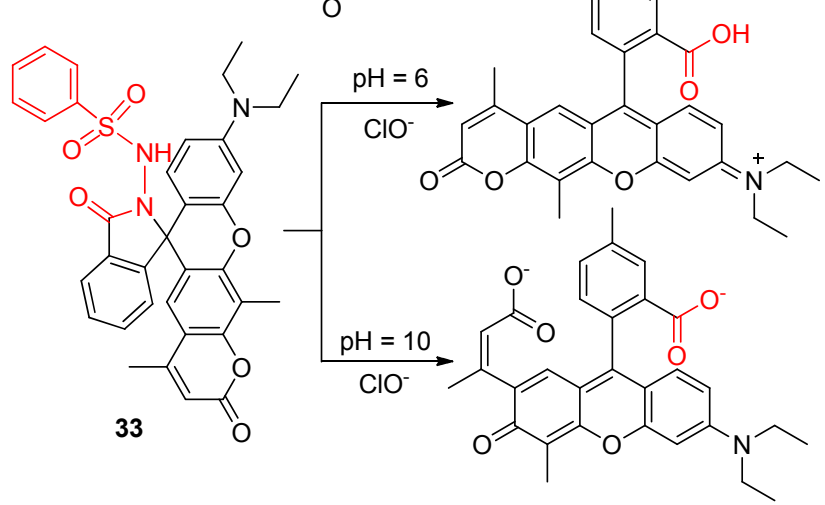

图式 6 探针 32 和 33 与 $\mathrm{ClO}^{-}$的反应机理

Scheme 6 Reaction mechanism of probes 32 and 33 with $\mathrm{ClO}^{-}$ 
针溶液颜色的明显变化和荧光强度显著增强. 碱性条件 下, $\mathrm{ClO}^{-}$的加入使五元螺环和六元内酯环都打开, 引起 不同于酸性条件下的溶液颜色变化, 并且荧光强度增强 更明显. 该探针还被成功应用于自来水和 84 消毒液中 $\mathrm{ClO}^{-}$的定性和定量检测.

2015 年, Chang 等 ${ }^{[52]}$ 报道一种基于罗丹明-丹酰二 亚胺两种荧光团的具有显色和比率荧光信号的 HClO 传 感器 34 (Eq. 23). 首次利用磺酰肼与 $\mathrm{HClO}$ 的选择性氧 化水解反应, 以罗丹明-丹酰二亚胺作为信号传感器, 磺酰肼结构作为 $\mathrm{HClO}$ 的识别触发开关, 实现了对 $\mathrm{HClO}$ 的识别检测. 在 $\mathrm{pH}=8$ 的 $\mathrm{PBS}$ 缓冲液中, 探针 34 本身无色, $\mathrm{ClO}^{-}$的加入使之变为粉色, 并出现紫外可见 吸收光谱的相应变化. 由于丹磺酰苂光团的作用, 探针 34 本身在 $494 \mathrm{~nm}$ 处表现出中等强度的荧光, 而该探针 中内酰胺的闭环状态使得罗丹明苂光团并没有表现出 荧光发射, $\mathrm{ClO}^{-}$的加入使探针开环, 出现 $578 \mathrm{~nm}$ 处罗丹 明的荧光发射 $\left(\lambda_{\mathrm{ex}}=400 \mathrm{~nm}\right)$, 从而出现 578 和 $494 \mathrm{~nm}$ 的 比率变化 $\left(I_{578} / I_{494}\right)$. 并且探针 34 的选择性好, 其他 $\mathrm{ROS} / \mathrm{RNS}$ ，金属离子和阴离子几乎不会引起探针 34 的 苂光强度比率的变化. 最后还成功将探针 34 制作成测 试条用于自来水中 $\mathrm{HClO}$ 的肉眼和半定量检测.

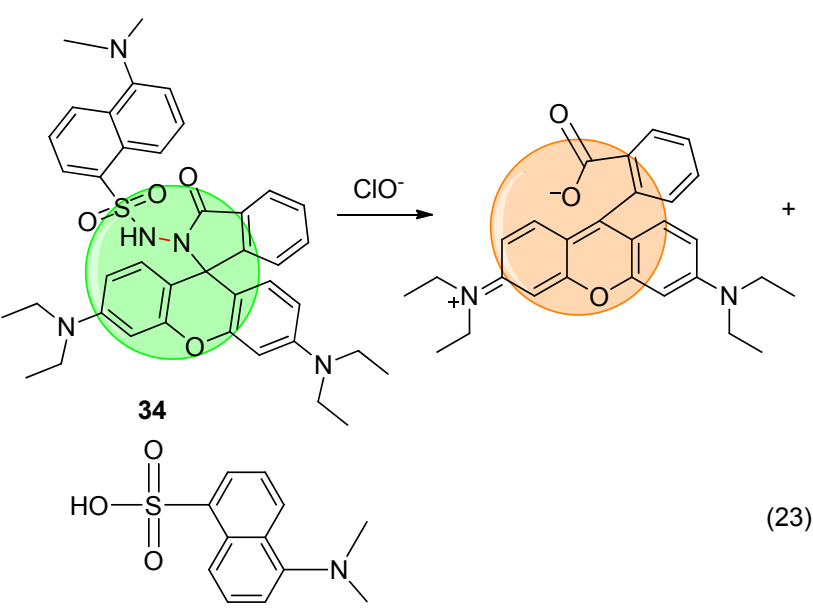

(a) $0 \mathrm{mM} \quad 0.2 \mathrm{mM} \quad 0.4 \mathrm{mM} \quad 0.6 \mathrm{mM} \quad 0.8 \mathrm{mM} \quad 1.0 \mathrm{mM}$

(b) $0 \mathrm{mM} 0.2 \mathrm{mM} 0.4 \mathrm{~mm} 0.6 \mathrm{~mm} 0.8 \mathrm{mM} 1.0 \mathrm{~mm}$

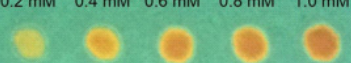

最近, 张志强等 ${ }^{[53]}$ 报道了一种基于上转换发光的 新型纳米探针 35 (Eq. 24), 将其应用于活体动物和细胞 中 $\mathrm{HClO}$ 的无背景比率苂光成像. 通过 LRET 原理, 以 钌-二硝基苯肼作为 $\mathrm{HClO}$ 的识别部分和能量受体, 上 转换纳米颗粒为能量供体, 利用 $\mathrm{HClO}$ 的强氧化性, 使 纳米探针 35 在水溶液中发生颜色、苂光比率和上转换 发光的变化, 从而实现对 $\mathrm{HClO}$ 的定性和定量检测. 该
纳米探针具有选择性和灵敏度高及反应迅速等优点，已 被制作成测试纸，成功实现了无背景干扰的 $\mathrm{HClO}$ 比色 和发光检测, 并实现了活细胞和活体动物中 $\mathrm{HClO}$ 的荧 光成像.
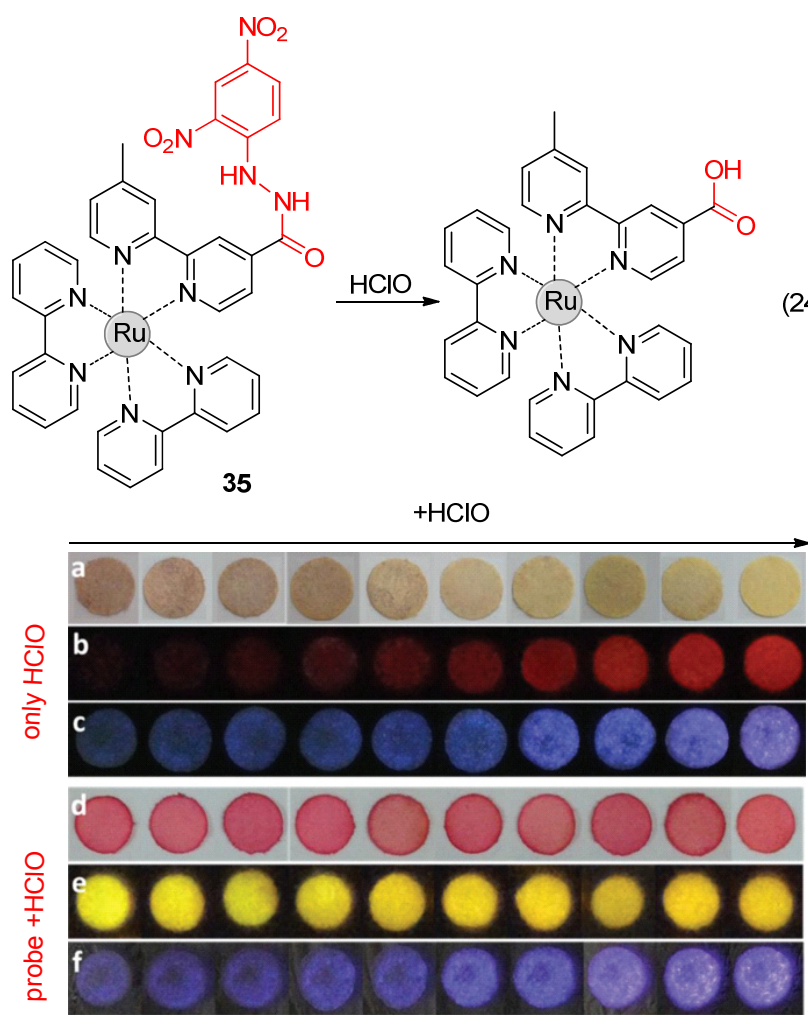

\section{3 酰腙与 $\mathrm{HClO}$ 的氯化水解反应}

$\mathrm{C}=\mathrm{N}$ 异构化是激发态的主要衰变过程 ${ }^{[54]}$, 酰腙结 构包含 $\mathrm{C}=\mathrm{N}$ 键使化合物通常无荧光发射, 利用 $\mathrm{HClO}$ 的强氧化性去除 $\mathrm{C}=\mathrm{N}$ 键可以使化合物的苂光恢复.

近几年, 吴淑褓课题组 ${ }^{[55]}$ 、周艳梅课题组 ${ }^{[56]}$ 和张小 玲等 ${ }^{[57]}$ 基于 BODIPY 苂光团, 分别设计合成了三个不同 的高选择性和高灵敏度的 $\mathrm{HClO}$ 显色荧光探针 36 38 (Scheme 7). 在 PBS 缓冲液中, 三个探针由于 $\mathrm{C}=\mathrm{N}$ 异构 化, 本身都表现出很微弱的荧光, $\mathrm{ClO}^{-}$以 $\mathrm{C}=\mathrm{N}$ 键为识 别基团, 特异性的氧化探针 36 中的 BODIPY一腙形成 分子内环化生成三坐, 而通过氧化去除探针 37 和 38 中 的 $\mathrm{C}=\mathrm{N}$ 键生成醛基，从而恢复探针 36 38 中 BODIPY 的强苂光, 并引起三个探针溶液颜色变化和苂光的显著 增强, 从而实现对 $\mathrm{HClO}$ 的特异性识别. 特别是探针 38 对 $\mathrm{HClO}$ 的反应超快速 $(<0.2 \mathrm{~s}), \mathrm{pH}$ 范围广 $(\mathrm{pH}=4 \sim 13)$, 检测限低至 $7.5 \mathrm{nmol} / \mathrm{L}$. 并且, 探针 36 和 37 成功实现了 活细胞中内源性 $\mathrm{HClO}$ 的荧光成像, 探针 38 实现了活细 胞中内源性和外源性 $\mathrm{HClO}$ 的荧光成像.

2015 年, 蒋石梅课题组 ${ }^{[58]}$ 以 $\mathrm{HClO}$ 对苯腙的特异性 反应设计合成了一种基于萠的高选择性 $\mathrm{HClO}$ 苂光比色 探针 39. 由于共轭的苯腙(电子给体)与萠(电子供体)之 

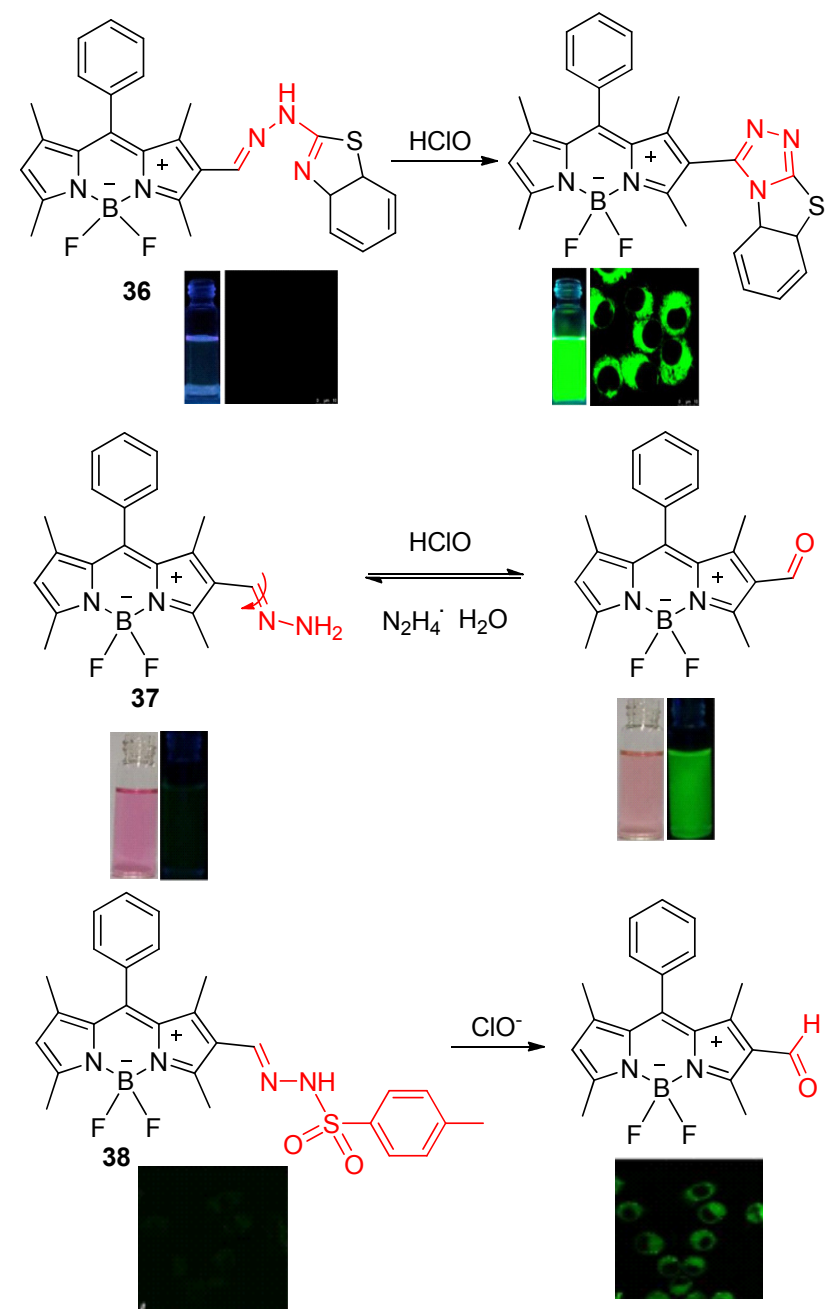

图式 7 探针 $\mathbf{3 6} \sim \mathbf{3 8}$ 与 $\mathrm{HClO} / \mathrm{ClO}^{-}$的反应机理以及加入 $\mathrm{HClO} / \mathrm{ClO}^{-}$后的颜色变化或在活细胞中 $\mathrm{HClO} / \mathrm{ClO}^{-}$荧光成像 Scheme 7 Reaction mechanism of probes $36 \sim 38$ with $\mathrm{HClO} / \mathrm{ClO}^{-}$and the color changes in the absence/presence of $\mathrm{HClO} / \mathrm{ClO}^{-}$and $\mathrm{HClO} / \mathrm{ClO}^{-}$fluorescence imaging in living cell

间的 PET 作用产生的强苂光淬灭效应，该探针本身无荧 光, 利用 $\mathrm{HClO}$ 的强氧化性消除了苯腙基团, PET 作用消 失, 恢复了芘的强荧光, 同时溶液从黄色变为无色, 其 他 ROS 和常见离子几乎不会引起探针 39 的苂光强度变 化. 该探针还被成功用于活细胞中 $\mathrm{HClO}$ 的生物成像.

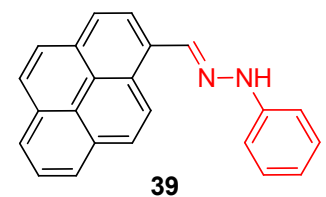

同年，陈小强等 ${ }^{[59]}$ 基于甲酰化菼光素衍生物设计 合成了一种高选择性和高灵敏度的 $\mathrm{HClO}$ 苂光比色探针 40. 2018 年, 张迪等 ${ }^{[60]}$ 同样用腙基修饰荧光素设计合成 了一种新的 “关-开” 型 $\mathrm{HClO}$ 苂光比色探针 41. 以 $\mathrm{C}=\mathrm{N}$ 键作为识别基团, 在生理条件下, $\mathrm{ClO}^{-}$的加入去
除了两个探针中的 $\mathrm{C}=\mathrm{N}$ 异构化并生成酫基，并使探针 40 和 41 的螺环开环, 恢复了甲酰化的苂光素 (Scheme 8), 溶液颜色都发生了明显改变, 并伴随着荧光显著增 强, 探针 $\mathbf{4 1}$ 的检测限为 $17.5 \mathrm{nmol} / \mathrm{L}$, 探针 $\mathbf{4 0}$ 的检测限 低至 $7.3 \mathrm{nmol} / \mathrm{L}$. 两个探针都具有良好的细胞膜通透性, 成功实现了活细胞中 $\mathrm{HClO}$ 的苂光成像.<smiles>O=Cc1c(O)ccc2c(-c3ccccc3C(=O)O)c3ccc(=O)cc-3oc12</smiles><smiles>O=Cc1c(O)ccc2c(-c3ccccc3C(=O)O)c3ccc(=O)cc-3oc12</smiles>

图式 8 探针 40 和 41 与 $\mathrm{HClO} / \mathrm{ClO}^{-}$的反应机理和加入 $\mathrm{ClO}^{-}$ 后的颜色变化

Scheme 8 Reaction mechanism of probes 40 and 41 with $\mathrm{HClO} / \mathrm{ClO}^{-}$and the color changes in the absence/presence of $\mathrm{ClO}^{-}$

赵宝祥等 ${ }^{[61]}$ 于 2016 年报道了包含 3-丁基-1-氯咪唑 [1,5-a $]$ 吡啶荧光团的具有双信号的 $\mathrm{HClO}$ 荧光探针 42 (Eq. 25). 通过 $\mathrm{ClO}^{-}$氧化去除了 $\mathrm{C}=\mathrm{N}$ 键, 使腙生成䅈 酸, 恢复了探针 42 的苂光, 在生理条件下, $\mathrm{ClO}^{-}$的加入 使探针 42 的溶液从黄色变为无色，同时苂光强度显著 增强, 检测限低至 $0.43 \mathrm{nmol} / \mathrm{L}$, 其他常见的分析物不影 响探针 42 对 $\mathrm{ClO}^{-}$的识别. 该探针还被成功用于活细胞 中 $\mathrm{ClO}^{-}$的苂光成像.

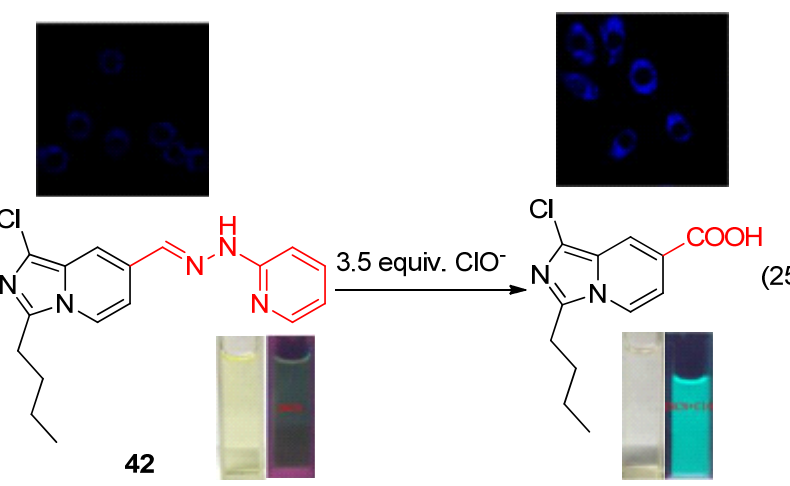


2018 年, 孟庆涛团队 ${ }^{[62]}$ 设计合成了基于 1,8 -萗二甲 酰亚胺的双功能 $\mathrm{HClO}$ 苂光比色探针 43 (Eq. 26), 并将 其应用于缓冲液和生物样本中 $\mathrm{HClO}$ 的定性及定量检 测. 在 PBS 缓冲液中, $\mathrm{ClO}^{-}$的加入使探针溶液的颜色从 粉色变为淡黄色, 并发生紫外可见吸收光谱的巨大变化 和苂光强度的显著增强, 这可能是由于 $\mathrm{HClO}$ 的强氧化 性引起 $\mathrm{C}=\mathrm{N}$ 键的消除生成羧酸基团. 而其他干扰离子 并未引起 43 的任何改变. 该探针具有高选择性和抗干 扰性, 且灵敏度高, 检测限低至 $50 \mathrm{nmol} / \mathrm{L}, \mathrm{pH}$ 范围广, 并能实现对 $\mathrm{HClO}$ 的超快速反应 $(<2 \mathrm{~s})$. 更重要的是, 该探针被已经成功用于活 Hela 细胞、 J774A.1 巨噬细胞 和斑马鱼中内源性及外源性 $\mathrm{HClO}$ 的苂光成像.

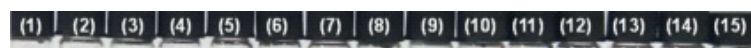
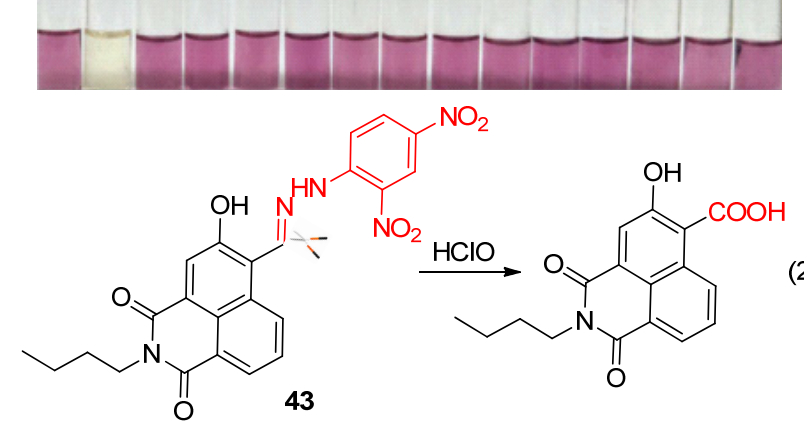

\section{4 其他肼或席夫碱 $\mathrm{HClO}$ 的氧化反应}

由于席夫碱或其他肼结构中包含的 $\mathrm{C}=\mathrm{N}$ 异构化, 用席夫碱或肼修饰的苂光团表现出无苂光状态, 而 $\mathrm{C}=\mathrm{N}$ 键容易被 $\mathrm{HClO}$ 氧化消除生成醛基或羧酸或腈氧化物从 而恢复了苂光团的强荧光, 实现检测 $\mathrm{HClO}$ 的目的.

2015 年, Goswami 等 ${ }^{[3]}$ 设计合成了基于脱二氨基顺丁烯 二腈反应, 以 $\mathrm{C}=\mathrm{N}$ 键作为 $\mathrm{HClO}$ 识别基团并氧化生成 醛基的 $\mathrm{HClO}$ 苂光比色探针 44 (Eq. 27). 探针 44 通过 $\mathrm{HClO}$ 的强氧化性抑制探针的 ICT 机制, 使其发生显著 的溶液颜色变化和荧光增强. $\mathrm{HClO}$ 的加入使探针的溶 液从黄色变为无色. 并使其溶液的苂光强度呈现比率型 增强. 使用薄层色谱板实现了探针 $\mathbf{4 4}$ 对 $\mathrm{HClO}$ 的检测, 并将其成功用于人类血细胞中 $\mathrm{HClO}$ 的苂光成像.

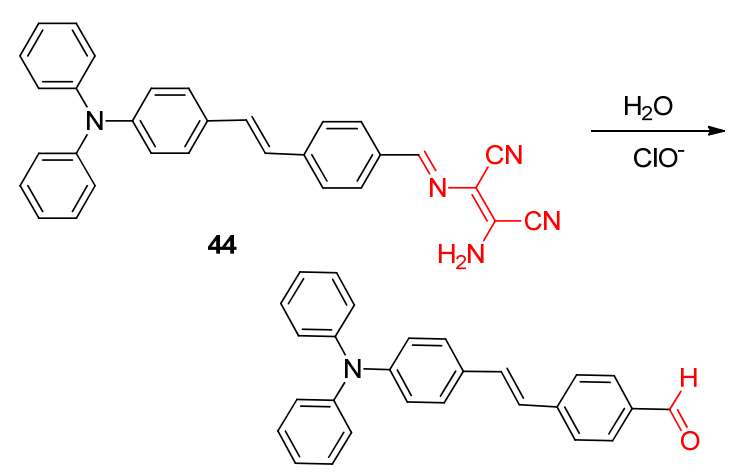

2018 年, 吴少平等 ${ }^{[64]}$ 同样基于席夫碱将二氨基顺
丁烯二腈基团同 7-(二甲氨基)-4,5-二氢萗 [1,2- $b$ ]塞吩- 2甲醛(DTC) 菼光团连接起来, 设计合成了以 $\mathrm{C}=\mathrm{N}$ 键作 为 $\mathrm{HClO}$ 识别基团并氧化生成 DTC 的 $\mathrm{HClO}$ “关一开” 型苂光比色探针 45 (Eq. 28). 该探针能实现对 $\mathrm{HClO}$ 的 肉眼快速、高灵敏和高选择性检测, 且 $\mathrm{pH}$ 范围广, 斯托 克斯位移大 $(80 \mathrm{~nm})$, 并被成功用于亚细胞中 $\mathrm{HClO}$ 的苂 光成像.

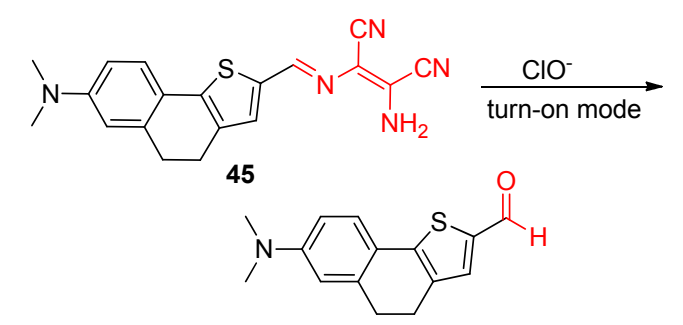

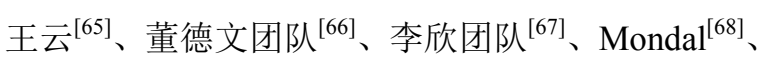
孟庆涛 ${ }^{[69]}$ 和闵立强等 ${ }^{[70]}$ 分别于 2016 年和 2018 年, 同样 利用二氨基顺丁烯二腈与 $\mathrm{HClO}$ 的氧化反应, 设计合成 了双功能 $\mathrm{HClO}$ 比色荧光探针 46 51 (Scheme 9). 46 和 48 基于 BODIPY 衍生物, 47 基于萠席夫碱衍生物, 通过 去除 $\mathrm{C}=\mathrm{N}$ 键, 恢复 BODIPY 或萠苂光团的强苂光. 探 针 48 首次利用 $\mathrm{HClO}$ 诱导的分子内环化反应来识别检 测 $\mathrm{HClO}$, 而 46, 47, 49 和 50 通过 $\mathrm{HClO}$ 氧化消除 $\mathrm{C}=\mathrm{N}$ 键生成醛基实现对 $\mathrm{HClO}$ 的识别, 探针 $\mathbf{5 1}$ 是通过 $\mathrm{C}=\mathrm{N}$ 键将香豆素和二氨基顺丁烯二腈结合起来, 利用 $\mathrm{ClO}^{-}$ 诱导的分子内环化生成咪唑结构. 在生理 $\mathrm{pH}$ 下, $\mathrm{ClO}^{-}$ 的加入使 6 个探针的溶液颜色都发生显著变化, 并伴随 着紫外可见吸收光谱的改变和苂光强度的显著增强. 探 针 50 和 51 分别只需 4 和 $5 \mathrm{~s}$ 就可以识别出 $\mathrm{HClO}$, 探针 46 48 也表现出对 $\mathrm{HClO}$ 的快速反应 $(<15 \mathrm{~s})$, 并具有 比较高的选择性和灵敏度. 其中, 探针 $\mathbf{5 1}$ 和 $\mathbf{5 0}$ 的检测 限分别低至 9 和 $17.3 \mathrm{nmol} / \mathrm{L}$. 探针 46 的检测限低至 19.8 $\mathrm{nmol} / \mathrm{L}$, 苂光量子产率从 0.008 增加到 0.64 , 该探针还 被成功用于自来水、长江水和 84 消毒液中 $\mathrm{ClO}^{-}$的定量 检测. 通过加标回收率实验也成功将探针 47 和 51 用于 自来水中 $\mathrm{ClO}^{-}$的定量检测. 探针 49 可以比率型识别 $\mathrm{HClO}$, 还成功将其制作成薄层色谱板, 用于 $\mathrm{HClO}$ 的实 时定性检测, 并用于糖尿病人单核细胞中 $\mathrm{HClO}$ 的苂光 成像分析. 生物成像表明, 探针 50 能够在体内诊断和评 估次氯酸介导的类风湿关节炎的治疗反应.

阴彩霞团队 ${ }^{[71]}$ 于 2018 年基于 1,8 -荎二甲酰亚胺衍 生物设计合成了一个 “关-开” 型和一个比率型的 $\mathrm{HClO}$ 荧光比色探针 52 和 53 . 二者都是利用 $\mathrm{ClO}^{-}$氧化清除 $\mathrm{C}=\mathrm{N}$ 键, 实现对 $\mathrm{HClO}$ 的活细胞荧光成像 (Scheme 10).

最近, 颜范勇等 ${ }^{[72]}$ 报道了以 $\mathrm{C}=\mathrm{N}$ 键作为 $\mathrm{HClO}$ 识别 基团, 通过去除 $\mathrm{C}=\mathrm{N}$ 键并阻断 PET 过程实现对 $\mathrm{HClO}$ 识别的比色苂光探针 54 (Scheme 11). 生理条件下, $\mathrm{ClO}^{-}$ 


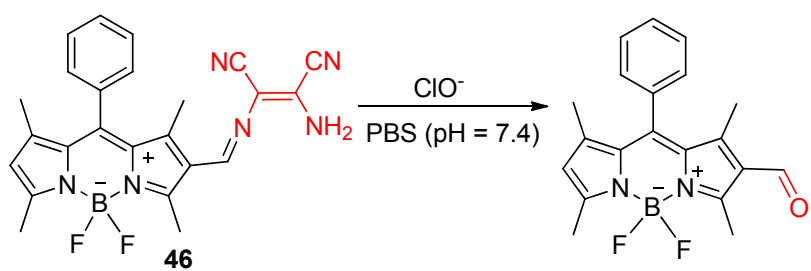<smiles>N#C/C(N)=C(\N=C\[O-])/N=C/c1ccc2ccc3cccc4ccc1c2c34</smiles>

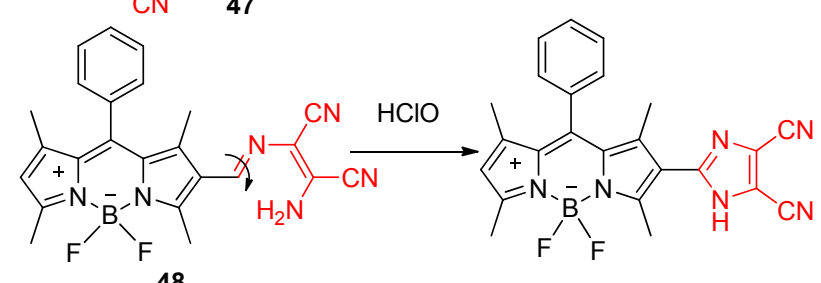

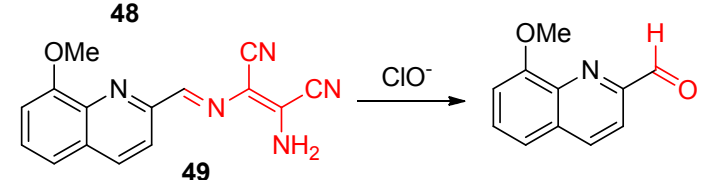<smiles>CCCCN1C(=O)c2cccc3c(CO)c(O)c(C)c(c23)C1=O</smiles>

图式 9 探针 $46 \sim 51$ 与 $\mathrm{HClO} / \mathrm{ClO}^{-}$的反应机理

Scheme 9 Reaction mechanism of probes $46 \sim 51$ with $\mathrm{HClO} / \mathrm{ClO}^{-}$

的加入使该探针溶液颜色从棕色变为绿色, 荧光显著增 强, 苂光量子产率从 0.13 增至 0.79 . 该探针具有 $\mathrm{pH}$ 范围 广、选择性好和灵敏度高等优点, 成功用于自然水样中 $\mathrm{HClO}$ 的定量检测和活细胞中 $\mathrm{HClO}$ 荧光成像.

\section{3 碳碳双键作为识别组}

$\mathrm{HClO}$ 具有强氧化性, 在温和的条件下能氧化 $\mathrm{C}=\mathrm{C}$ 双键, 使含有 $\mathrm{C}=\mathrm{C}$ 双键的 $\mathrm{HClO}$ 探针被氧化裂解成各 种不同的双键裂解产物. 利用这一性质, 将有机化合物 通过 $\mathrm{C}=\mathrm{C}$ 双键与菼光基团连接起来就能实现对 $\mathrm{HClO}$ 的识别.

近几年, 樊江莉团队 ${ }^{[73]}$ 和钱鹰等 ${ }^{[74]}$ 分别报道了两 种基于 BODIPY 苂光团, 以 $\mathrm{C}=\mathrm{C}$ 双键为识别位点的 $\mathrm{HClO}$ 荧光显色探针 55 和 56 (Scheme 12). 在模拟的生 理条件下, $\mathrm{HClO}$ 能选择性地引起两个探针表现出明显

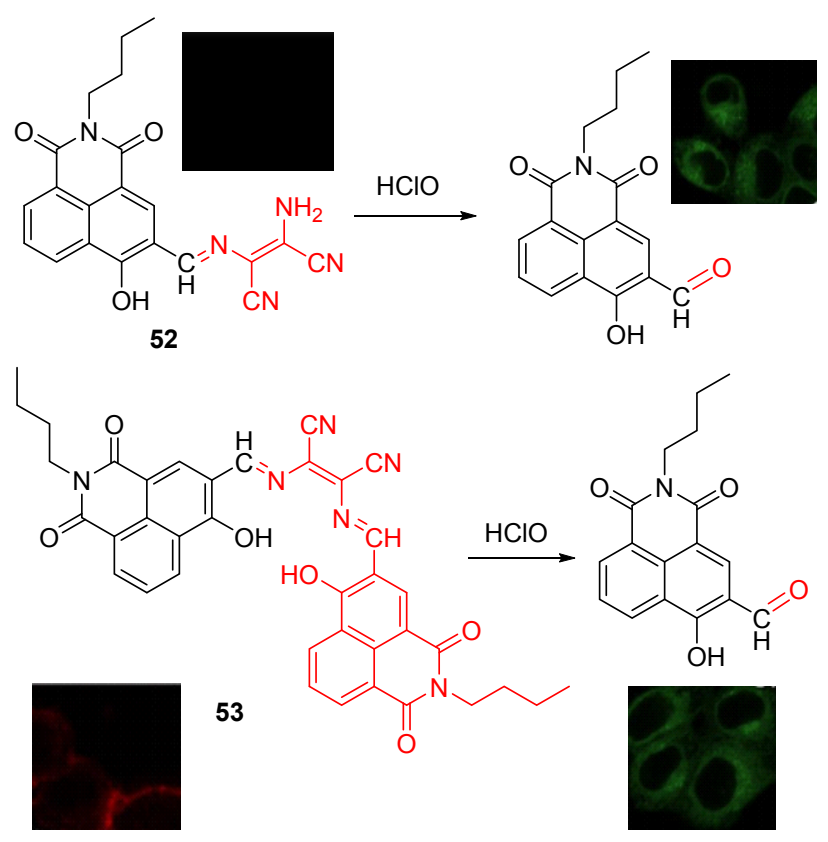

图式 10 探针 $\mathbf{5 2}$ 和 $\mathbf{5 3}$ 与 $\mathrm{HClO}$ 的反应机理以及 $\mathrm{HClO}$ 在活 细胞中的苂光成像

Scheme 10 Reaction mechanism of probes $\mathbf{5 2}$ and $\mathbf{5 3}$ with $\mathrm{HClO}$ and the $\mathrm{HClO}$ fluorescence imaging in living cell

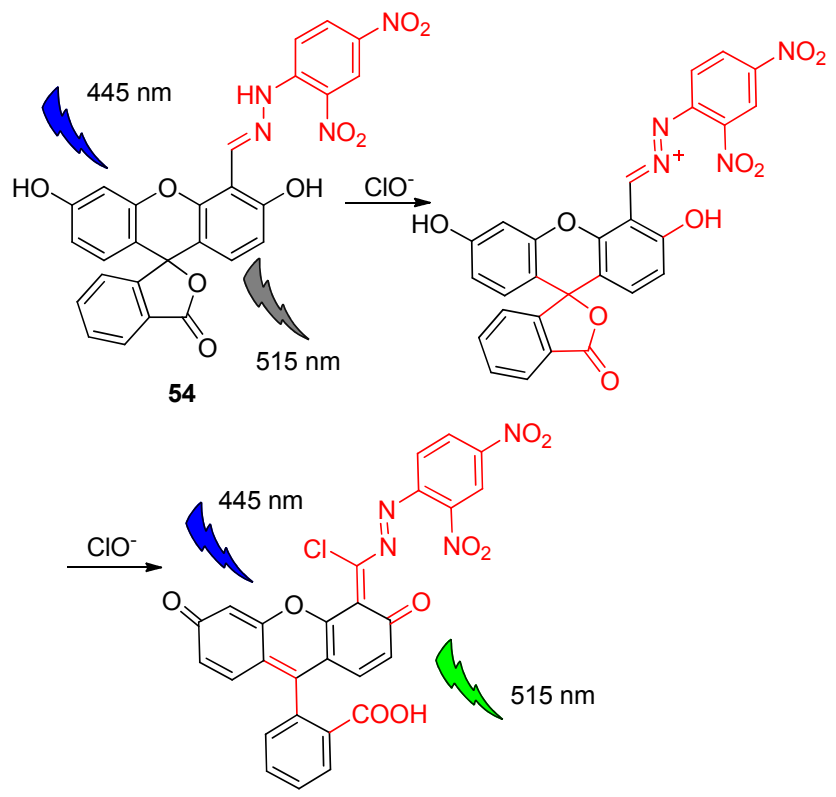

图式 11 探针 54 和 $\mathrm{HClO}$ 的反应机理

Scheme 11 Reaction mechanism of probe 54 with $\mathrm{HClO}$

的溶液颜色、紫外可见吸收光谱和荧光光谱的变化, 其 中探针 55 表现出苂光信号比率的显著增强. 探针 55 对 $\mathrm{HClO}$ 反应更迅速 $(<10 \mathrm{~s})$, 具有更低的检测限 $(10.6$ $\mathrm{nmol} / \mathrm{L})$, 并且 $\mathrm{pH}$ 范围广; 共聚焦荧光成像表明, 该探 针能实时监测活细胞溶酶体中内源性的 HClO. 而探针 56 已经成功实现癌细胞和活体斑马鱼中内源性 $\mathrm{HClO}$ 的 菼光成像, 并且不需要药物诱导产生 $\mathrm{HClO}$. 
韩克利 ${ }^{[75]}$ 、王素华 ${ }^{[18]}$ 、孙民泰 ${ }^{[76]}$ 、周立义 ${ }^{[77]}$ 和马 志伟等 ${ }^{[78]}$ 在近几年基于花菁染料, 利用 $\mathrm{HClO}$ 的强氧化

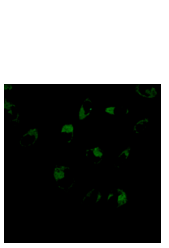<smiles></smiles>

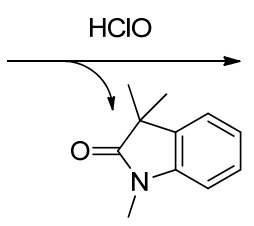

性使烯烃断键分别设计合成了 $\mathrm{HClO}$ 苂光比色探针 57 61 (Scheme 13). 这五个探针都对 $\mathrm{HClO}$ 表现出紫外可见

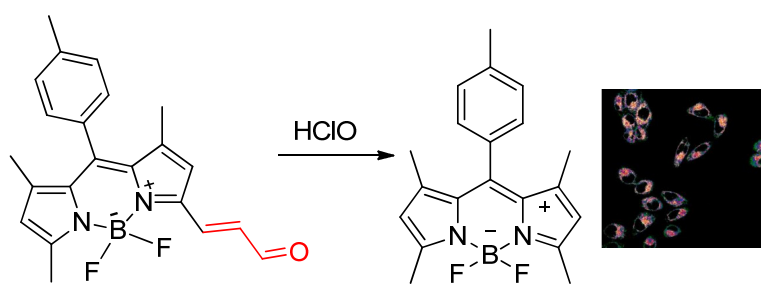

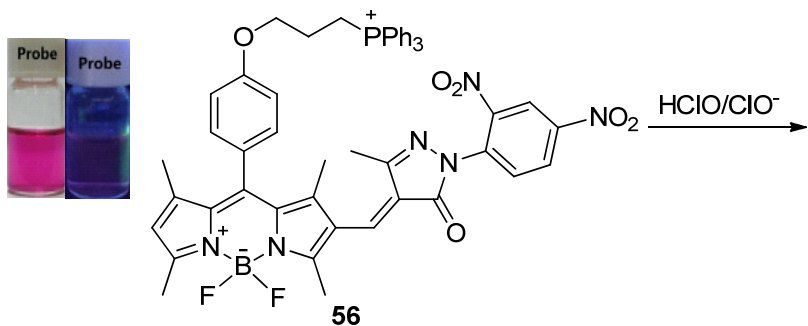

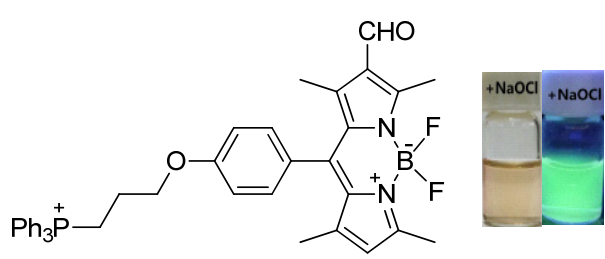

图式 12 探针 55 和 56 与 $\mathrm{HClO} / \mathrm{ClO}^{-}$的反应机理及加入 $\mathrm{HClO} / \mathrm{ClO}^{-}$前后在日光灯和 $365 \mathrm{~nm}$ 紫外灯下的颜色变化或 $\mathrm{HClO}$ 细胞成像 Scheme 12 Reaction mechanism of probes $\mathbf{5 5}$ and $\mathbf{5 6}$ with $\mathrm{HClO} / \mathrm{ClO}^{-}$and the color changes of the probe with $\mathrm{HClO} / \mathrm{ClO}^{-}$under sunlight and $365 \mathrm{~nm}$ UV light or $\mathrm{HClO}$ fluorescence imaging in living cell
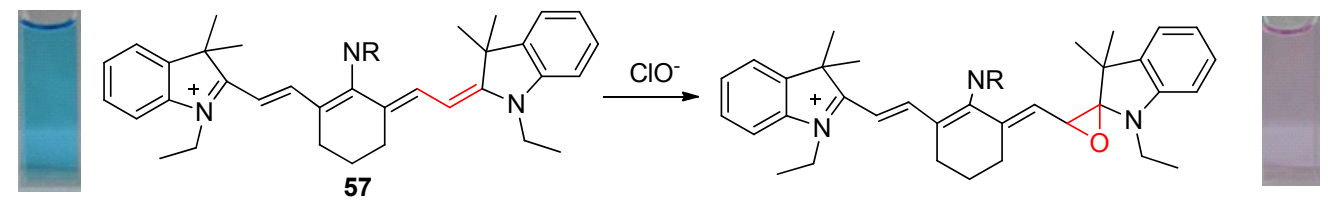<smiles>CCCc1cccc2c1N(CC)C(/C=C/C1=C(N(Cc3ccccn3)Cc3ccco3)/C(=C/C=C3/N(CC)c4ccccc4C3(C)C)CCC1)C2(C)C</smiles>

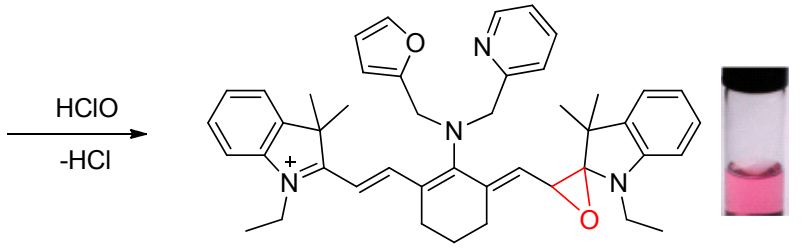<smiles></smiles>

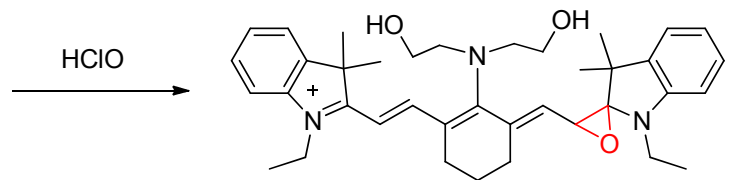

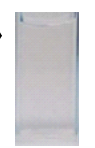

59

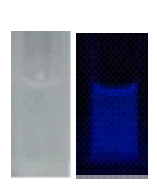<smiles>Cn1c(/C=C/C2=CC(C3NC(=O)c4ccccc4N3)C(C)(C)c3ccccc32)cccc1=O</smiles><smiles>O=Cc1ccc(O)c(-c2nc3ccccc3c(=O)[nH]2)c1</smiles><smiles>C1CC1</smiles>

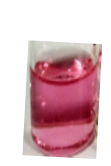<smiles>CC1(C)c2ccccc2N(CCCS(=O)(=O)[O-])C1/C=C/c1ccc(N)cc1</smiles><smiles>CC(=O)Cc1cc(C=O)ccc1C=O</smiles><smiles>CC1(C)C(=O)N(CCCS(=O)(=O)O)c2ccccc21</smiles><smiles></smiles>

图式 13 探针 57 61 与 $\mathrm{HClO} / \mathrm{ClO}^{-}$的反应机理以及在加入 $\mathrm{HClO} / \mathrm{ClO}^{-}$前后在自然光或 $365 \mathrm{~nm}$ 紫外灯下的颜色改变 Scheme 13 Reaction mechanism of probes $57 \sim 61$ with $\mathrm{HClO} / \mathrm{ClO}^{-}$and the color changes of probes with $\mathrm{HClO} / \mathrm{ClO}^{-}$under sunlight or $365 \mathrm{~nm}$ UV light 
吸收光谱和荧光光谱的双信号响应, 并能肉眼识别检测 $\mathrm{HClO}$, 也具有好的选择性和相对较好的灵敏度，也都 被成功用于活细胞中内源性 $\mathrm{HClO}$ 的苂光成像, 而且探 针 60 还成功用于活细胞溶酶体中内源性 $\mathrm{HClO}$ 的苂光 成像. 其中, 探针 57 和 60 表现出对 $\mathrm{HClO}$ 的荧光比率 响应, 探针 58, 59 和 61 在模拟生理条件下的强荧光因 $\mathrm{HClO}$ 的氧化而淬灭. 探针 $\mathbf{5 9}$ 的水溶性好, 对 $\mathrm{HClO}$ 有 着近红外的荧光发射、更快速的反应 $(<5 \mathrm{~s})$ 和更低的灵 敏度(检测限为 $22 \mathrm{nmol} / \mathrm{L}$ ).

赵宝祥课题组 ${ }^{[79,80]}$ 分别在 2016 年、2018 年开发了 两例以 $\mathrm{C}=\mathrm{C}$ 双键的断裂来识别 $\mathrm{HClO} / \mathrm{ClO}^{-}$的新型比率 型 $\mathrm{HClO} / \mathrm{ClO}^{-}$苂光比色探针 62 和新型近红外比率型苂 光比色探针 63 (Scheme 14). 探针 62 以线粒体为靶向, 利用 $\mathrm{ClO}^{-}$氧化 $\mathrm{C}=\mathrm{C}$ 双键破坏其共轭系统以抑制 FRET 过程, 从而引起探针 62 的苂光强度比率 $\left(I_{480} / I_{580}\right)$ 增加 123 倍. 在 PBS-DMF ( $V: V=9: 1, \mathrm{pH}=7)$ 的混合体系 中, 10 equiv. $\mathrm{ClO}^{-}$的加入使探针 62 的溶液从橙色变成 无色，苂光发射光谱带发生蓝移，苂光量子产率从 0.85 减少 0.014 , 并且反应迅速 $(<30 \mathrm{~s})$, 灵敏度高(检测限低 至 $41.8 \mathrm{nmol} / \mathrm{L})$, 探针 62 适用的 $\mathrm{pH}$ 范围广 $(\mathrm{pH}=4 \sim 10)$, 其他阴离子和 ROS 几乎不影响其对 $\mathrm{ClO}^{-}$的识别. 另外, 该探针还被成功用于活 RAW 264.7 细胞线粒体中内源
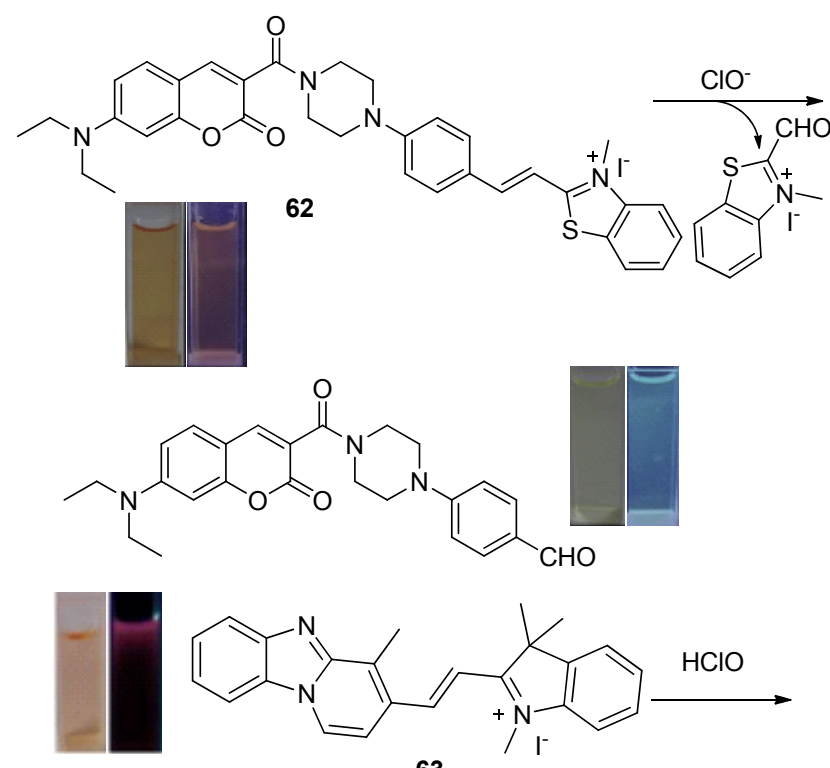

63

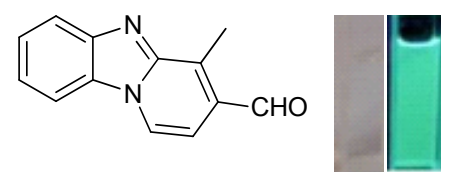

图式 14 探针 62 和 63 与 $\mathrm{HClO} / \mathrm{ClO}^{-}$的反应机理以及在加入 $\mathrm{ClO}^{-}$前后在自然光或 $365 \mathrm{~nm}$ 紫外灯下的颜色改变

Scheme 14 Reaction mechanism of probes 62 and 63 with $\mathrm{HClO} / \mathrm{ClO}^{-}$and the color changes of probes with $\mathrm{ClO}^{-}$under sunlight or $365 \mathrm{~nm}$ UV light
性 $\mathrm{ClO}^{-}$苂光比率成像. 同样, 15 equiv. $\mathrm{HClO}$ 也使得探 针 63 结构中的 $\mathrm{C}=\mathrm{C}$ 双键被破坏, 苂光强度比率 $\left(I_{512} / I_{653}\right)$ 增加, 一定浓度范围内的 $\mathrm{HClO}$ 与探针 $\mathbf{6 3}$ 的荧 光强度比率 $\left(I_{512} / I_{653}\right)$ 呈线性关系, 检测限为 $56 \mathrm{nmol} / \mathrm{L}$, 同时伴随着溶液红色褪去. 探针 63 同样选择性高，可以 用于比较广的 $\mathrm{pH}$ 范围(6 10), 并且具有很好的细胞膜 通透性和低毒性，被成功用于活 RAW264.7 细胞中内源 性和外源性 $\mathrm{HClO}^{-}$苂光成像.

最近，曾林涛等 ${ }^{[81 ~ 85]}$ 报道了 5 个基于香豆素苂光 团、以 $\mathrm{C}=\mathrm{C}$ 双键为识别位点的近红外比率型双信号 $\mathrm{HClO}$ 荧光显色探针 $\mathbf{6 4} \sim \mathbf{6 8}$ (Scheme 15). 由于 $\mathrm{HClO}$ 的 强氧化性, 5 个探针中的不饱和 $\mathrm{C}=\mathrm{C}$ 双键被氧化断裂, 引起共轭系统被破坏; 其中探针 64 和 65 的分子结构由 于 $\mathrm{C}=\mathrm{C}$ 双键的破坏，抑制了 $\mathrm{ICT}$ 效应， $\mathrm{ClO}^{-}$抑制了探 针 68 的 FRET 过程, 而抑制了探针 66 存在的 ICT 和 FRET 双效应，从而引起探针在模拟的生理条件下发生 溶液颜色的明显变化, 实现裸眼识别, 并伴随着出现紫 外可见吸收光谱的相应变化和荧光光谱的比率型变化. 探针 66 能实现对 $\mathrm{HClO}$ 的快速识别 $(<13 \mathrm{~s})$, 并且检测 限低 $(25 \mathrm{nmol} / \mathrm{L})$; 探针 68 具有超大的斯托克斯位移 $(262$ $\mathrm{nm})$. 另外, 5 个探针都成功实现了活细胞中 $\mathrm{HClO}$ 的荧 光比率成像.

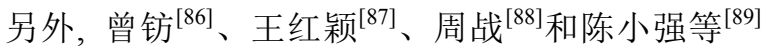
基于萠衍生物和荧光素衍生物分别设计合成了 4 种通过 $\mathrm{HClO}$ 氧化断裂 $\mathrm{C}=\mathrm{C}$ 双键的 $\mathrm{HClO}$ 比率型比色苂光探 针 69 72 (Scheme 16). 由于 $\mathrm{HClO}$ 的强氧化性, 在模拟 生理条件下，4 个探针分子中的 $\mathrm{C}=\mathrm{C}$ 双键都被选择性 地氧化断裂, 表现出苂光和比色的双模式显著改变. 其 中探针 69 成功实现了实际水样和活细胞中内源性和外 源性 $\mathrm{HClO}$ 的可视化检测. 探针 70 和 72 是以线粒体为 特异靶向的苂光探针, 且能定量检测 $\mathrm{ClO}^{-}$, 并具有很大 的斯托克斯位移 (107 $\mathrm{nm}$ ), 成功实现了活 HeLa 细胞中 内源性 $\mathrm{HClO}$ 成像和动态检测, 而且通过比率荧光成像 实现了活细胞内由 $\mathrm{HClO}$ 介导的氧化还原平衡的可视 化. 探针 72 具有相对较低的检测限 $(68 \mathrm{nmol} / \mathrm{L})$, 而探针 71 能较快速地识别 $\mathrm{ClO}^{-}(<30 \mathrm{~s})$, 并成功实现活细胞和 斑马鱼中 $\mathrm{ClO}^{-}$的实时监测.

2016 年和 2017 年, 霍方俊团队 ${ }^{[00,91]}$ 基于 1,8 -萗二甲 酰亚胺衍生物分别报道了 3 个以 $\mathrm{C}=\mathrm{C}$ 双键作为识别位 点的 $\mathrm{HClO}$ 苂光比色探针 73 75 (Scheme 17). 在模拟 的生理条件下, 探针 73 的荧光强度明显增强, 并有潜力 实现自来水和河水中 $\mathrm{ClO}^{-}$的定性和定量检测. 在探针 74 和 75 的分子结构中，1,8-萗二甲酰亚胺为供体，吲哚 碘化物作为受体, 形成 ICT 效应, $\mathrm{ClO}^{-}$选择性地氧化裂 解 $\mathrm{C}=\mathrm{C}$ 双键, 阻止 ICT 过程, 从而实现探针对 $\mathrm{ClO}^{-}$ 


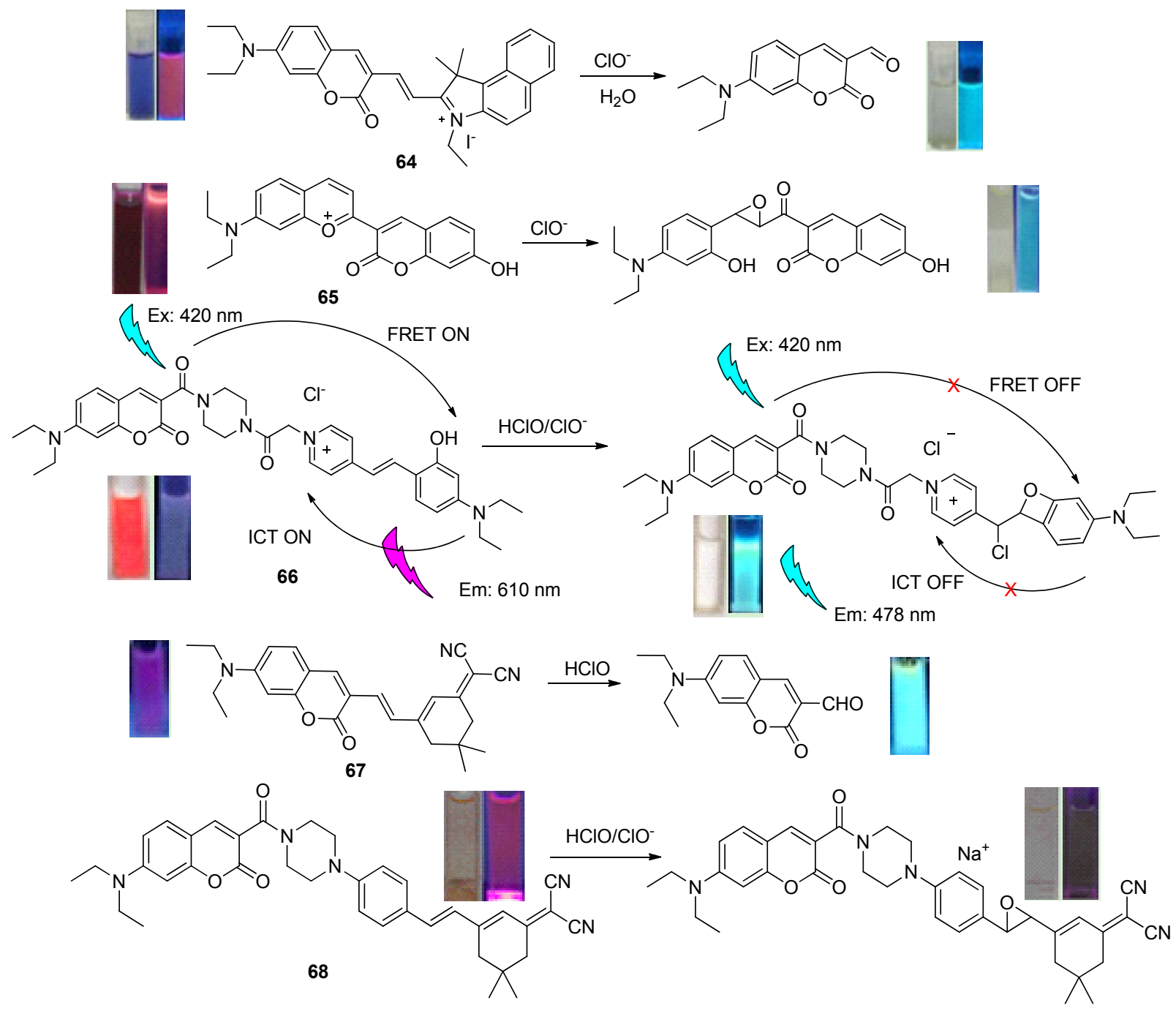

图式 15 探针 $64 \sim 68$ 与 $\mathrm{HClO} / \mathrm{ClO}^{-}$的反应机理以及在加入 $\mathrm{HClO} / \mathrm{ClO}^{-}$前后在自然光或 $365 \mathrm{~nm}$ 紫外灯下的颜色改变 Scheme 15 Reaction mechanism of probes $\mathbf{6 4} \sim \mathbf{6 8}$ with $\mathrm{HClO} / \mathrm{ClO}^{-}$and the color changes of probes with $\mathrm{HClO}^{-} \mathrm{ClO}^{-}$under sunlight or $365 \mathrm{~nm}$ UV light
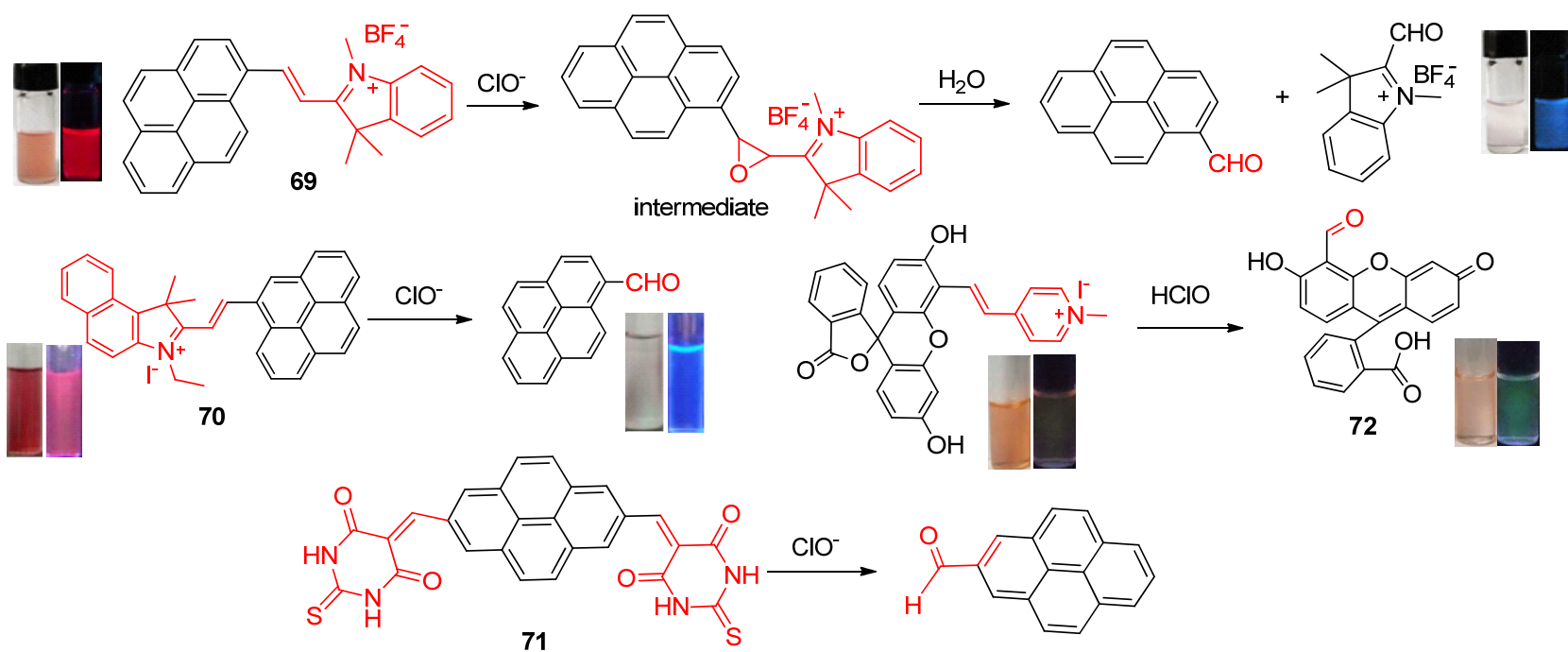

图式 16 探针 69 72 与 $\mathrm{HClO} / \mathrm{ClO}^{-}$的反应机理以及在加入 $\mathrm{HClO} / \mathrm{ClO}^{-}$前后在自然光或 $365 \mathrm{~nm}$ 紫外灯下的颜色改变 Scheme 16 Reaction mechanism of probes $69 \sim 72$ with $\mathrm{HClO} / \mathrm{ClO}^{-}$and the color changes of probes with $\mathrm{HClO} / \mathrm{ClO}^{-}$under sunlight or $365 \mathrm{~nm}$ UV light 
<smiles>CCCCN1C(=O)c2cccc3c(O)c(/C=C/c4cc[n+](C)cc4)cc(c23)C1=O</smiles><smiles>CCCCN1C(=O)c2c(O)cc3c(cccc3c2O)C(=O)N1CCCC</smiles><smiles>[Y4][NH+]1C(C=Cc2cc3c4c(cccc4c2O)C(=O)N(CCC)C3=O)=[N+](C)c2ccccc21</smiles>

74<smiles>CCCN1C(=O)c2cccc3c(O)c(/C=C/C4=[N+](C)c5ccc6ccccc6c5C4(C)C)cc(c23)C(=O)N1CCC</smiles>

图式 17 探针 73 75 与 $\mathrm{ClO}^{-}$的反应机理 Scheme 17 Reaction mechanism of probes $73 \sim 75$ with $\mathrm{ClO}^{-}$ 的可视化和比率型定量检测, 探针 74 的检测限低至 53 $\mathrm{nmol} / \mathrm{L}$, 并实现了在 HepG2 细胞中的荧光成像.

尹贵 ${ }^{[92]}$ 和张鹏等 ${ }^{[93]}$ 分别报道了 3 种以线粒体为靶 向, 以 $\mathrm{C}=\mathrm{C}$ 双键为识别位点的 $\mathrm{HClO}$ 双信号苂光探针 76 和 77 (Scheme 18). 探针 76 对 $\mathrm{HClO}$ 表现出很好的选 择性和抗干扰性, 并成功用于活 RAW 264.7 巨筮细胞线 粒体中 $\mathrm{HClO}$ 的荧光比率成像, 探针 76 还能检测活动物 体中的内源性 HClO. 基于 FRET 机制, 探针 77 具有聚 集诱导发光性质(AIE). 基于 $\mathrm{HClO}$ 的强氧化性, 通过 $\mathrm{C}=\mathrm{C}$ 双键的氧化裂解, 实现苂光强度的增强, 斯托克 斯位移大 $(150 \mathrm{~nm})$, 检测限低至 $13.2 \mathrm{nmol} / \mathrm{L}$, 并且, 该 探针能分别在水溶液、聚集形式、固体状态和活细胞中 实现对 $\mathrm{HClO}$ 的检测. 赵善超等 ${ }^{[94]}$ 于 2018 年报道了基于 $\mathrm{HClO}$ 氧化 $\mathrm{C}=\mathrm{C}$ 双键的 $\mathrm{HClO}$ 比率型荧光比色探针 78 (Scheme 18). 探针 78 对 $\mathrm{HClO}$ 表现出快速 $(<10 \mathrm{~s})$ 选择 性的红发射比率型苂光变化, 并能实现活细胞和斑马鱼 中 $\mathrm{ClO}^{-}$的比率型荧光成像.

\section{4 含有甲氧基苯酚或氨基苯酚类似物的传感器}

\section{1 甲氧基苯酚与 $\mathrm{HClO}$ 的氧化反应}

杨丹等 ${ }^{[95]}$ 在 2014 年基于 BODIPY 设计合成了 3 个 由 $\mathrm{HClO}$ 介导的 对甲氧基苯酚氧化生成对苯醌的 $\mathrm{HClO}$
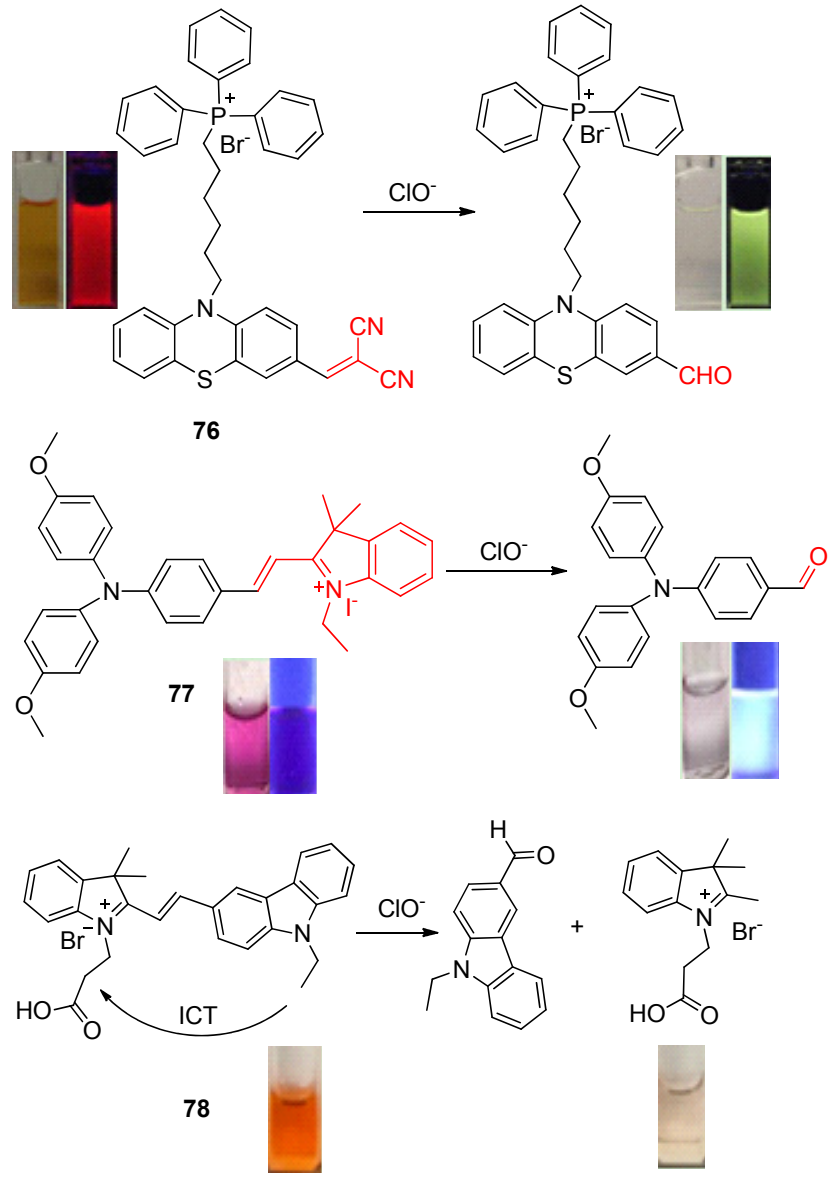

图式 18 探针 76 78 与 $\mathrm{ClO}^{-}$的反应机理以及在加入 $\mathrm{ClO}^{-}$前 后在自然光或 $365 \mathrm{~nm}$ 紫外灯下的颜色改变

Scheme 18 Reaction mechanism of probes $76 \sim 78$ with $\mathrm{ClO}^{-}$ and the color changes of probes with $\mathrm{ClO}^{-}$under sunlight or 365 nm UV light

荧光比色探针 79 $\sim 81$ (Eq. 29). 3 个探针由于分子结构中 的 PET 过程本身没有荧光, $\mathrm{HClO}$ 的强氧化性抑制了 PET 过程, 使探针的荧光强度显著增强. 3 个探针都表现 出对 $\mathrm{HClO}$ 良好的选择性和灵敏度, 其中探针 80 的检测 限低至 $18 \mathrm{nmol} / \mathrm{L}$, 并且在活细胞成像中, 探针 $\mathbf{8 0}$ 对各 种已建立的 $\mathrm{HOCl}$ 诱导刺激物(包括小鼠和人类巨噬细 胞中的聚丙烯酸甲酯和酵母聚糖) 做出快速启动荧光反 应.

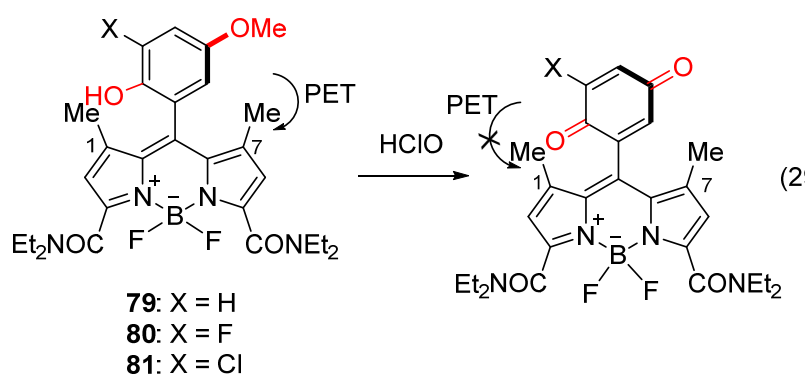

同年, 霍方俊等 ${ }^{[96]}$ 报道了一种天然药物姜黄素苂 光比色探针 82 (Eq. 30), 在检测实际样品中 $\mathrm{HClO}$ 和生 
物成像中得到应用. 可能的机制是 $\mathrm{HClO}$ 氧化探针结构 中的苯酚生成醌, 产生一种没有苂光的姜黄素衍生物, 并引起探针溶液颜色、紫外可见吸收光谱的显著变化. 该探针能快速 $(<6 \mathrm{~s})$ 定量地检测 84 消毒液中的 $\mathrm{ClO}^{-}$, 并能检测活细胞中(HepG2 细胞)的 $\mathrm{HClO}$.<smiles>COc1cc(/C=C/C(=O)CC(=O)/C=C/c2ccc(/C=C/C(O)=C/C(=O)/C=C/C3=CC(=O)C(=O)C=C3)c(OC)c2)ccc1O</smiles>

\section{2 氨基苯酚类似物与 $\mathrm{HClO}$ 的氧化反应}

徐玉芳 ${ }^{[97]}$ 和王芯团队 ${ }^{[16]}$ 基于 $\mathrm{HClO}$ 氧化消除氨基苯 酚类似物报道了两种 $\mathrm{HClO}$ 苂光比色探针 83 和 84 (Scheme 19). 2 个探针的分子结构中由于氨基苯酚部分 含有丰富的电子, 可以通过 PET 过程淬灭探针本身的苂 光, $\mathrm{HClO}$ 通过氧化消除氨基苯酚部分, 抑制了 PET 过 程, 从而引起探针的苂光强度显著增强. 探针 83 具有很 好的水溶性, $\mathrm{pH}$ 范围广, 并且能在几秒内实现对 $\mathrm{HClO}$ 的识别检测，该探针还被成功用于 $\mathrm{HeLa}$ 细胞中 $\mathrm{HClO}$ 荧光成像. 探针 84 对 $\mathrm{HClO}$ 具有很好的选择性和灵敏度 (检测限低至 $6.8 \mathrm{nmol} / \mathrm{L}$ ), 并被成功用于活细胞中内源 性 $\mathrm{HClO}$ 的苂光成像.<smiles>CC(=O)OCCOCCN1C(=O)c2cccc3cc(NC(=O)Oc4ccc(N)cc4)cc(c23)C(=O)N1CCOCCOC(C)=O</smiles>

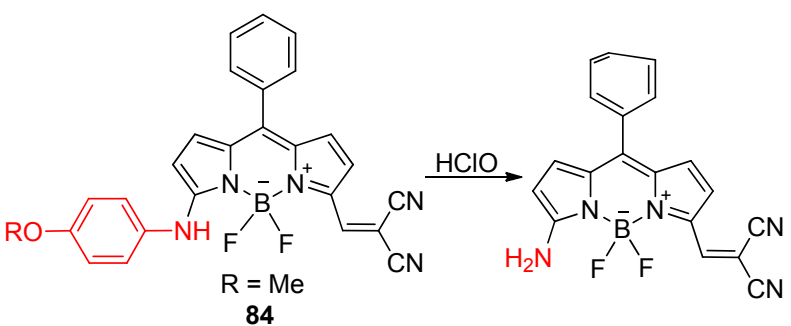

图式 19 探针 83 和 84 与 $\mathrm{ClO}^{-}$的反应机理 Scheme 19 Reaction mechanism of probes 83 and 84 with $\mathrm{ClO}^{-}$

近几年，朱宝存 ${ }^{[98] 、}$ 周艳梅 ${ }^{[99]}$ 和王世发等 ${ }^{[100]}$ 基于 $\mathrm{HClO}$ 氧化氨基生成亚硝基反应报道了 4 种 $\mathrm{HClO}$ 苂光 比色探针 85 88 (Scheme 20). 在模拟的生理条件下, 4 个探针在 $\mathrm{HClO}$ 的作用下都表现出溶液颜色、紫外可见
吸收光谱和苂光光谱的显著变化, 并对 $\mathrm{HClO}$ 具有很好 的选择性和灵敏度. 其中探针 85 和 86 在 $5 \mathrm{~s}$ 内能迅速 识别 $\mathrm{HClO}$, 探针 85 的检测限为 $4.1 \mathrm{nmol} / \mathrm{L}$, 成功定量 检测了 84 消毒液中的 $\mathrm{ClO}^{-}$浓度并定位细胞中的 $\mathrm{HClO}$, 探针 87 的检测限为 $2.41 \mathrm{nmol} / \mathrm{L}$, 探针 $\mathbf{8 8}$ 的检测限为 $3.17 \mathrm{nmol} / \mathrm{L}$, 而探针 86 的检测限更低 $(10.8 \mathrm{pmol} / \mathrm{L})$, 能 在皮摩尔水平实现对 $\mathrm{HClO}$ 的特异性定量检. 探针 86 可 用于跟踪活细胞线粒体内源性/外源性 $\mathrm{ClO}^{-}$水平的变 化; 而探针 87 水溶性好, 能红光发射检测识别活细胞中 酶促反应生成的 $\mathrm{HClO}$ 和外源性的 $\mathrm{HClO}$, 探针 87 在水 溶液中 $\mathrm{pH}$ 范围广，能实现在环境水样中定量检测 $\mathrm{ClO}^{-}$, 并成功定位 HeLa 细胞中外源性的 $\mathrm{ClO}^{-}$和 RAW 264.7 巨噬细胞中内源性的 $\mathrm{ClO}^{-}$.

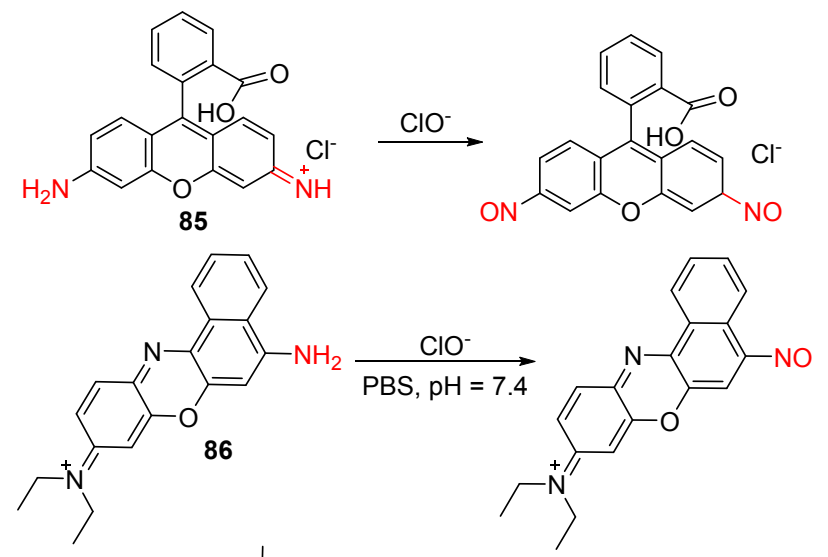

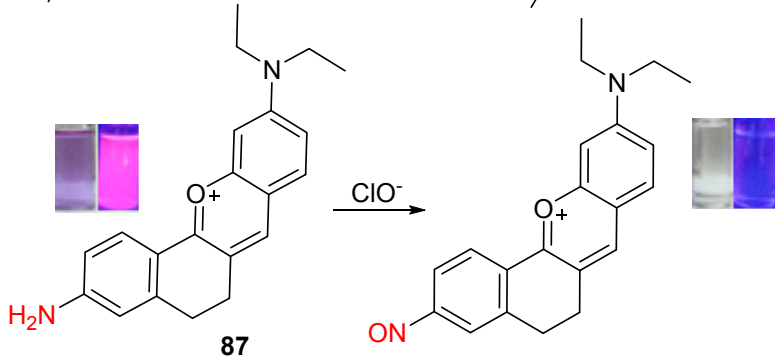<smiles>N#C/C(N)=C(\C#N)N=Cc1c2ccccc2cc2ccccc12</smiles>

图式 20 探针 $85 \sim 88$ 与 $\mathrm{ClO}^{-}$的反应机理以及在加入 $\mathrm{ClO}^{-}$前 后在自然光或 $365 \mathrm{~nm}$ 紫外灯下的颜色改变

Scheme 20 Reaction mechanism of probes $85 \sim 88$ with $\mathrm{ClO}^{-}$ and the color changes of probes with $\mathrm{ClO}^{-}$under sunlight or 365 nm UV light

\section{5 其他识别组}

王清明 ${ }^{[101]}$ 和柇江莉等 ${ }^{[102]}$ 基于香豆素染料设计合 成了 3 种用于识别 $\mathrm{HClO}$ 的双信号荧光比色探针 89 和 
90 (Scheme 21). 探针 89 和 90 本身由于 PET 过程而无 荧光, $\mathrm{ClO}^{-}$能引起探针 90 的荧光强度明显增强, 使探针 89 分子中的 $\mathrm{C}-\mathrm{O}$ 键断裂, 引起探针的荧光强度显著增 强. 两个探针对 $\mathrm{HClO}$ 的选择性好, 抗干扰性强, 检测 限分别低至 25 和 $22 \mathrm{nmol} / \mathrm{L}$, 探针 90 成功定位追踪活细 胞中内源性和外源性的 $\mathrm{ClO}^{-}$, 探针 89 被成功用于 $\mathrm{HepG} 2$ 细胞中内源性 $\mathrm{ClO}^{-}$荧光成像.<smiles>C=C1Oc2ccccc2C=C1C(=O)C(C)=O</smiles>

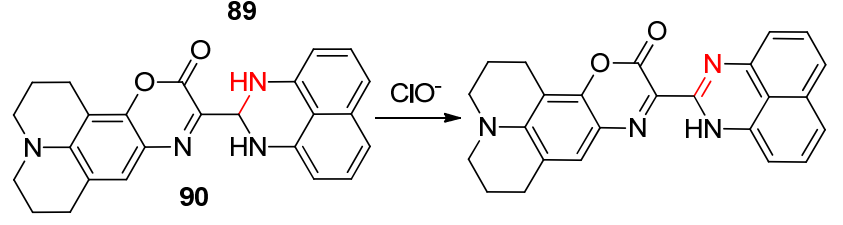

图式 21 探针 89 和 90 与 $\mathrm{ClO}^{-}$的反应机理以及在加入 $\mathrm{ClO}^{-}$ 前后在自然光或 $365 \mathrm{~nm}$ 紫外灯下的颜色改变

Scheme 21 Reaction mechanism of probes 89 and 90 with $\mathrm{ClO}^{-}$and the color changes of probes with $\mathrm{ClO}^{-}$under sunlight or $365 \mathrm{~nm}$ UV light

㚞江莉等 ${ }^{[103]}$ 报道了一种基于 3-吡咯 BODIPY 染料 的 $\mathrm{HClO}$ 苂光显色探针 91 (Eq. 31). 该探针分子中存在 从 3-吡咯基团到 BODIPY 分子的 ICT 过程, $\mathrm{HClO}$ 可以 阻断该过程, 引起探针荧光强度比率的明显增强, 并且 反应超快速 $(<1 \mathrm{~s})$, 并被成功制作成检测试纸用于水环 境和自来水中 $\mathrm{HClO}$ 的肉眼定性及定量检测, 也通过苂 光共聚焦成像用于活细胞中内源性 $\mathrm{HClO}$ 的检测.

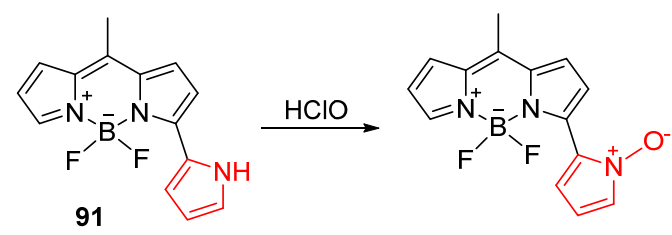

最近, Padmini ${ }^{[104]}$ 和陈建等 ${ }^{[105]}$ 分别基于花菁染料和 罗丹明染料衍生物报道了两种 $\mathrm{HClO}$ 荧光比色探针 92 和 93 (Scheme 22). $\mathrm{HClO}$ 以探针 92 分子吲哚中的 $\mathrm{N}-\mathrm{H}$ 键为识别位点, 抑制探针中的 ICT 过程, 从而使探针的 溶液颜色出现肉眼可见的变化和荧光强度的显著增强, 该探针还被成功制作成测试试纸用于 $\mathrm{HClO}$ 的裸眼检 测, 并被成功用于 $\mathrm{HeLa}$ 细胞中 $\mathrm{HClO}$ 的荧光成像. 纳米 探针 93 是由聚合物纳米颗粒表面的罗丹明 B ( $\mathrm{HClO}$ 传 感单元)和聚合物纳米颗粒核心的 AIE 苂光素(参考单 元)组成. 并且该纳米探针具有很好的水溶性、光稳定性 和生物相容性, 并成功用于活细胞溶酶体中内源性和外 源性 $\mathrm{HClO}$ 的比率型苂光成像.

韩守法 ${ }^{[106]}$ 、王芳 ${ }^{[107]}$ 和韩毅峰等 ${ }^{[108]}$ 基于苯并噻唑分 别设计合成了 4 个 $\mathrm{HClO}$ 双信号荧光比色探针 94 97
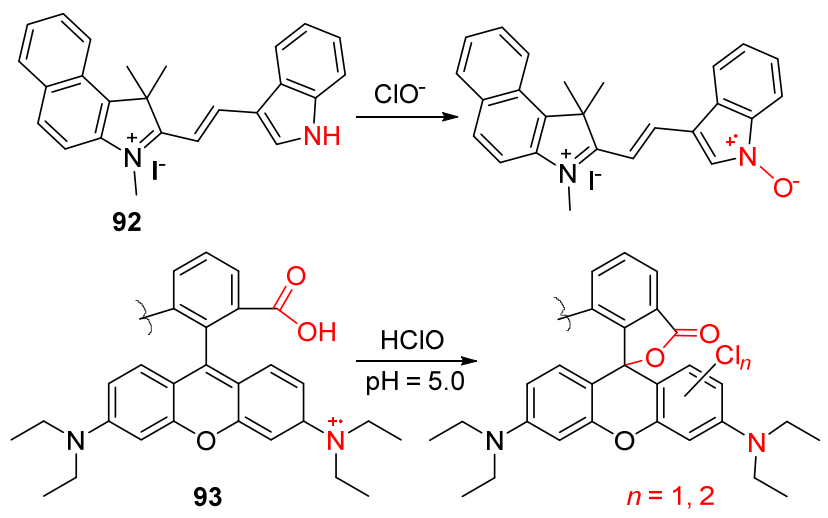

图式 22 探针 92 和 93 与 $\mathrm{ClO}^{-}$的反应机理

Scheme 22 Reaction mechanism of probes 92 and 93 with $\mathrm{ClO}$

(Scheme 23). 探针 94 和 95 本身无色、无苂光, $\mathrm{HClO}$ 可 以选择性地氧化探针 94 分子中的噻唑啉生成噻唑, 从 而引起探针 94 的苂光强度显著增强, $\mathrm{HClO}$ 氧化探针 95 引起分子内的 $\mathrm{C}-\mathrm{N}$ 键的开环, 从而引起显著的溶液颜 色变化和苂光强度的增强. 并且两个探针都被成功用于
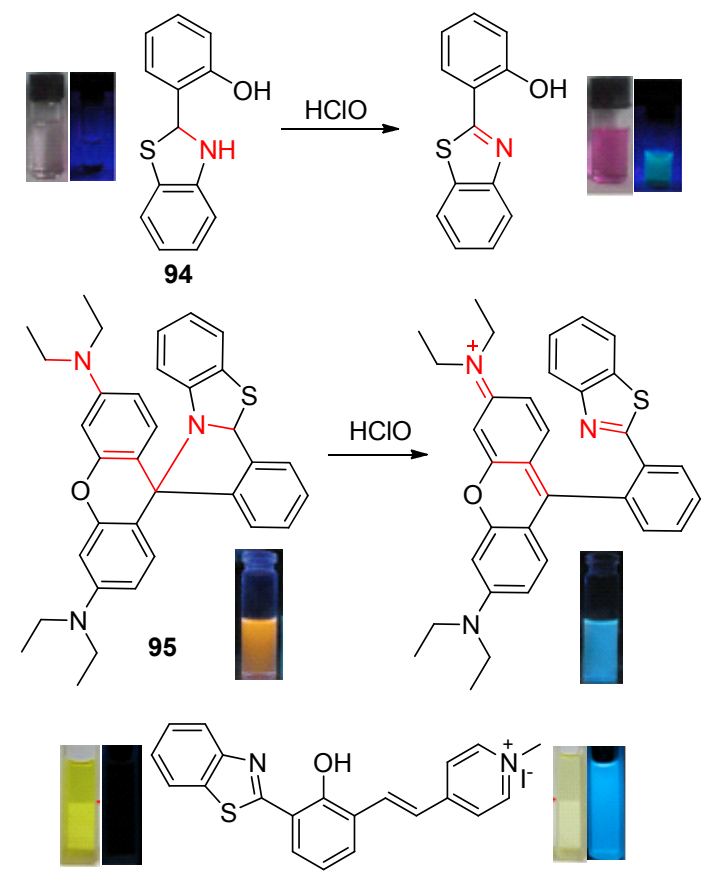

96

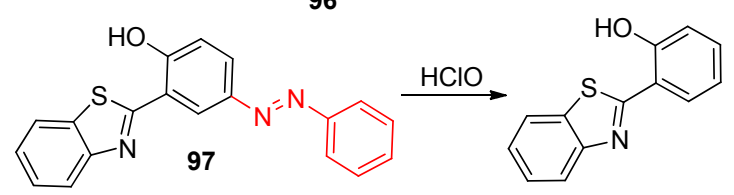

图式 23 探针 94 97 与 $\mathrm{ClO}^{-}$的反应机理以及在加入 $\mathrm{ClO}^{-}$前 后在自然光或 $365 \mathrm{~nm}$ 紫外灯下的颜色改变

Scheme 23 Reaction mechanism of probes 94 97 with $\mathrm{ClO}^{-}$ and the color changes of probes with $\mathrm{ClO}^{-}$under sunlight or 365 nm UV light 
活细胞中 $\mathrm{HClO}$ 苂光成像. $\mathrm{HClO}$ 通过抑制探针 96 和 97 分子中存在的 ESIPT 效应实现探针对 $\mathrm{HClO}$ 的识别. $\mathrm{HClO}$ 通过抑制探针 96 分子中苯并噻唑和羟基之间的 ESIPT 效应, 使探针溶液颜色发生肉眼可见的变化和苂 光强度比率的增强. 该探针成功实现了线粒体的靶向定 位, 成功实现 $\mathrm{HeLa}$ 细胞中内源性 $\mathrm{HClO}$ 苂光成像, 还被 成功制作成试纸用于自来水中 $\mathrm{HClO}$ 的可视化检测. $\mathrm{HClO}$ 与探针 97 中的苯偶氮基反应从而抑制其 ESIPT 效应，使水溶液中探针的颜色发生明显变化，苂光强度 明显增强, 该探针对 $\mathrm{HClO}$ 的选择性好, 灵敏度高(检测 限低至 $13.2 \mathrm{nmol} / \mathrm{L})$.

曾宪顺 ${ }^{[109]}$ 、朱宝存 ${ }^{[110]}$ 和李振等 ${ }^{[111]}$ 分别报道了 3 个 基于硼酸或硼酸盐的 $\mathrm{HClO}$ 苂光比色探针 $\mathbf{9 8} \sim \mathbf{1 0 0}$ (Scheme 24). 其中探针 98 被 $\mathrm{HClO}$ 氧化后, 苂光团上强 吸电子基团 $\left[\mathrm{B}(\mathrm{OH})_{2}\right]$ 被供电子基团 $(\mathrm{OH})$ 取代, 诱导 $\mathrm{ICT}$ 过程, 引起染料颜色、吸收光谱和荧光发射光谱的较大

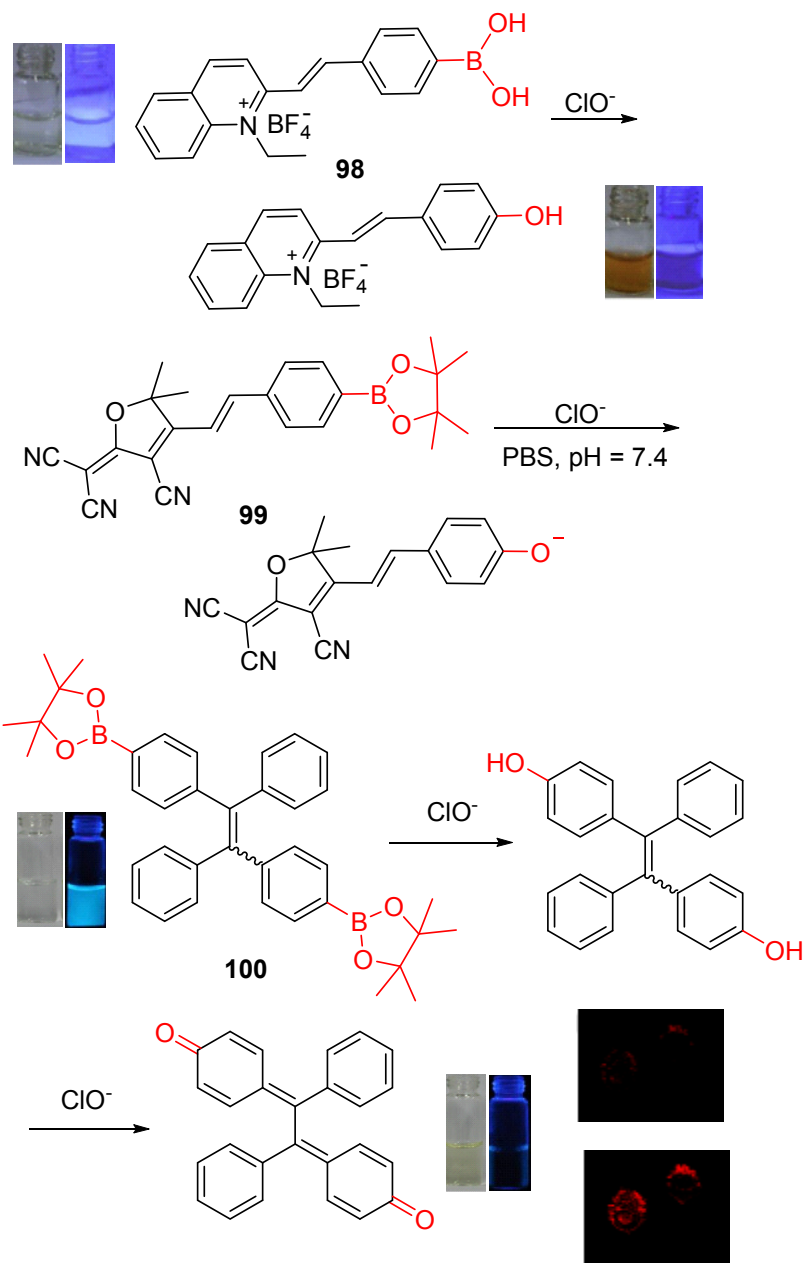

图式 24 探针 $98 \sim 100$ 与 $\mathrm{ClO}^{-}$的反应机理以及加入 $\mathrm{ClO}^{-}$前 后在日光灯和 $365 \mathrm{~nm}$ 紫外灯下的颜色变化或 $\mathrm{ClO}^{-}$细胞成像 Scheme 24 Reaction mechanism of probes $\mathbf{9 8} \sim \mathbf{1 0 0}$ with $\mathrm{ClO}^{-}$ and the color changes of the probe with $\mathrm{ClO}^{-}$under sunlight and $365 \mathrm{~nm} \mathrm{UV} \mathrm{light} \mathrm{or} \mathrm{ClO}^{-}$fluorescence imaging in living cell
变化, 从而引起苂光光谱的比率型变化, 并且探针 98 对 $\mathrm{HClO}$ 的选择性好. 探针 99 也是基于 $\mathrm{HClO}$ 识别芳香硼 酸盐，诱导形成 ICT 效应，形成在远红外区域的长波长 发射，并且该探针选择性和水溶性好，实现了在 $100 \%$ 水溶液中对 $\mathrm{HClO}$ 的识别，已经被成功用于活细胞中 $\mathrm{HClO}$ 水平的苂光成像. 纳米探针 $\mathbf{1 0 0}$ 基于 AIE 特征, 在 99\%的水体系中发射强烈的蓝光, $\mathrm{HClO}$ 的加入使探针 中的疏水芳香硼酸盐转化为酚，再被氧化为醌，伴随着 水溶性的增加，并且苂光强度明显降低并淬灭，并且检 测限低 $(49 \mathrm{nmol} / \mathrm{L})$. 此外，该探针还被制备成了试纸, 并对 $0.1 \mathrm{mmol} / \mathrm{L} \mathrm{ClO}^{-}$表现出高敏感性.

霍方俊等 ${ }^{[112]}$ 于 2017 年报道了一个基于苍醌和 $1,8-$ 菜二甲酰亚胺 $\mathrm{HClO}$ 苂光显色传感器 $\mathbf{1 0 1}$ (Eq. 32). 探针 101 中的羟基被 $\mathrm{HClO}$ 氧化成羰基，从而引起的溶液颜 色的明显变化和苂光发射强度的明显增强，探针 101 对 $\mathrm{HClO}$ 的反应迅速 $(<3 \mathrm{~s})$, 已经被成功用于自来水和河 水中 $\mathrm{ClO}^{-}$的加标回收, 并利用苂光成像技术用于活细 胞中 $\mathrm{HClO}$ 的识别检测
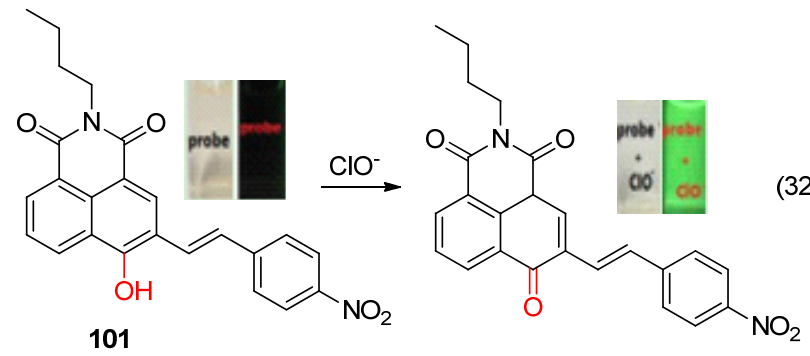

阴彩霞团队 ${ }^{[113]}$ 在 2016 年基于萗酚及其衍生物报道 了两个用于 $\mathrm{HClO}$ 识别的双信号比色苂光探针 102 和 103 (Scheme 25). 由于 $\mathrm{HClO}$ 介导的分子内脱氢反应,
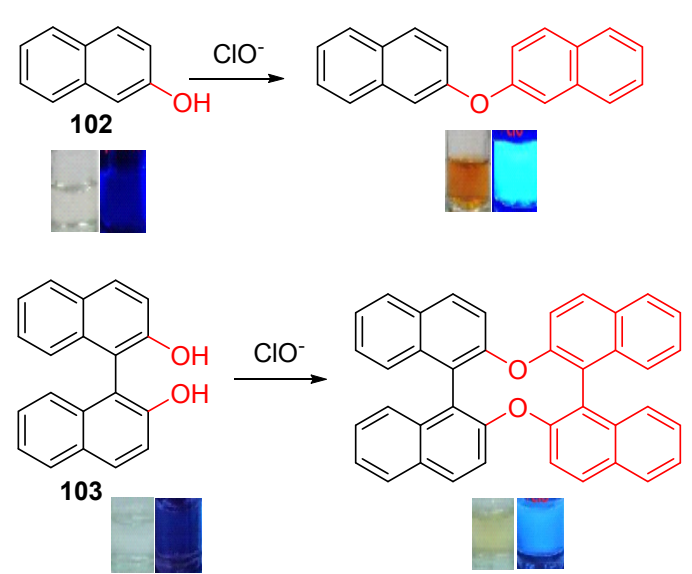

图式 25 探针 102 和 103 与 $\mathrm{ClO}^{-}$的反应机理以及加入 $\mathrm{ClO}^{-}$ 前后在日光灯或 $365 \mathrm{~nm}$ 紫外灯下的颜色变化

Scheme 25 Reaction mechanism of probes 102 and 103 with $\mathrm{ClO}^{-}$and the color changes of the probe with $\mathrm{ClO}^{-}$under sunlight or $365 \mathrm{~nm}$ UV light 
两个探针分别在 24 和 $6 \mathrm{~s}$ 实现对 $\mathrm{HClO}$ 的快速识别, 检 测限分别为 81 和 $49 \mathrm{nmol} / \mathrm{L}$.

王炳祥的团队 ${ }^{[114]}$ 在 2018 年以胺基为识别基团设计 合成了两个 $\mathrm{HClO}$ 比色荧光探针 104 (Eq. 33). $\mathrm{HClO}$ 具有 强氧化性, $\mathrm{HClO}$ 的加入能使探针 104 中的胺基氧化成亚 硝基, 出现溶液颜色和紫外可见吸收光谱的显著变化, 荧光发射光谱呈比率型改变, 探针 104 对 $\mathrm{HClO}$ 的检测 限低至 $0.5 \mathrm{nmol} / \mathrm{L}$, 低于大多数报道过的 $\mathrm{HClO}$ 苂光探 针, 并且这类探针还被成功用于活细胞中内源性 $\mathrm{HClO}$ 的苂光成像.<smiles>CN(C)c1ccc(/C=N/C(C#N)=C(/N)C(=O)N(C)c2ccc(/C=N/C(C#N)=C(/C#N)[N+](=O)[O-])cc2)cc1</smiles>

最近，王世发等 ${ }^{[115]}$ 报道了 3 个基于樟脑的 $\mathrm{HClO}$ 比 色荧光比率型探针 105 107 (Scheme 26). 3 个探针中的 酚羟基直接与 $\mathrm{HClO}$ 反应生成羰基，引起探针溶液颜色 发生肉眼可见的变化, 并出现苂光发射光谱的明显红移 和荧光强度比率的显著增强. 三个探针检测 $\mathrm{HClO}$ 的 $\mathrm{pH}$ 范围广, 检测限低, 分别为 $5.16,6.85$ 和 $3.55 \mathrm{nmol} / \mathrm{L}$, 并 被成功用于活细胞中内源性 $\mathrm{HClO}$ 的荧光成像.
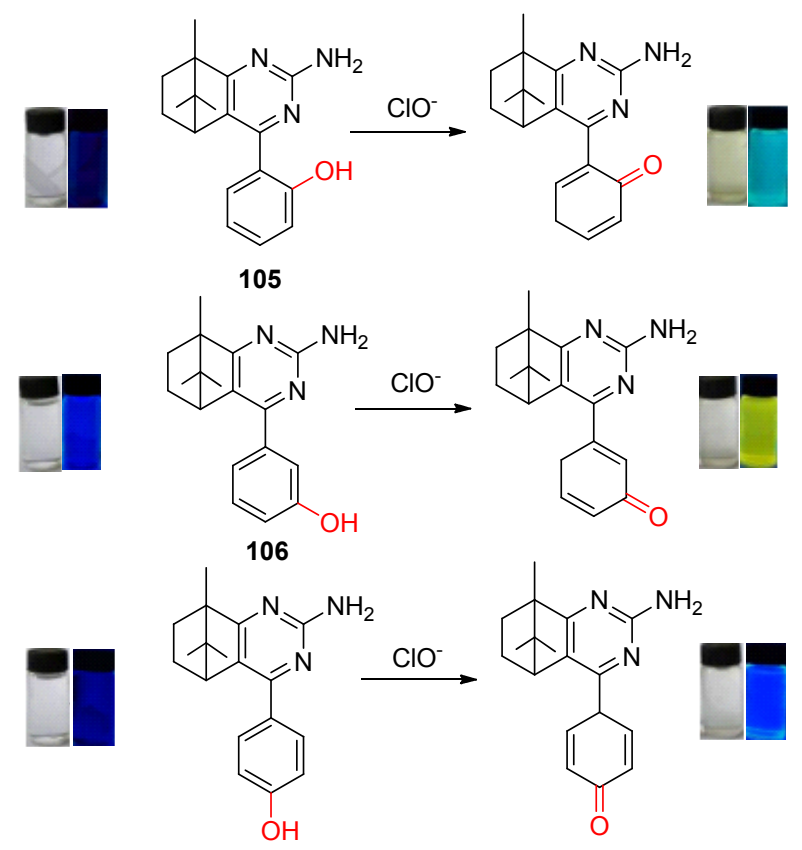

107

图式 26 探针 $105 \sim 107$ 与 $\mathrm{ClO}^{-}$的反应机理以及加入 $\mathrm{ClO}^{-}$前 后在日光灯和 $365 \mathrm{~nm}$ 紫外灯下的颜色变化

Scheme 26 Reaction mechanism of probes $105 \sim 107$ with $\mathrm{ClO}^{-}$and the color changes of the probe with $\mathrm{ClO}^{-}$under sunlight and $365 \mathrm{~nm}$ UV light

\section{6 结论}

$\mathrm{HClO}$ 作为生物体内的重要物质, 对生命体的影响 至关重要. 主要综述了近几年来检测次氯酸的比色荧光 探针及其在实际水环境或生命体系中的应用进展，并根 据检测机理不同分为五大部分，分别简述了各个探针识 别检测 $\mathrm{HClO}$ 的优点. 比色荧光探针既能实现简单、便 捷的定性及定量检测，又能结合荧光共聚焦成像技术将 其应用于生命体细胞内 $\mathrm{HClO}$ 的实时、原位示踪, 对水 环境科学领域以及生物学领域的研究具有重要意义. 但 目前对水环境中 $\mathrm{HClO}$ 的定量检测和生物系统中 $\mathrm{HClO}$ 的实时定量荧光成像仍然存在挑战. 设计合成具有专一 性强、水溶性好、低毒性、高灵敏度以及对生物体损伤 小、比率型近红外和双光子发射的 $\mathrm{HClO}$ 比色荧光探针, 并将其应用于生命体中 $\mathrm{HClO}$ 的实时定量荧光成像将是 以后致力于 $\mathrm{HClO}$ 研究工作的重心.

\section{References}

[1] Steinbeck, M. J.; Nesti, L. J.; Sharkey, P. F.; Javad, P. J. Orthop. Res. 2010, 25, 1128.

[2] Strzepa, A.; Pritchard, K. A.; Dittel, B. N. Cell Immunol. 2017, 317, 142.

[3] Shi, L.; Li, X.; Zhou, M.; Muhammad, F.; Ding, Y.; Wei, H. Analyst 2017, 142, 2104

[4] Liu, Z.; Jiang, T.; Wang, B.; Ke, B.; Zhou, Y.; Du, L.; Li, M. Anal. Chem. 2016, 88, 1511.

[5] Mohammadi, A.; Dehghan, Z.; Rassa, M.; Chaibakhsh, N. Sens. Actuators, $B$ 2016, 230, 388.

[6] Kim, H. N.; Ren, W. X.; Kim, J. S.; Yoon, J. Chem. Soc. Rev. 2012 $41,3210$.

[7] Jung, Y. K.; Park, H. G. Biosens. Bioelectron. 2015, 72, 127.

[8] Abnous, K.; Danesh, N. M.; Ramezani, M.; Emrani, A. S.; Taghdisi, S. M. Biosens. Bioelectron. 2016, 78, 80.

[9] Kim, S. K.; Lee, D. H.; Hong, J. I. Acc. Chem. Res. 2009, 42, 23.

[10] Cui, K.; Zhang, D.; Zhang, G.; Zhu, D. Tetrahedron Lett. 2010, 51, 6052.

[11] Zhang, W.; Guo, C.; Liu, L.; Qin, J.; Yang, C. Org. Biomol. Chem. 2011, 9,5560 .

[12] Cheng, X.; Jia, H.; Long, T.; Feng, J.; Qin, J.; Li, Z. Chem. Commun. 2011, 47, 11978 .

[13] Zhou, Y.; Pei, W.; Wang, C.; Zhu, J.; Wu, J.; Yan, Q.; Zhang, Q. Small 2014, 10, 3560.

[14] Cao, L.; Zhang, R.; Zhang, W.; Du, Z.; Liu, C.; Ye, Z.; Yuan, J. Biomaterials 2015, 68, 21

[15] Lu, F.; Nabeshima, T. Dalton Trans. 2014, 43, 9529.

[16] Zhao, C.; An, J.; Zhou, L.; Fei, Q.; Wang, F.; Tan, J.; Zhu, W. H. Chem. Commun. 2015, 52, 2075.

[17] Xiao, H.; Xin, K.; Dou, H.; Yin, G.; Quan, Y.; Wang, R. Chem. Commun. 2015, 51, 1442.

[18] Sun, M.; Yu, H.; Zhu, H.; Ma, F.; Zhang, S.; Huang, D.; Wang, S. Anal. Chem. 2014, 86, 671.

[19] Wang, Y. B.; Zhao, B. X. Chin. J. Org. Chem. 2016, 36, 1539 (in Chinese). (王延宝，赵宝祥，有机化学，2016, 36, 1539.)

[20] Zhang, Y. R.; Liu, Y.; Feng, X.; Zhao, B. X. Sens. Actuators, B 2017, 240, 18.

[21] Shen, Y.; Zhang, X.; Huang, X.; Wen, S.; Liu, M.; Deng, Y.; Yao, S. RSC Adv. 2015, 5, 1039.

[22] Cao, J.; Jiang, D. M.; Ren, X.; Li, T.; Gong, X. T.; Yang, Y. R.; Zhang, H. L. Dyes Pigm. 2017, 146, 279. 
[23] Choi, M. G.; Ryu, H.; Cho, M. J.; Lee, S. K.; Chang, S. K. Sens. Actuators, B 2017, 244, 307.

[24] Soni, D.; Gangada, S.; Duvva, N.; Roy, T. K.; Nimesh, S.; Arya, G.; Chitta, R. New J. Chem. 2017, 41, 5322.

[25] Wu, L.; Wu, I. C.; DuFort, C. C.; Carlson, M. A.; Wu, X.; Chen, L.; Chiu, D. T. J. Am. Chem. Soc. 2017, 139, 6911.

[26] Yin, C.; Zhen, X.; Fan, Q.; Huang, W.; Pu, K. ACS Nano 2017, 11, 4174 .

[27] Zhang, B.; Yang, X.; Zhang, R.; Liu, Y.; Ren, X.; Xian, M.; Ye, Y.; Zhao, Y. Anal. Chem. 2017, 89, 10384.

[28] Feng, H.; Meng, Q.; Wang, Y.; Duan, C.; Wang, C.; Jia, H.; Zhang, R. Chem.-Asian. J. 2018, 13, 2611.

[29] He, L.; Zhang, Y.; Xiong, H.; Wang, J.; Geng, Y.; Wang, B.; Song, X. Dyes Pigm. 2019, 166, 390.

[30] Song, H.; Zhou, Y.; Xu, C.; Wang, X.; Zhang, J.; Wang, Y.; Peng, X. Dyes Pigm. 2019, 162, 160.

[31] Wu, X.; Li, Z.; Yang, L.; Han, J.; Han, S. Chem. Sci. 2013, 4, 460.

[32] Liu, F.; Tang, Y.; Kuang, Y.; Pan, D., Liu, X.; Yu, R. Q.; Jiang, J. H. RSC Adv. 2016, 6, 107910.

[33] Lin, Q. S.; Huang, Y. L.; Fan, X. X.; Zheng, X. L.; Chen, X. L.; Zhan, X. Q.; Zheng, H. Talanta 2017, 170, 496.

[34] Shen, S. L.; Huang, X. Q.; Zhang, Y. Y.; Zhu, Y.; Hou, C.; Ge, Y. Q.; Cao, X. Q. Sens. Actuators, B 2018, 263, 252.

[35] Shen, S. L.; Huang, X. Q.; Jiang, H. L.; Lin, X. H.; Cao, X. Q. Anal. Chim. Acta 2019, 1046, 185.

[36] Yao, S. K.; Qian, Y. Sens. Actuators, B 2017, 252, 877.

[37] Gong, Y. J.; Lv, M. K.; Zhang, M. L.; Kong, Z. Z.; Mao, G. J. Talanta 2019, 192, 128.

[38] Wu, Z.; Wu, X.; Li, Z.; Yang, Y.; Han, J.; Han, S. Bioorg. Med. Chem. Lett. 2013, 23, 4354.

[39] Mei, Q.; Deng, W.; Yisibashaer, W.; Jing, H.; Du, G.; Wu, M.; Zhang, Y. Small 2015, 11, 4568 .

[40] Zhu, B.; Wu, L.; Zhang, M.; Zhao, Z.; Wang, Z.; Duan, Q.; Liu, C. Sens. Actuators, B 2018, 267, 589 .

[41] Wu, G.; Zeng, F.; Wu, S. Anal. Methods 2013, 5, 5589

[42] Cheng, G.; Fan, J.; Sun, W.; Sui, K.; Jin, X.; Wang, J.; Peng, X. Analyst 2013, 138, 6091.

[43] Guo, B.; Nie, H.; Yang, W.; Tian, Y.; Jing, J.; Zhang, X. Sens. Actuators, $B$ 2016, 236, 459

[44] Xu, X. X.; Qian, Y. Spectrochim. Acta, Part A 2017, 183, 356.

[45] Goswami, S.; Das, S.; Aich, K.; Nandi, P. K.; Ghoshal, K.; Quah, C. K.; Abdel-Aziz, H. A. RSC Adv. 2014, 4, 24881.

[46] Goswami, S.; Das, A. K.; Manna, A.; Maity, A. K.; Saha, P.; Quah, C. K.; Abdel-Aziz, H. A. Anal. Chem. 2014, 86, 6315.

[47] Long, Y.; Zhou, J.; Yang, M. P.; Liu, X. J.; Zhang, M.; Yang, B. Q. Sens. Actuators, B 2016, 232, 327.

[48] Ren, M.; Deng, B.; Zhou, K.; Kong, X.; Wang, J. Y.; Xu, G.; Lin, W. J. Mater. Chem. B 2016, 4, 4739.

[49] Xia, Y.; Liu, X.; Wang, D.; Wang, Z.; Liu, Q.; Yu, H.; Song, Y. Chin. Chem. Lett. 2018, 29, 1517.

[50] Shen, S. L.; Zhao, X.; Zhang, X. F.; Liu, X. L.; Wang, H.; Dai, Y. Y.; Zhao, B. X. J. Mater. Chem. B 2017, 5, 289.

[51] Zhu, J. H.; Wong, K. M. C. Sens. Actuators, B 2018, 267, 208

[52] Lee, H. J.; Cho, M. J.; Chang, S. K. Inorg. Chem. 2015, 54, 8644.

[53] Zhang, R.; Liang, L.; Meng, Q.; Zhao, J.; Ta, H. T.; Li, L.; Zhang, Z.; Sultanbawa, Y.; Xu, Z. P. Small 2019, 15, 1803712.

[54] Wu, J.; Liu, W.; Ge, J.; Zhang, H.; Wang, P. Chem. Soc. Rev. 2011, $40,3483$.

[55] Chen, W. C.; Venkatesan, P.; Wu, S. P. Anal. Chim. Acta 2015, 882, 68.

[56] Wang, E.; Qiao, H.; Zhou, Y.; Pang, L.; Yu, F.; Zhang, J.; Ma, T. RSC Adv. 2015, 5, 73040.

[57] Qiao, L.; Nie, H.; Wu, Y.; Xin, F.; Gao, C.; Jing, J.; Zhang, X. J. Mater. Chem. B 2017, 5, 525.

[58] Zang, L.; Liang, C.; Wang, Y.; Bu, W.; Sun, H.; Jiang, S. Sens. Actuators, $B$ 2015, 211, 164 .

[59] Wang, B.; Chen, D.; Kambam, S.; Wang, F.; Wang, Y.; Zhang, W.; Chen, X. Dyes Pigm. 2015, 120, 22.
[60] Li, J.; Yang, X.; Zhang, D.; Liu, Y.; Tang, J.; Li, Y.; Ye, Y. Sens. Actuators, $B$ 2018, 265, 84

[61] Wu, W. L.; Zhao, Z. M.; Dai, X.; Su, L.; Zhao, B. X. Sens. Actuators, $B$ 2016, 232, 390.

[62] Jia, H.; Xia, S.; Feng, H.; Meng, Q.; Duan, C.; Zhang, Z.; Zhang, R. Org. Biomol. Chem. 2018, 16, 2074.

[63] Goswami, S.; Aich, K.; Das, S.; Pakhira, B.; Ghoshal, K.; Quah, C. K., Sarkar, S. Chem.-Asian J. 2015, 10, 694.

[64] Ning, Y.; Cui, J.; Lu, Y.; Wang, X.; Xiao, C.; Wu, S.; Zhang, Y. Sens. Actuators, B 2018, 269, 322.

[65] Wang, Y.; Xia, J.; Han, J.; Bao, X.; Li, Y.; Tang, X.; Gao, M. Talanta 2016, 161, 847

[66] Yang, Y.; Gao, C. Y.; Chen, J.; Zhang, N.; Dong, D. Anal. Methods 2016, 8, 805.

[67] Chen, B.; Fu, H.; Lv, Y.; Li, X.; Han, Y. Tetrahedron Lett. 2018, 59, 1116.

[68] Das, S.; Aich, K.; Patra, L.; Ghoshal, K.; Gharami, S.; Bhattacharyya, M.; Mondal, T. K. Tetrahedron Lett. 2018, 59, 1130.

[69] Feng, H.; Zhang, Z.; Meng, Q.; Jia, H.; Wang, Y.; Zhang, R. Adv. Sci. 2018, 5, 1800397

[70] Yan, L.; Hu, C.; Li, J. Anal. Bioanal. Chem. 2018, 410, 7457.

[71] Huo, F.; Zhang, Y.; Yin, C. Sens. Actuators, B 2018, 269, 180.

[72] Yan, F.; Fan, K.; Ma, T.; Xu, J.; Wang, J.; Ma, C. Spectrochim. Acta, Part A 2019, 213, 254.

[73] Zhang, Z.; Fan, J.; Cheng, G.; Ghazali, S.; Du, J.; Peng, X. Sens. Actuators, B 2017, 246, 293

[74] Xu, C.; Qian, Y. Dyes Pigm. 2019, 161, 303.

[75] Lou, Z.; Li, P.; Song, P.; Han, K. Analyst 2013, 138, 6291

[76] Li, H.; Guan, L.; Zhang, X.; Yu, H.; Huang, D.; Sun, M.; Wang, S. Talanta 2016, 161, 592.

[77] Zhou, L.; Lu, D. Q.; Wang, Q.; Hu, S.; Wang, H.; Sun, H.; Zhang, X. Spectrochim. Acta, Part A 2016, 166, 129.

[78] Ma, Z.; Wang, X.; Wang, C.; Chen, X.; Lv, Q. Spectrochim. Acta, Part $A$ 2019, 213, 370.

[79] Wu, W. L.; Zhao, X.; Xi, L. L.; Huang, M. F.; Zeng, W. H.; Miao, J. Y.; Zhao, B. X. Anal. Chim. Acta 2017, 950, 178.

[80] Zhang, L. J.; Ning, J. Y.; Miao, J. Y.; Liu, J. T.; Zhao, B. X. New J. Chem. 2018, 42, 2989.

[81] Xu, J.; Yuan, H.; Qin, C.; Zeng, L.; Bao, G. M. RSC Adv. 2016, 6, 107525

[82] Song, X.; Dong, B.; Kong, X.; Wang, C.; Zhang, N.; Lin, W. Spectrochim. Acta, Part A 2018, 188, 394.

[83] Yan, Y. H.; Ma, H. L.; Miao, J. Y.; Zhao, B. X.; Lin, Z. M. Anal. Chim. Acta 2019, 1064, 87.

[84] Huang, Y.; Zhang, Y.; Huo, F., Chao, J.; Yin, C. Sens. Actuators, B 2019, 287, 453.

[85] Wu, W. L.; Ma, H. L.; Xi, L. L.; Huang, M. F.; Wang, K. M.; Miao, J. Y.; Zhao, B. X. Talanta 2019, 194, 308

[86] Wu, Y.; Wang, J.; Zeng, F.; Huang, S.; Huang, J.; Xie, H.; Wu, S. ACS Appl. Mater. Interfaces 2016, 8, 1511.

[87] Hu, Q.; Qin, C.; Huang, L.; Wang, H.; Liu, Q.; Zeng, L. Dyes Pigm. 2018, 149, 253.

[88] Lv, J.; Chen, Y.; Wang, F.; Wei, T.; Zhang, Z.; Qiang, J.; Chen, X. Dyes Pigm. 2018, 148, 353.

[89] Gu, J.; Li, X.; Zhou, Z.; Liao, R.; Gao, J.; Tang, Y.; Wang, Q. Chem. Eng. J. 2019, 368, 157.

[90] Li, J.; Liu, T.; Huo, F.; Chao, J.; Zhang, Y.; Yin, C. Spectrochim. Acta, Part A 2017, 174, 17

[91] Li, J.; Li, P.; Huo, F.; Yin, C.; Liu, T.; Chao, J.; Zhang, Y. Dyes Pigm. 2016, 130, 209.

[92] Xiao, H.; Li, J.; Zhao, J.; Yin, G.; Quan, Y.; Wang, J.; Wang, R. J. Mater. Chem. B 2015, 3, 1633

[93] Zhang, Q.; Zhang, P.; Gong, Y.; Ding, C. Sens. Actuators, B 2019, $278,73$.

[94] Chen, H.; Sun, T.; Qiao, X. G.; Tang, Q. O.; Zhao, S. C.; Zhou, Z. Spectrochim. Acta, Part A 2018, 204, 196.

[95] Hu, J. J.; Wong, N. K.; Gu, Q.; Bai, X.; Ye, S.; Yang, D. Org. Lett 2014, 16, 3544 . 
[96] Yue, Y.; Yin, C.; Huo, F.; Chao, J.; Zhang, Y. Sens. Actuators, B 2014, 202, 551-556.

[97] Guo, T.; Cui, L.; Shen, J.; Wang, R.; Zhu, W.; Xu, Y.; Qian, X. Chem. Commun. 2013, 49, 1862.

[98] Zhu, B.; Wu, L.; Zhang, M.; Wang, Y.; Liu, C.; Wang, Z.; Jia, P. Biosens. Bioelectron. 2018, 107, 218.

[99] Wang, X.; Xu, C.; Song, H.; Liu, X.; Xie, X.; Pang, X.; Zhou, Y. J. Lumin. 2019, 210, 472.

[100] Wang, Z.; Zhang, Y.; Song, J.; Li, M.; Yang, Y.; Gu, W.; Wang, S. Dyes Pigm. 2019, 161, 172.

[101] Wang, Q.; Jin, L.; Wang, W.; Dai, L.; Tan, X.; Zhao, C. Spectrochim. Acta, Part A 2019, 211, 239.

[102] Fan, J.; Mu, H.; Zhu, H.; Wang, J.; Peng, X. Analyst 2015, 140, 4594.

[103] Fan, J.; Mu, H.; Zhu, H.; Du, J.; Jiang, N.; Wang, J.; Peng, X. Ind. Eng. Chem. Res. 2015, 54, 8842.

[104] Ponnuvel, K.; Ramamoorthy, J.; Sivaraman, G.; Padmini, V. ChemistrySelect 2018, 3, 91.

[105] Xue, M.; Wang, H.; Chen, J.; Ren, J.; Chen, S.; Yang, H.; Zhang, P. Sens. Actuators, B. 2019, 282, 1.
[106] Wu, Z.; Wu, X.; Li, Z.; Yang, Y.; Han, J.; Han, S. Bioorg. Med. Chem. Lett. 2013, 23, 4354.

[107] Chen, Y.; Wei, T.; Zhang, Z.; Zhang, W.; Lv, J.; Chen, T.; Chen, X. Chin. Chem. Lett. 2017, 28, 1957.

[108] Pan, Y.; Han, Y. Tetrahedron Lett. 2017, 58, 1301.

[109] Wang, Q.; Liu, C.; Chang, J.; Lu, Y.; He, S.; Zhao, L.; Zeng, X. Dyes Pigm. 2013, 99, 733.

[110] Shu, W.; Yan, L.; Wang, Z.; Liu, J.; Zhang, S.; Liu, C.; Zhu, B. Sens. Actuators, $B$ 2015, 221, 1130 .

[111] Wang, C.; Ji, H.; Li, M.; Cai, L.; Wang, Z.; Li, Q.; Li, Z. Faraday Discuss. 2017, 196, 427

[112] Li, J.; Yin, C.; Liu, T.; Wen, Y.; Huo, F. Sens. Actuators, B 2017, $252,1112$.

[113] Li, J.; Yin, C.; Huo, F.; Xiong, K.; Chao, J.; Zhang, Y. Sens. Actuators, $B$ 2016, 231, 547.

[114] Jiang, Y.; Wu, S.; Jin, C.; Wang, B.; Shen, J. Sens. Actuators, B 2018, 265, 365.

[115] Wang, Z.; Zhang, Y.; Song, J.; Li, M.; Yang, Y.; Xu, X.; Wang, S. Sens. Actuators, B 2019, 284, 148. 